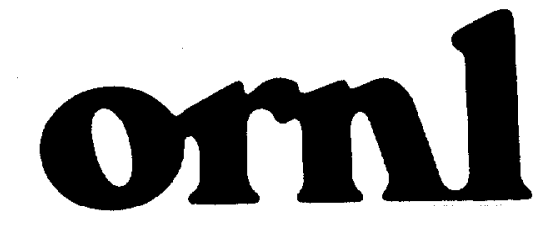

OAK RIDGE NATIONAL LABORATORY
MARTIN MARUETTA

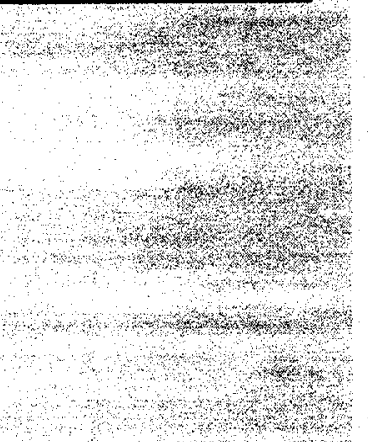

\section{Electric Utility Industry Experience with Geomagnetic Disturbances}

\author{
P. R. Barnes \\ D. T. Rizy \\ B. W. McConnell \\ Oak Ridge National Laboratory \\ F. M. Tesche \\ Consultant \\ E. R. Taylor, Jr. \\ ABB Power Systems, Inc.
}

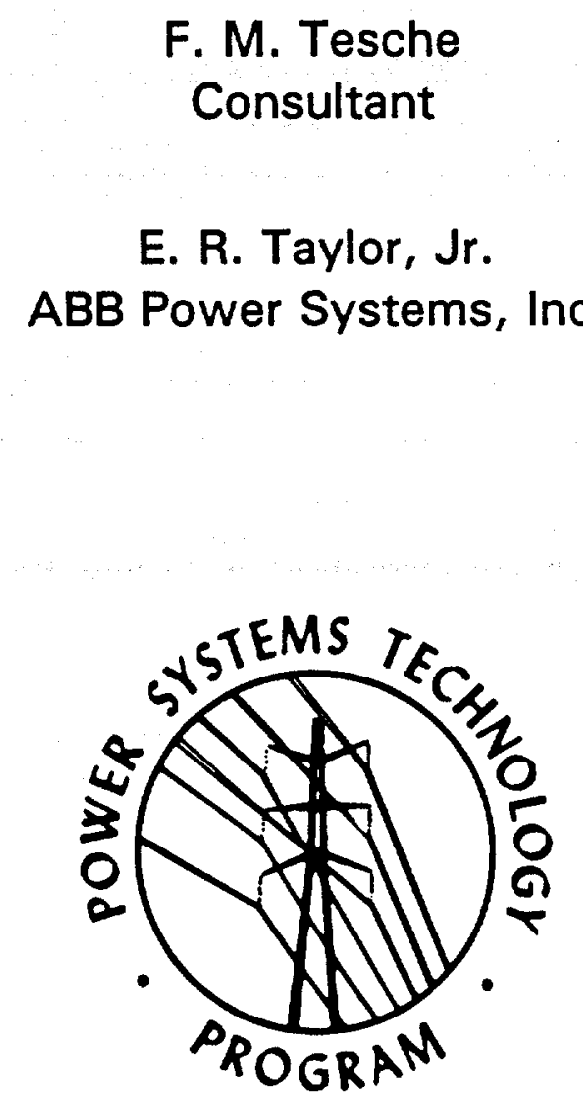





\title{
ELECTRIC UTILITY INDUSTRY EXPERIENCE WITH GEOMAGNETIC DISTURBANCES
}

\author{
P. R. Barnes \\ D. T. Rizy \\ B. W. McConnell \\ Oak Ridge National Laboratory \\ F. M. Tesche \\ Consultant \\ E. R. Taylor, Jr. \\ ABB Power Systems, Inc.
}

\author{
Prepared by the \\ Oak Ridge National Laboratory \\ Power Systems Technology Program \\ Oak Ridge, Tennessee 37831
}

Date Published - September 1991

Research jointly sponsored by

Defense Nuclear Agency

Washington, DC 20585

DNA IACRO 90-822
Department of Energy Office of Energy Management

Washington, DC 20585

under Interagency Agreement No. 0046-C156-A1

OAK RIDGE NATIONAL LABORATORY is managed by

MARTIN MARIETTA ENERGY SYSTEMS, INC. for the

U.S. DEPARTMENT OF ENERGY under contract no. DE-AC05-84OR21400 
. 


\section{ACKNOWLEDGEMENTS}

The research for this report was jointly sponsored by the Defense Nuclear Agency (DNA) through Interagency Agreement No. 0046-C156-A1 and the Office of Energy Management of the U.S. Department of Energy (DOE) under contract DE-AC05-84OR21400 with Martin Marietta Energy Systems, Inc. The report was prepared by the Energy Division of the Oak Ridge National Laboratory, which is managed by Martin Marietta Energy Systems, Inc. The authors wish to acknowledge and thank Dr. George H. Baker and Lt. Col. Clinton R. Gordon of DNA and Dr. Imre Gyuk of DOE for their interest, support, and review of this work.

The authors also wish to acknowledge and thank Dr. Steinar Dale and John Stovall of the Oak Ridge National Laboratory for their reviews and helpful suggestions; and Michel Granger of Hydro-Québec, Don A. Fagnan and Paul Sullivan of Philadelphia Electric, Phil R. Gattens of Allegheny Power, and Cliff Bush of Atlantic Electric for measured data and information on component and system impacts. The authors also wish to thank John Kappenman of Minnesota Power for providing useful insight on many issues and measured data, and Dr. M. Lee Sloan of Austin Research Associates for providing calculated data. We also wish to thank Professor Vern Albertson of the University of Minnesota, John N. Bombardt of Jaycor, William S. Kehrer of R\&D Associates, Jim Towle of diversifed EM, Leonard Bolduc of Institut de recherche d'HydroQuébec, Michel Granger of Hydro-Québec, Don A. Fagnan of Philadelphia Electric Company, William A. Radasky of Metatech, and Ron W. Zwickl of the Space Environment Laboratory for their reviews of the manuscripts and helpful suggestions and corrections. Thanks are also due Pamela S. Gillis for editing the manuscript and making editorial corrections and Janice E. Johnson for assisting in typing the manuscript. 


\section{TABLE OF CONTENTS}

ACKNOWLEDGEMENTS $\ldots \ldots \ldots \ldots \ldots \ldots \ldots \ldots \ldots \ldots \ldots \ldots$ iii

TABLE OF CONTENTS $\ldots \ldots \ldots \ldots \ldots \ldots \ldots \ldots \ldots \ldots \ldots \ldots$

LIST OF TABLES $\ldots \ldots \ldots \ldots \ldots \ldots \ldots \ldots \ldots \ldots \ldots \ldots \ldots$

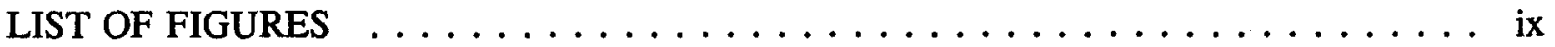

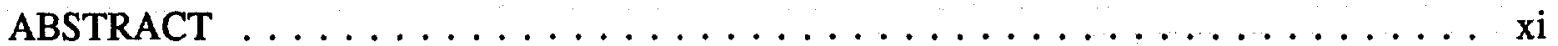

EXECUTIVE SUMMARY $\ldots \ldots \ldots \ldots \ldots \ldots \ldots \ldots \ldots \ldots \ldots \ldots$

ABBREVIATIONS, ACRONYMS, AND INITIALISMS $\ldots \ldots \ldots \ldots \ldots \ldots$

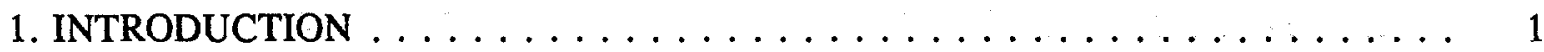

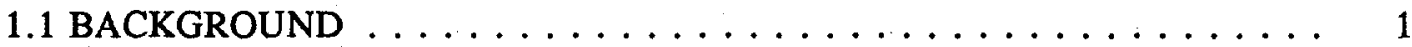

1.2 PURPOSE AND CONTENT $\ldots \ldots \ldots \ldots \ldots \ldots \ldots$

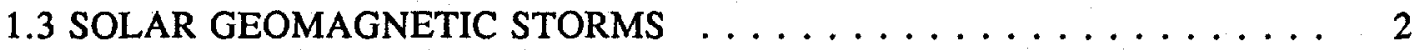

1.4 VULNERABILITY TRENDS $\ldots \ldots \ldots \ldots \ldots \ldots \ldots \ldots$

1.5 EARTH-SURFACE-POTENTIAL MODEL $\ldots \ldots \ldots \ldots \ldots \ldots$

2. EFFECTS ON ELECTRIC POWER SYSTEMS $\ldots \ldots \ldots \ldots \ldots \ldots \ldots$

2.1 GENERAL SYSTEM PROBLEMS $\ldots \ldots \ldots \ldots \ldots \ldots \ldots \ldots$

2.2 TRANSMISSION AND DISTRIBUTION EQUIPMENT PROBLEMS . . . . . 9

2.2.1 Transformers and Load-Tap-Changing Equipment . . . . . . . 10

2.2.2 Surge Arresters . . . . . . . . . . . . . . . . . . . . 13

2.2.3 Protection Systems and Circuit Breakers ............ 13

2.2 .4 Capacitors . . . . . . . . . . . . . . . . . . . 15

2.2.5 Static VAR Compensators (SVCs) $\ldots \ldots \ldots \ldots \ldots \ldots \ldots \ldots$

2.2.6 Distribution System Problems . . . . . . . . . . . . . . . 17

2.3 COMMUNICATIONS AND CONTROL FACILITIES . . . . . . . . . 18

2.3.1 Radio Communications and Controls . . . . . . . . . . 18

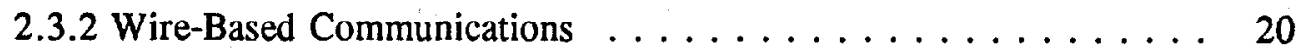

2.3.3 Fiber Optics . . . . . . . . . . . . . . . . . . 21

2.3.4 Powerline Carrier . . . . . . . . . . . . . . . . 21

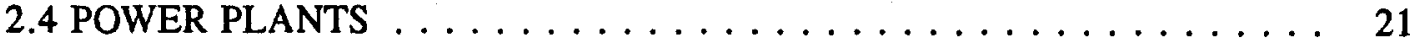

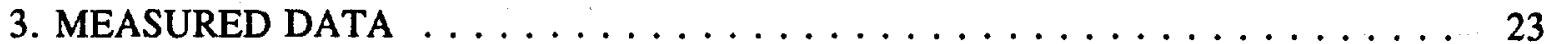

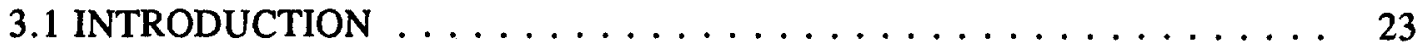

3.2 GEOMAGNETIC FIELD MEASUREMENTS $\ldots \ldots \ldots \ldots \ldots \ldots$

3.3 GIC MEASUREMENTS . . . . . . . . . . . . . . . . . . . . . . . 24

3.4 ESP AND ELECTRIC FIELD MEASUREMENTS $\ldots \ldots \ldots \ldots \ldots$

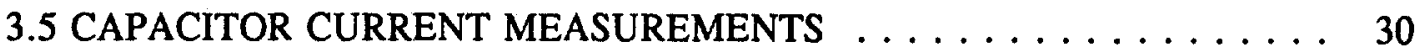




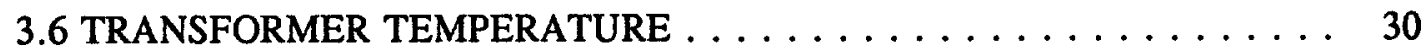

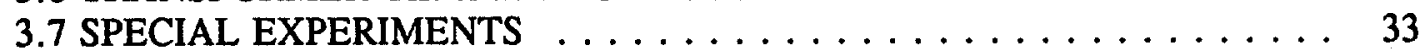

3.7.1 Transformer Dc Excitation Field Test . . . . . . . . . . 33

3.7.2 Dc Injection in the Ac Transmission System . . . . . . . . 33

3.7.3 Distribution Transformer Test . . . . . . . . . . . . . 34

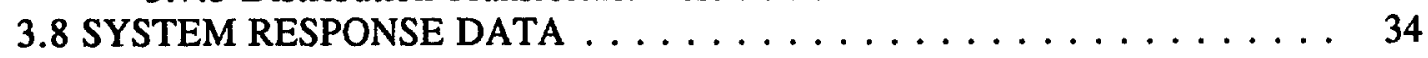

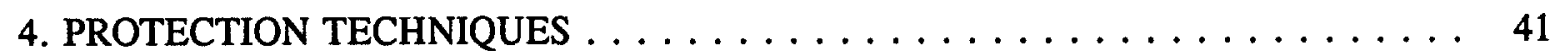

4.1 ANALYTICAL TOOLS $\ldots \ldots \ldots \ldots \ldots \ldots \ldots \ldots \ldots \ldots \ldots \ldots$

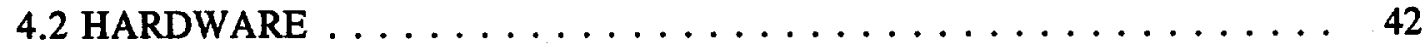

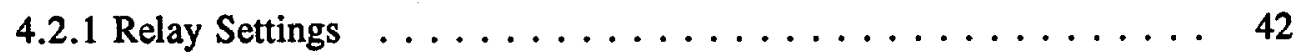

4.2.2 Neutral Blocking and Bypass Device for Transformers . . . . . . 43

4.2.3 Capacitor Protection . . . . . . . . . . . . . . . 44

4.3 OPERATIONAL CHANGES $\ldots \ldots \ldots \ldots \ldots \ldots \ldots \ldots$

5. MAGNETOHYDRODYNAMIC ELECTROMAGNETIC PULSE AND GEOMAGNETIC STORMS $\ldots \ldots \ldots \ldots \ldots \ldots \ldots \ldots \ldots$

5.1 INTRODUCTION $\ldots \ldots \ldots \ldots \ldots \ldots \ldots \ldots \ldots \ldots \ldots \ldots \ldots$

5.2 COMPARISON OF THE GEOMAGNETIC STORM EARTH ELECTRIC

FIELD AND THE MAGNETOHYDRODYNAMIC

ELECTROMAGNETIC PULSE INDUCED FIELDS . . . . . . . . . 47

5.3 EXTRAPOLATION OF GEOMAGNETIC STORM EFFECTS TO E $\mathrm{E}_{3} \ldots \ldots$

6. SUMMARY AND CONCLUSIONS $\ldots \ldots \ldots \ldots \ldots \ldots \ldots \ldots \ldots$

6.1 ELECTRIC UTILITY EXPERIENCE $\ldots \ldots \ldots \ldots \ldots \ldots \ldots \ldots \ldots$

6.2 MEASURED DATA $\ldots \ldots \ldots \ldots \ldots \ldots \ldots \ldots \ldots \ldots$

6.3 MAGNETOHYDRODYNAMIC ELECTROMAGNETIC PULSE $\ldots \ldots \ldots 5$

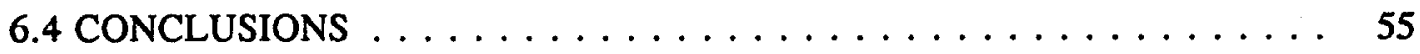

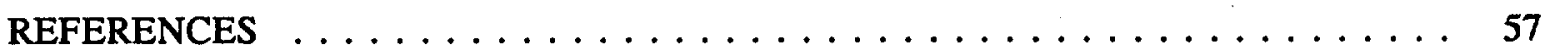

APPENDIX - POWER SYSTEM DISTURBANCES DUE TO MARCH 13, 1989, GEOMAGNETIC STORM ..................... 61 


\section{LIST OF TABLES}

Table 1.1 Relationship between $\mathrm{K}$ and $\mathrm{a}$ indices $\ldots \ldots \ldots \ldots$

Table 1.2 Geomagnetic storm intensity $\ldots \ldots \ldots \ldots \ldots \ldots \ldots$

Table 3.1 Geomagnetically induced currents recorded in transformer neutrals from March 1969 to September 1972 (39 months), ranked by maximum GIC . . . . 27 
$\cdots$ 


\section{LIST OF FIGURES}

Fig. 1.1. Geomagnetic storms expected during solar cycle 22. Source: Space

Environmental Laboratory. . . . . . . . . . . . . . . . . .

Fig. 1.2. Models for GIC coupling analysis: (a) earth-surface-potential (ESP) model and (b) dc model for calculating GIC (per phase). . . . . . . . . . .

Fig. 2.1. Events and $\mathrm{K}$ intensity recorded in North America during the March 13, 1989, geomagnetic storm. Source: North American Electric Reliability

Fig. 2.2 Half-cycle saturation of power transformers due to geomagnetically induced currents. Source: L. Bolduc and J. Aubin, "Effects of Direct Current in Power Transformers: Part I, A General Theoretical Approach and Part II, Simplified Calculations for Large Transformers," Electric Power Systems Research, 1, 291-304 (1977/1978). . . . . . . . . . . . . . . .

Fig. 3.1. Geomagnetic fields measured on March 13, 1989, by Poste-de-la-Baleine Magnetic Observatory, James Bay, Quebec, Canada. (a) North-south direction, (b) east-west direction.

Fig. 3.2. Transformer neutral geomagnetically induced current at the Minnesota Power Arrowhead substation, Duluth, Minnesota, August 4, 1972.

Fig. 3.3. Neutral current measured at the Missouri Ave. 6.9-kV/12-kV substation starting on April 4, 1990. (a) GIC Measured over a 100-h period, (b) GIC measured over a 6 -h period. Source: C.K. Bush, Atlantic Electric Co.

Fig. 3.4. ESP gradient measured at Hydro-Québec's Boucherville substation. (a) East-west direction, (b) north-south direction. Source: M. Granger of Hydro-Québec.

Fig. 3.5. Geomagnetic and electric fields at Hydro-Québec's Boucherville substation on July 13, 1982. (a) Measured north-south geomagnetic field disturbance, (b) computed east-west electric field for a ground resistivity

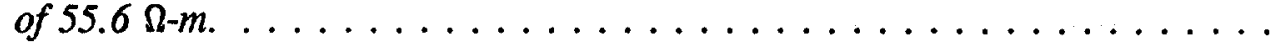

Fig. 3.6. Conditions of the Hydro-Québec system at 2:45 a.m. prior to the system

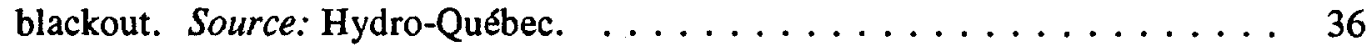

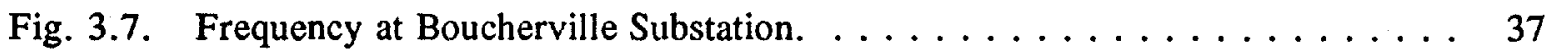


Fig. 3.8. Geomagnetic field disturbance recorded at the Ottawa Magnetic Observatory on March 13,1989, between the hours of midnight and 8 a.m. (a) East-west geomagnetic field, (b) north-south geomagnetic

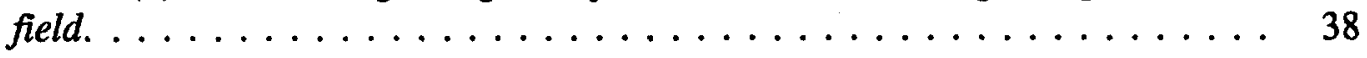

Fig. 3.9. Geomagnetic field disturbance recorded at the Ottawa Magnetic Observatory between 2:30 and 3:00 a.m. on March 13, 1989. (a) Eastwest geomagnetic field, (b) north-south geomagnetic field.

Fig. 3.10. Electric field for a ground conductivity of $1.0 \times 10^{-4} \mathrm{mhos} / \mathrm{m}$. (a) Northsouth electric field, (b) east-west electric field. . . . . . . . . . . . . . 40

Fig. 5.1. Global magnetohydrodynamic electromagnetic pulse electric field pattern at 3.0 seconds. Source: Dr. M. L. Sloan of Austin Research Associates.

Fig. 5.2. Computed electric fields for measured fields in Fig. 3.1 with $\sigma=1.0 \times$ $10^{-4}$ mhos/meter. (a) North-south field, (b) east-west field.

Fig. 5.3. Normalized worst-case magnetohydrodynamic electromagnetic pulse electric field. . . . . . . . . . . . . . . . . . . . 50

Fig. 5.4. Typical geomagnetic storm electric field. $\ldots \ldots \ldots \ldots \ldots \ldots \ldots$

Fig. 5.5. Comparison of the spectra of the magnetohydrodynamic electromagnetic pulse electric field (shown separately in Fig. 5.3) and the geomagnetic storm electric field (shown separately in Fig. 5.4). . . . . . . . . . . 52 
ABSTRACT

A geomagnetic disturbance (GMD) by its nature occurs globally and almost simultaneously. Severe geomagnetic storms cause problems for electric power systems. The vulnerability of electric power systems to such events has apparently increased during the last 10 to 20 years because power system transmission lines have become more interconnected and have increased in length and because power systems are now operated closer to their limits than in the past. In this report, the experience of electric utilities during geomagnetic storms is examined and analyzed. Measured data, effects on power system components, and power system impacts are considered. It has been found that electric power systems are susceptible to geomagnetically induced earth-surface potential gradients as small as a few (2 to 3 ) volts per kilometer, corresponding to a storm of K-6 intensity over an area of high earth resistivity. The causes and effects are reasonably well understood, but additional research is needed to develop a better understanding of solar-induced geomagnetic storms and the responses of power systems to these types of storms. A better understanding of geomagnetic storms and the power systems' responses to GMDs is needed so that mitigation measures can be implemented that will make power systems less susceptible to severe geomagnetic disturbances. A GMD caused by a large high-altitude nuclear detonation is similar in many ways to that of solar-induced geomagnetic storms except that a nuclear-caused disturbance would be much more intense with a far shorter duration. 


\section{EXECUTIVE SUMMARY}

The earth's atmosphere and magnetic field are constantly being bombarded by charged particles emitted from the sun that are called solar wind. A large amount of these charged particles are emitted from the sun during solar flares, coronal holes, or disappearing filaments. These phenomena are associated with solar activity and produce very intense bursts of solar wind of several days' duration. In the northern hemisphere, visual evidence of the auroral electrojets or currents that result from solar-emitted particles during geomagnetic storms is provided by the aurora borealis, often called the northern lights. The auroral electrojets are currents of 1 million amperes or more that follow circular paths around the earth's geomagnetic poles at altitudes of about $100 \mathrm{~km}$. These auroral electrojets cause variations in the earth's magnetic field that are termed a geomagnetic storm.

\section{Geomagnetic Storms}

A geomagnetic disturbance (GMD) occurs when the magnetic field embedded in the solar wind is opposite that of the earth. This disturbance, which results in distortions to the earth's magnetic field, can be of varying intensity and has in the past impacted the operation of pipelines, communications systems, and electric power systems. Solar GMDs follow the so-called sunspot cycle and vary in intensity over an eleven-year cycle. The peak activity level for the present cycle, cycle 22 (the 22nd since record-keeping of sunspots started), is expected later this year or early in 1991. The most severe geomagnetic disturbances during a cycle have been observed to follow the peak in sunspot activity by 2 to 3 years. Thus, power system disturbances resulting from cycle 22 are expected to peak in 1993-94.

Unfortunately, no accurate method is presently available to predict either the onset or the magnitude of a geomagnetic disturbance. Two indices ( $K$ and $A)$ are generally used to indicate the intensity of a geomagnetic disturbance, but neither has been shown to be useful in predicting the impact on electric power systems. An attempt to use the indices as a warning system would result in too many false alarms. 
xiv Executive Summary

\section{Overview of Power System Problems Caused by GIC}

An important factor in the response of electric power systems to GSDs is the earth-surface potential (ESP) induced by the disturbance. ESP is a source of geomagnetically induced currents (GICs) that flow in the neutrals of grounded power transformers. Even low-level ESP gradients (1 to $2 \mathrm{~V} / \mathrm{km}$ ) can produce GICs that can saturate the steel used in transformer's core. This saturation results in transformer heating and possible failure as well as injection of harmonics into the power system and increased consumption of reactive power by transformers.

To date the most severe power system disturbance resulting from a geomagnetic storm occurred on March 13, 1989, at a storm level of K-9. The geomagnetic storm on that date produced GICs that caused widespread electric power system problems, the most severe being a power-system-wide blackout on the Hydro-Québec power system. The blackout of the HydroQuébec system (of Québec, Canada) resulted from the saturation of transformers by GICs and the ensuing operation of protection equipment because of the injection of harmonics from the transformers. Restoration of $83 \%$ (of $21,500 \mathrm{MW}$ ) of the Hydro-Québec system generation took over nine hours .

GICs are a function of power system, earth, and storm parameters. East-west transmission lines normally have larger GIC levels because the gradient of the ESP is normally greater in the east-west direction than in the north-south direction, but this observation is not absolute. GIC flow is increased in the vicinity of igneous rock geology because of the high earth resistivity. The flow is very dependent on the resistance of the grounding points, the system topology at the time of the geomagnetic disturbance (i.e., the length and connectivity of the transmission lines), and the specific locations of the points where the system is connected to earth grounds.

Electric utilities have adopted operational strategies and made some minor hardware modifications based primarily on system operating problems experienced during the March 13, 1989, geomagnetic storm, and are working on GIC blocking hardware for transformers that help mitigate GIC impacts, but additional mitigation studies are needed. So that GIC effects can be better understood and real-time assessment of equipment conditions can be provided, monitoring systems are being installed in electric power systems to collect data during future solar geomagnetic storms. 


\section{Magnetohydrodynamic Electromagnetic Pulse (MHD-EMP) and Geomagnetic Storms}

A high-altitude nuclear explosion produces not only the steep-front short-duration electromagnetic radiation pulse, but, at later times, the expanding and subsequently collapsing envelope of weapons debris and highly ionized plasma which displaces the earth's magnetic field lines. This time-changing magnetic behavior, referred to as MHD-EMP, induces quasi-dc currents in the neutral of the electric power system that are similar to solar GICs.

The magnitudes of these MHD-EMP currents are dependent on the transmission line length and magnetic field strength, and the currents do not persist as long as solar GICs. Because of its short duration, it is unlikely that MHD-EMP will produce permanent damage from overheating in transformer cores .

The March 13, 1989, Hydro-Québec blackout probably resulted from fields that were about ten volts per kilometer. It is possible that MHD-EMP could cause a similar widespread disturbance provided that power transformers can be driven into saturation in less than a minute, as preliminary experimental results have indicated. Since the early-time portion of the MHDEMP waveform is less than ten seconds, the power transmission system response is not clear. If a large quasi-dc voltage can drive the large transmission-line power transformers into saturation in a few seconds, then the early-time fields are important for transmission systems. Results of tests on distribution transformers indicate that core saturation can occur in about 1 second or less from dc currents on the order of $5 \mathrm{~A}$. The large peak value of the early-time MHD-EMP wave implies that it could be important for relatively short distribution and sub-transmission lines that could respond to GIC in a few seconds. The increased VAR demand on the power system from saturated distribution transformers could adversely reduce system voltage, generate profuse harmonics, and result in a potential system-wide outage. Also, if the late-time MHD-EMP is larger than $10 \mathrm{~V} / \mathrm{km}$ over distances of hundreds of kilometers, then power transmission systems may be affected in a manner similar to that of Hydro-Québec on March 13, 1989. 


\begin{tabular}{|c|c|c|}
\hline A & $=$ & ampere \\
\hline ABB & $=$ & ASEA Brown Boveri \\
\hline ac & $=$ & alternating current \\
\hline APS & $=$ & Allegheny Power System \\
\hline CST & $=$ & Central Standard Time \\
\hline CT & $=$ & current transformer \\
\hline $\mathrm{dc}$ & $=$ & direct current \\
\hline DNA & $=$ & Defense Nuclear Agency \\
\hline EHV & $=$ & extra-high voltage \\
\hline EMF & $=$ & electromagnetic field \\
\hline EMP & $=$ & electromagnetic pulse \\
\hline ESP & $=$ & earth-surface potential \\
\hline EST & $=$ & Eastern Standard Time \\
\hline GIC & $=$ & geomagnetically-induced currents \\
\hline GMD & $=$ & geomagnetic disturbance \\
\hline HEMP & $=$ & high-altitude electromagnetic pulse \\
\hline HQ & $=$ & Hydro-Québec \\
\hline IEEE & $=$ & Institute of Electrical and Electronics Engineers \\
\hline km & $=$ & kilometer \\
\hline MHD-EMP & $=$ & magnetohydrodynamic electromagnetic pulse \\
\hline MW & $=$ & megawatt \\
\hline $\mathrm{NB} / \mathrm{GD}$ & $=$ & neutral blocking and grounding device \\
\hline NOAA & $=$ & National Oceanic and Atmospheric Administration \\
\hline NPCC & $=$ & Northeast Power Coordinating Council \\
\hline $\mathrm{nT}$ & $=$ & nano Tesla \\
\hline ORNL & $=$ & Oak Ridge National Laboratory \\
\hline PCA & $=$ & polar cap absorption \\
\hline PJM & $=$ & Pennsylvania-New Jersey-Maryland Interconnection \\
\hline PNM & $=$ & Public Service Company of New Mexico \\
\hline SESC & $=$ & NOAA Space Environment Services Center \\
\hline SVC & $=$ & static VAR compensator \\
\hline T\&D & $=$ & transmission and distribution \\
\hline UHF & $=$ & ultra-high-frequency \\
\hline VAR & $=$ & volt-ampere reactive \\
\hline VHF & $=$ & very-high-frequency \\
\hline WAPA & $=$ & Western Area Power Administration \\
\hline
\end{tabular}


-

".

. 


\section{INTRODUCTION}

\subsection{BACKGROUND}

Electricity is essential to our industries, communications, water supply, and general social welfare. Although electric utility power systems are very dependable under most conditions, they are also highly vulnerable to widespread disturbances. This vulnerability was demonstrated on March 13, 1989, when an intense geomagnetic storm caused a blackout of the Hydro-Québec power system that left most of the Canadian province of Québec without power. The blackout resulted in the loss of $21,500 \mathrm{MW}$ of electricity generation, and restoration of $83 \%$ of the load took nine hours. ${ }^{1}$ Large-scale blackouts can have serious economic impacts even if power is restored in a few hours. A four-hour major blackout in France cost 1 billion dollars. In a recent study of the economic impact of a major blackout in the U.S., it was estimated that the cost of a blackout in the northeast could easily exceed several billion dollars. ${ }^{2,3}$ Understanding power system vulnerabilities and developing methods to mitigate or reduce them is therefore in the national interest.

\subsection{PURPOSE AND CONTENT}

The purpose of this report is to review and document electric utility experience with geomagnetic storms to determine the probable impact of severe geomagnetic storms and to identify technical areas of uncertainty that should be addressed in a comprehensive research program. In addition, geomagnetic field disturbances caused by solar-induced geomagnetic storms will be compared and contrasted with the geomagnetic field disturbances caused by a high-altitude nuclear detonation to provide insight into the likely power system consequences of such a nuclear event.

This section introduces geomagnetic storms and their threat to the electrical power supply and delivery system. Section 2 describes geomagnetic impacts that have been experienced by electric utilities. The very limited data measured by utilities during solar storms and during special experiments conducted on power system components are discussed in Section 3. Methods that have been implemented and developed to protect electric power systems against the effects 
of geomagnetic storms are discussed in Section 4. The implications of geomagnetic storm experience for the probable electric power system impacts of magnetohyrodynamic electromagnetic pulse (MHD-EMP) from a high-altitude nuclear detonation is addressed in Section 5.

\subsection{SOLAR GEOMAGNETIC STORMS}

Geomagnetic storms are associated with activity on the sun's surface, i.e., sunspots and solar flares. Coronal mass ejections, $x$-rays, and charged particles shower the earth one to six days after a solar flare erupts on the sun. Solar flares result in direct electromagnetic radiation traveling to earth at the speed of light, which is approximately eight minutes of travel time from the sun. If properly oriented, the magnetic field produced by the current within this plasma cloud, which is often called a gust of solar wind, can interact with the earth's magnetic field and result in a geomagnetic storm. Very intense storms with auroral electrojets of solar particles (1 million amperes or more) produce the brilliant northern auroras and cause distortions in the earth's magnetic field that upset communications and electric power systems. ${ }^{4}$ During maximum solar activity, it is estimated that 50 to 100 small- to medium-sized solar flares occur each day, that large flares that noticeably affect communications occur weekly, and that very large flares that significantly affect communications occur less often. ${ }^{5}$ The severity of geomagnetic storms peaks about every 11 years. Storm cycle 22 began in 1986, and its sunspot activity is expected to peak in the 1990-1991 time period. However, the maximum geomagnetic storm activity often lags sunspot activity by two to three years, so the most intense geomagnetic storm activity for cycle 22 is not expected until the 1993-1994 time period, as shown in Fig. 1.1.

The intensity of geomagnetic storms is assessed by several indices. Variations of the earth's magnetic field are measured continuously at a number of locations around the globe (data may be stored using a sample rate on the order of 2 seconds). At the end of a three-hour period, the variation in the magnetic field relative to a "quiet day" is converted to a $\mathrm{K}$ index, a number ranging from 0 to 9 , by using a table appropriate for a particular observation site. Another measure is the $\mathrm{A}$ index, which combines the eight $\mathrm{K}$ indexes for a given day by first converting the $\mathrm{K}$ index to an " $\mathrm{a}$ " index. The eight " $\mathrm{a}$ " indexes are then averaged to yield 


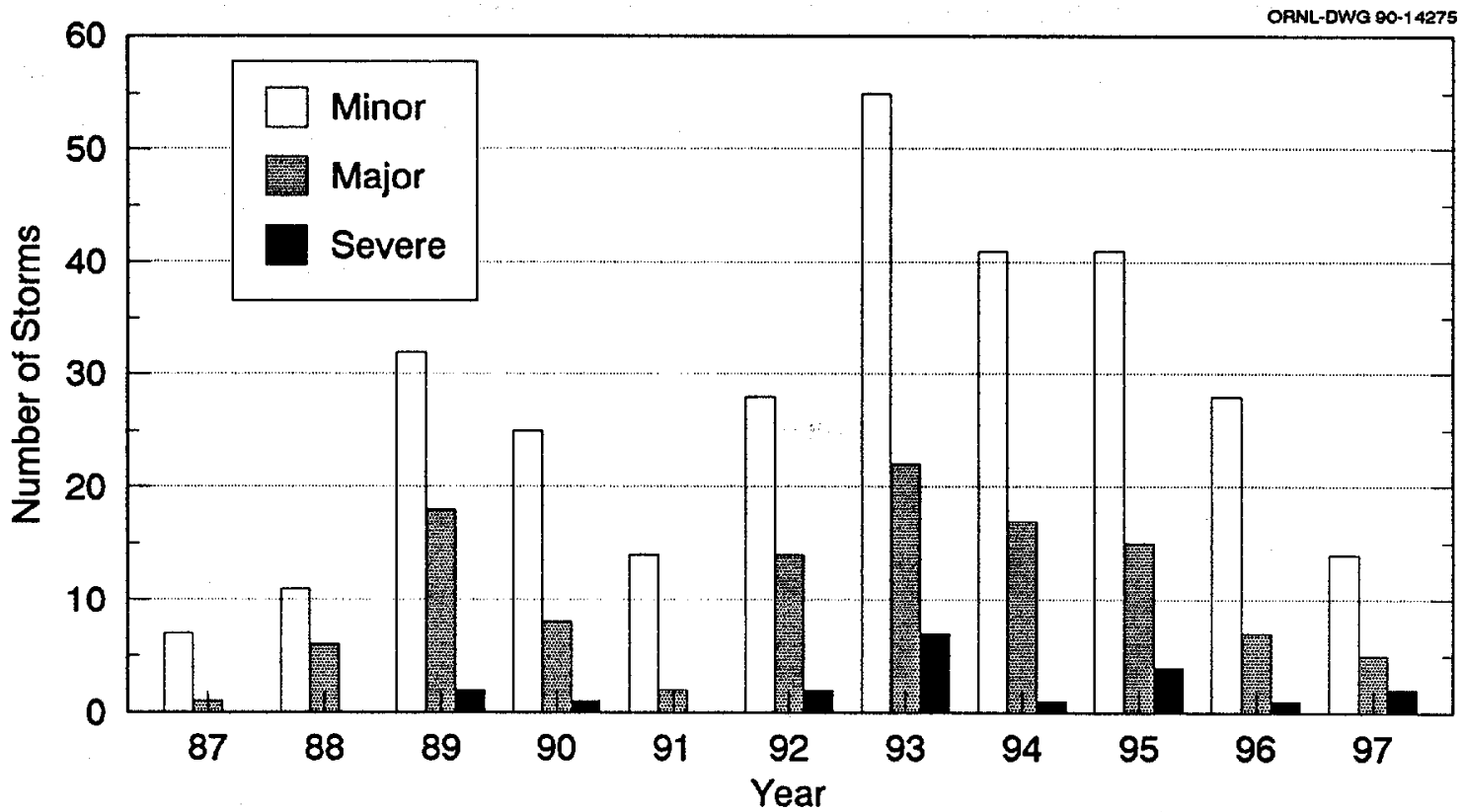

Fig. 1.1. Geomagnetic storms expected during solar cycle 22. Source: Space Environmental Laboratory.

the daily $\mathrm{A}$ index. Geomagnetic field fluctuations are measured in units of nano Teslas (nT). Another unit of measure is the gamma: 1 gamma $=1 \mathrm{nT}=10^{-5}$ gauss. The earth's magnetic field at the poles is approximately equal to $70,000 \mathrm{nT}=0.7$ gauss. The relationship between the $\mathrm{K}$ and " $\mathrm{a}$ " indexes is shown in Table 1.1. The storm intensity categories are summarized in Table 1.2 below.

Table 1.1 Relationship between $K$ and $a$ indices

\begin{tabular}{|l|r|r|r|r|r|r|r|r|r|r|}
\hline $\mathrm{K}$ & 0 & 1 & 2 & 3 & 4 & 5 & 6 & 7 & 8 & 9 \\
\hline $\mathrm{a}$ & 0 & 3 & 7 & 15 & 27 & 48 & 80 & 140 & 240 & 400 \\
\hline
\end{tabular}

The $\mathrm{K}$ index is not a useful indicator of how an intense storm will severely impact electric utility systems, since it does not account for the rate of change associated with the variation. A K-9 storm that slowly changes the earth's magnetic field will have less impact than a K-9 storm with relatively fast variations. Magnetic field fluctuations result in an electric potential gradient 
of low frequency (quasi-dc) along the earth's surface in a generally east-west direction. This potential gradient is a function of the earth's conductivity and the rate of change in the magnetic field. The greater the rate of change, the greater the potential difference, called the earth-surface potential (ESP), between two points on the earth's surface; hence, the geomagnetically induced currents (GICs) will be greater. This characteristic is not represented well in the $\mathrm{K}$ index.

Table 1.2 Geomagnetic storm intensity

\begin{tabular}{||l|r|r|r||}
\hline \multicolumn{1}{|c|}{ Category } & \multicolumn{1}{c|}{ A } & \multicolumn{1}{c|}{ K } & Measured Deviation* \\
\hline Quiet & $0-7$ & $0-2$ & $0-19 \mathrm{nT}$ \\
Minor storm & $30-49$ & 5 & $70-119 \mathrm{nT}$ \\
Major storm & $50-99$ & 6 & $120-199 \mathrm{nT}$ \\
Severe storm & $100-400$ & $7-9$ & $200-500+\mathrm{nT}$ \\
\hline
\end{tabular}

Source: J. A. Joselyn and C. C. Balch, "SESC Geomagnetic Services," NOAA Space Environment Laboratory, Space Environment Services Division, Boulder, Colorado, presented at EPRI GIC Conference, Burlingame, Calif., November 8-10, 1989.

* For Boulder, Colorado, observations

Geomagnetic storms influence electric power systems by causing GICs to flow in power lines through the neutrals of grounded-wye transformers. In general, the longer the transmission line, the larger the GICs, except for those lines that have series capacitors installed which can limit the flow of dc current. Electric power systems in more northern latitudes that are located near the auroral electrojet current and systems in regions of low-earth conductivity such as regions of igneous rock geology will be subjected to the largest ESP gradients, on the order of $6 \mathrm{~V} / \mathrm{km}$ or larger. Thus, power systems located in these regions are more likely to be affected by geomagnetic storms. 


\subsection{VULNERABILITY TRENDS}

The geomagnetically induced (quasi-dc) currents that flow through the grounded neutral of a transformer during a geomagnetic disturbance cause the core of the transformer to magnetically saturate on alternate half-cycles. Saturated transformers result in harmonic distortions and additional reactive power or VAR demands on electric power systems. The increased VAR demands can cause both a reduction in system voltage and overloading of long transmission tie-lines. In addition, harmonics can cause protective relays to operate improperly and shunt capacitor banks to overload. These conditions can lead to major power failures.

The electric power network in North America has changed during the past 25 years in a manner that has increased its vulnerability to widespread geomagnetic disturbances. Since 1965 , an extensive high-voltage transmission network has been developed that forms our modern power grid. At the same time, generation plants have not been built in the northeastern U.S. to keep up with power demands. As a result, large amounts of electrical energy have to be transmitted great distances from Canada and the Midwest over long transmission lines that are operating near their limits. There is little capacity for the additional reactive power demand that results during geomagnetic storms when transformers saturate or static VAR compensators (SVCs) trip. As more and more power is transmitted over longer distances to meet growth demands, stability margins are further reduced. The trend over the past several years has been a continued increase of about $2 \%$ per year in the demand for electric energy. ${ }^{6}$ Continued load growth in highpopulation load centers without a corresponding growth in generation capacity will cause even larger blocks of power to be transmitted over even longer distances. Public resistance to the construction of higher voltage, higher capacity lines could make the power grid even more vulnerable to disturbances such as geomagnetic storms during the 1990 s and early into the 21 st century.

\subsection{EARTH-SURFACE-POTENTIAL MODEL}

The earth is a partially conducting sphere of which a portion experiences a slow timevarying magnetic field. This induces currents in the earth that result in an ESP. According to Faraday's law of induction, a time variation of the geomagnetic field is accompanied by an electric field. A formula to compute the electric field has been developed by Pirjola. ${ }^{7}$ A line 
integral of the electric field should provide the ESP between two points; however, the path of integration may be important for a nonconservative field. One assumes that the integration path is the same as that taken by the power line to connect the two points.

The ESP model has been used extensively by Albertson to estimate GICs in electric power systems. ${ }^{4}$ The ESP model for a three-phase transmission line is shown in Fig. 1.2(a). The ESP is a voltage source that is impressed between the grounded neutral points of the wye-connected transformers or autotransformers that are located on the opposite ends of a long transmission line. Since the resulting voltage source is of very low frequency, a dc model for the transmission line system can be used to compute the GIC. The dc model is shown in Fig. 1.2(b). For a threephase distribution line with a neutral conductor, a fourth conductor can be added to a more detailed model with the various grounding paths along the line. This more detailed ESP model was used in a recent study sponsored by EPRI. ${ }^{8}$

The ESP model does not always give good results, however. For example, the induced current in a 103-mile-long 138-kV transmission line in Alaska during a geomagnetic storm on September 28, 1978, showed at least 2-to-1 variability of induced line currents and the ESP.' At the same time, the maximum magnitude for the observed ESP gradient ( $500 \mathrm{mV} / \mathrm{km}$ ) did not show exact correlation with the magnitude of the rate of change of the magnetic field. The discrepancy in the correlation may have resulted from such factors as the accuracy of the ESP measurement, the variability in earth properties, and the geomagnetic storm environment. 
ORNL-DWG 00-14273
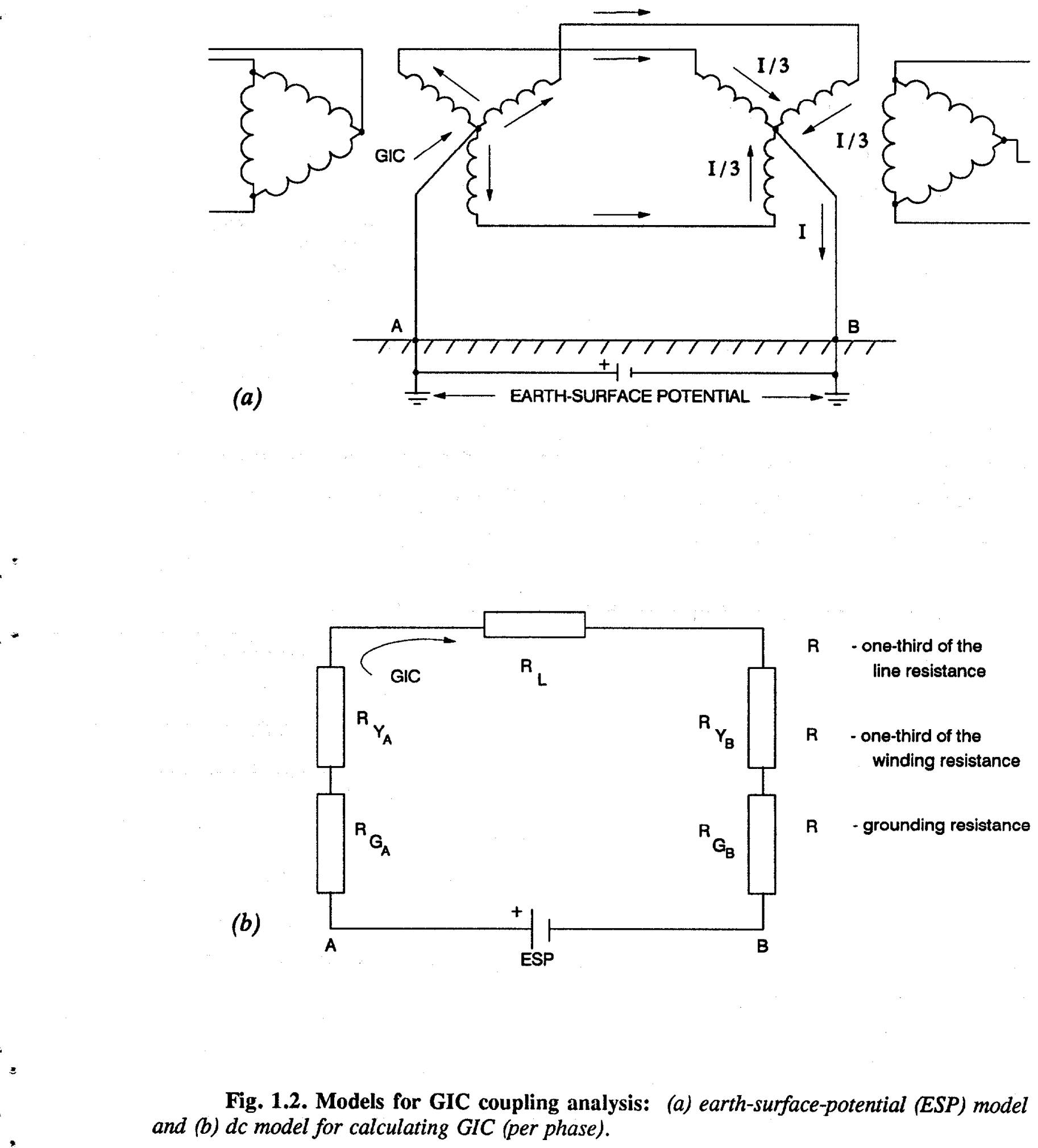

Fig. 1.2. Models for GIC coupling analysis: (a) earth-surface-potential (ESP) model and (b) dc model for calculating GIC (per phase). 


\section{EFFECTS ON ELECTRIC POWER SYSTEMS}

\subsection{GENERAL SYSTEM PROBLEMS}

The first reports of geomagnetic storm effects on electric power systems in the United States resulted from the solar storm on March 24, 1940 during solar cycle 17. ${ }^{10}$ Disturbances were reported in the northern United States and Canada. The Philadelphia Electric Company system experienced reactive power swings of $20 \%$ and voltage surges. In the same period, two transformers in this system and several power transformers on the Central Maine Power Co. and Ontario Hydro system tripped out. The Consolidated Edison Company in New York City also experienced voltage disturbances and dips up to $10 \%$ due to the large increase in reactive power on that system. ${ }^{11}$ Since that time, power system disturbances have been recorded for geomagnetic storms that occurred during solar cycles that followed. Some of the more severe disturbances occurred on August 17, 1959 (solar cycle 19); August 4, 1972 (solar cycle 20); and March 13, 1989 (solar cycle 22).

In general, geomagnetic storms have had little or no noticeable effects on electric power systems unless the intensity is classified above $\mathrm{K}-5 .{ }^{12}$ Also, in general, the higher the $\mathrm{K}$ number, the larger the number of power system events that occur. This is not always the case, however, since a K-8 storm can have a greater impact than a K-9 storm. ${ }^{4}$ A weakness in the present methods of classifying geomagnetic storms is that they do not provide a good indication of the rate of change in the magnetic field deviation.

An example of disturbances caused by a severe geomagnetic storm is shown in Fig. 2.1, which is a histogram of the events that were recorded in North America on March 13, 1989. Note that all events occurred for $K \geq 6$, and the largest number of events occurred during changes from one $\mathrm{K}$ classification to another. 
In this section, geomagnetic storm impacts on transmission and distribution systems and on communications and control equipment are discussed. In addition, concerns about possible impacts on power plants are considered.

ORNLL-DWG 90-14274

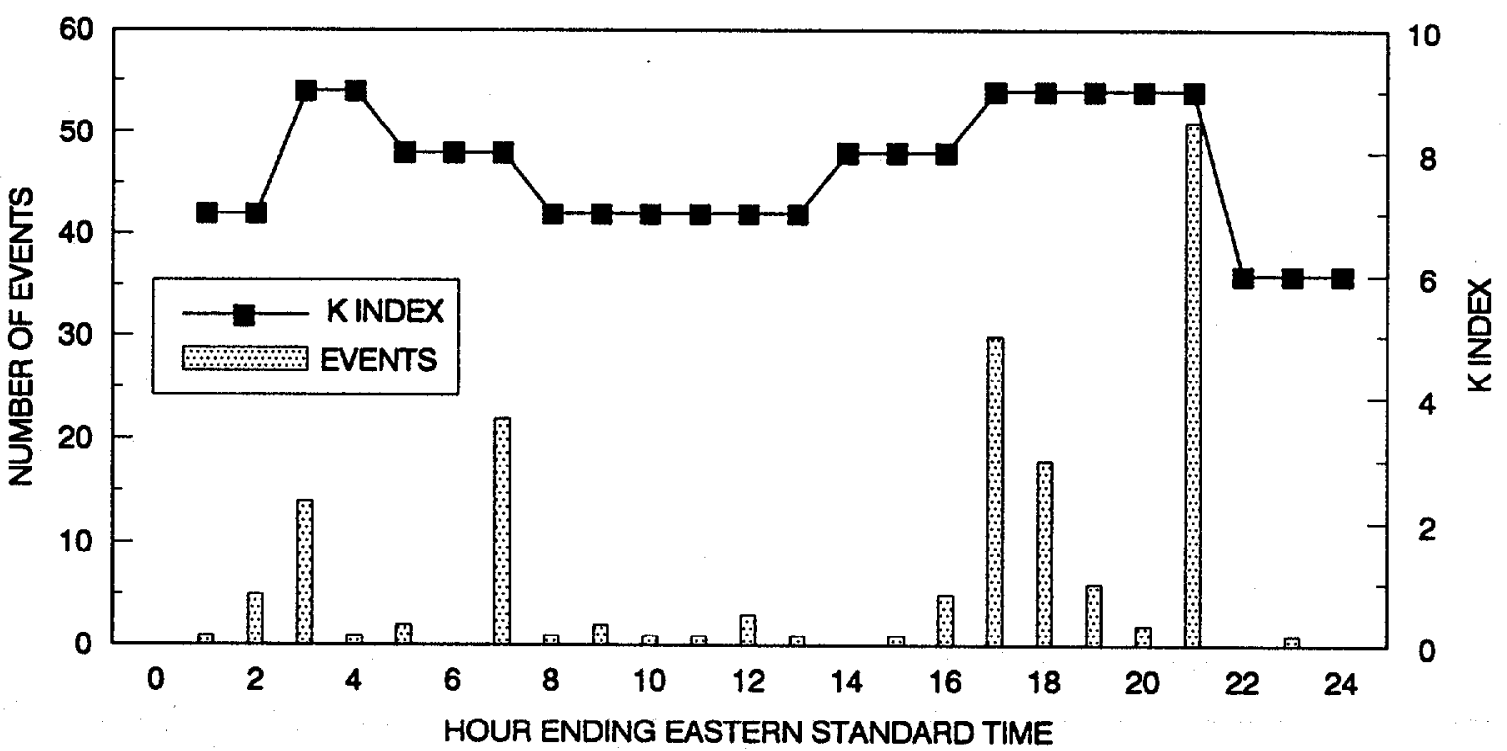

Fig. 2.1. Events and $K$ intensity recorded in North America during the March 13, 1989, geomagnetic storm. Source: North American Electric Reliability Council.

\subsection{TRANSMISSION AND DISTRIBUTION EQUIPMENT PROBLEMS}

As discussed earlier, geomagnetic storms cause variations in the earth's magnetic field that induce ESPs. These ESP gradients can reach about $6 \mathrm{~V} / \mathrm{km}$ during severe disturbances and can last for several minutes. A K-6 storm can result in ESP gradients of 2-3 V/km based on analysis of magnetometer data from typical geomagnetic storms. The induced voltages produce slowly oscillating GICs on electric power systems that can be on the order of tens to hundreds of amperes and are in the millihertz frequency range. The flow of GICs can result in saturation of transformer cores and subsequent changes in system VAR requirements, increased harmonic current levels, and problems with voltage control and protection. As a result, power system equipment can fail to operate properly in the presence of GICs. Transformers and current transformers (CTs) have been known to saturate because of GICs. The increased injection of 
harmonic currents into the system from saturated transformers can increase burden on static capacitors as well as interfere with the operation of control and protection systems. ${ }^{13}$

\subsubsection{Transformers and Load-Tap-Changing Equipment}

GICs are a real concern for extra-high-voltage (EHV) grounded-wye transformer banks, which provide conducting paths for GICs and zero-sequence currents. The presence of the quasidc GICs in the transformer windings causes a half-cycle saturation or shift of the transformer operating range on the magnetization curve as shown in Figure 2.2. GICs offset the magnetic flux of the transformer, resulting in a magnetizing current waveform with a greatly increased amplitude that is present for only half a cycle. Transformers are usually operated over a narrow range of the magnetization curve producing a relatively small excitation current as shown in the figure. Asymmetrical or half-cycle saturation of transformer cores can be caused by GICs on the order of 10 to 100 amperes.

GICs also cause an increase in reactive power or VAR consumption by the transformers and an increase in even and odd harmonics which are generated by the half-cycle saturation. The half-cycle saturation of a transformer for a long enough time can cause stray flux to enter transformer structural tank members or current windings and produce overheating resulting in shortening of transformer lifespan or other permanent damage. GIC-induced saturation can cause transformers to be vulnerable to thermal degradation and excessive gas evolution. Besides outright failure, the evidence of distress is increased gas content in transformer oil, especially those gases generated by decomposition of cellulose, vibration of the transformer tank and core, and increased noise levels of the transformer (a 24- $\mathrm{dB}$ increase in at least one instance and an 80$\mathrm{dB}$ increase in another have been recorded associated with GIC). ${ }^{14}$

The susceptibility of transformers to GIC-induced saturation can be determined from the flux path of zero-sequence open-circuit excitation. As a result, the susceptibility of transformer banks to GIC-induced saturation can be categorized as either strong or weak. Three-phase and single-phase shell form, three-phase five-leg core form, and single-phase core form transformers are strongly susceptible. Three-phase three-leg core form transformers are weakly susceptible. ${ }^{13}$ 


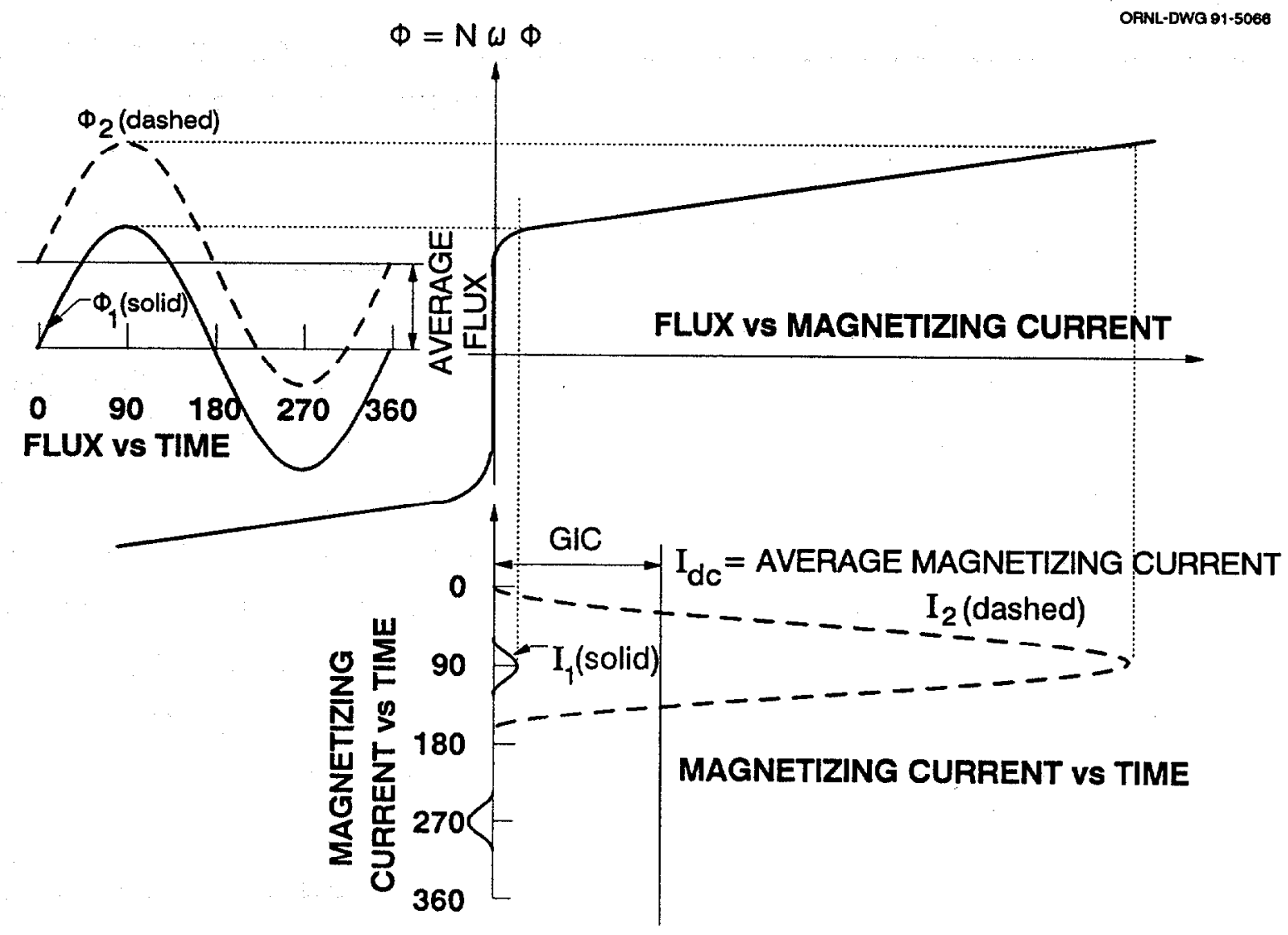

$\Phi_{1}$ - CURVE OF NORMAL MAGNETIZING FLUX

$\Phi_{2}$ - FLUX DURING HALF-CYCLE SATURATION DUE TO THE PRESENCE OF GIC

I 1 - CURVE OF NORMAL MAGNETIZING CURRENT

$I_{2}$ - CURRENT RESULTING FROM HALF-CYCLE SATURATION

Fig. 2.2 Half-cycle saturation of power transformers due to geomagnetically induced currents. Source: L. Bolduc and J. Aubin, "Effects of Direct Current in Power Transformers: Part I, A General Theoretical Approach and Part II, Simplified Calculations for Large Transformers," Electric Power Systems Research, 1, 291-304 (1977/1978).

A few transformer failures and problems over the decades have been attributed to geomagnetic storms. In December 1980, a $735-\mathrm{kV}$ transformer failed eight days after a geomagnetic storm at James Bay, Canada. A replacement $735-\mathrm{kV}$ transformer at the same 
location failed on April 13, 1981, again during a geomagnetic storm. ${ }^{9}$ However, analysis and tests by Hydro-Québec determined that GIC could not explain the failures and that abnormal operating conditions may have caused the damage. ${ }^{15}$ The failures of the generator step-up transformers at the Salem Unit 1 nuclear generating station of Public Service Electric \& Gas Co. during the March 13, 1989, storm probably have attracted the most attention. ${ }^{16}$ The 288.8/24$\mathrm{kV}$ single-phase shell-form transformers, which are rated at $406 \mathrm{MVA}$, are connected groundedwye. The damage to the transformers included damage to the low-voltage windings, thermal degradation of the insulation of all three phases, and conductor melting. The Salem plant occupies a vulnerable position in the power system network with respect to GICs since it is located at the eastern end of a long EHV transmission system traversing a region of igneous rock (on the Delaware river near the Atlantic Ocean) and is therefore very well grounded. (This position thus acts as a collection point for ground currents since the eastern end of the power network is close to the Atlantic ocean and that station has a very low grounding resistance.) During the March 13th disturbance, Salem Unit 1 experienced VAR excursions of 150 to 200 MVAR. Additional VARs were consumed by the saturated step-up transformers.

An empirical equation developed by $\mathrm{EPRI}^{17}$ indicates that the transformer reactive power consumption can be calculated as follows:

$$
\text { transformer reactive power }(\mathrm{VA})=V\left(I_{\text {exc }}+2.8 I_{d c}\right)
$$

where $I_{e x c}=$ transformer exciting current (without dc),

$I_{d c}=$ direct current in the transformer winding.

The North American Electric Reliability Council (NERC) used the above equation to estimate the $\mathrm{dc}$ current level that caused the Salem transformer to consume the extra VARs. ${ }^{18}$ They estimated the dc current to be $224 \mathrm{~A}$ (74.7 A per phase). A current of this magnitude is capable of saturating the transformer core. It is speculated that the combination of an above-normal level of eddy current losses and the uneven distribution of the increased magnetizing current damaged the Salem Unit 1 step-up transformers. ${ }^{18}$ Transformer manufacturers claim that transformers with newer designs do not have this problem. 
Load-tap-changing transformers have also been affected by GICs. Voltage regulating transformers have been known to perform more voltage adjustments and thus operate more frequently than normal during geomagnetic storm activity. ${ }^{11}$ The increase in adjustments is likely due to the system voltage variations caused by increased VAR demands.

\subsubsection{Surge Arresters}

A few surge arrester failures during solar geomagnetic storms have been reported. It is believed that the failures were caused by abnormal neutral overvoltages caused by saturated transformers. ${ }^{11}$

\subsubsection{Protection Systems and Circuit Breakers}

GICs can cause relay and protection systems to fail in three different ways. First, relays for static VAR compensators, capacitors, and line relay operations can mistake the harmonic currents produced by saturated transformers for a fault or current overload. This failure mode is the most common. Second, the protection system can fail to operate as desired. For example, the output of a CT for a transformer differential protection scheme can become distorted due to GICs and cause the protection scheme not to operate when there is a fault condition. Third, the protection system can operate slower than desired because of the presence of remanent flux in a CT caused by GICs. The remanent flux reduces the CT's time-to-saturation. This failure is difficult to directly associate with a GIC event because the CT error may not occur until several days after the occurrence of the GIC that produced the remanence. ${ }^{19}$ The relay systems that have the most problem with GICs are those for current unbalance, transformer neutral current, line residual current, and voltage unbalance protection systems. ${ }^{20}$

Past mishaps attributed to GIC include the tripping of circuit breakers from protection system malfunctions. On September 22, 1957, a 230-kV circuit breaker at Jamestown, North Dakota, tripped because of excessive third harmonic currents in the ground relays produced by saturated transformer cores. ${ }^{11}$ On November 13, 1960, a severe geomagnetic disturbance caused 30 circuit breakers to trip simultaneously on the 400-220-130-kV Swedish power system. ${ }^{21}$ In October 1980 and again in April 1986, a new 749-km 500-kV transmission line linking Winnipeg, 
Manitoba, with Minneapolis-St.Paul, Minnesota was tripped by protection system malfunctions due to GICs.

Small current transformers and potential transformers have been investigated to determine how dc currents affect their operating characteristics. ${ }^{2,23,24}$ One conclusion was that the harmonics generated by saturation of the instrument transformers would affect operation of a relay system not having harmonic desensitization..$^{22}$

Differential relay schemes on transformers are particularly susceptible to malfunction in the presence of GICS. This malfunction can be caused by CT saturation as well as by harmonics generated by saturation of the power transformers being protected. Saturation of a power transformer can cause the relay to fail to operate if there is a simultaneous fault in the power transformer..$^{23,24}$ Occurrence of undesired differential trips has been lessened, however, by the harmonic restraint originally incorporated in many modern relays to limit sensitivity to harmonics generated during transformer energization current inrush.

Concerns about circuit breaker operation during GIC include the possibility of increased secondary arc currents for single-pole switching on three-phase systems, and increased breaker recovery voltages. Secondary arc current refers to the current that flows through a fault arc during a single-line-to-ground fault and after the opening of circuit breaker poles on the faulted phase. It is caused by electromagnetic and electrostatic coupling from the two energized phases. Single-pole switching of only the faulted phase improves system reliability by allowing the two unfaulted phases to remain energized and still transmit power. Normally, the secondary arc current is primarily fundamental frequency with some harmonic content. When GIC is present, however, the magnitude of the secondary arc current is considerably increased - as much as tenfold - and the harmonic content of the current is increased. The increased magnitude of the secondary arc current caused by GIC increases the time needed for the arc to extinguish and decreases the probability of a successful line reclosure for a given single-phase dead time. Dead time refers to the time between circuit interruption in the single-pole on the opening stroke and reenergization of the circuit on the reclosing stroke. Since GICs alter the current-zeros (the instants at which the phase currents go to zero) and the time interval between current-zeros, the breaker recovery voltages can be excessive. Even when the EHV transmission line is de- 
energized, GICs can flow through the wye-connected shunt reactors on either end of the line, endangering the safety of line maintenance personnel attempting to switch out the reactors for maintenance. It is postulated that if a circuit breaker were to attempt to clear an unloaded saturated transformer or shunt reactor, a current-zero may not occur and chopping could result. ${ }^{25}$ The hypothesis has not been put to test, however, because to date no circuit breaker failures have been reported.

\subsubsection{Capacitors}

Capacitors that are affected by geomagnetic storms include grounded-wye shunt capacitor banks and capacitors used at static VAR compensator installations. All the capacitor banks that tripped out on March 13,1989, were grounded-wye-connected capacitor banks that were adjacent to power transformers and thus provided a current path to ground. In all of the cases, the protection system was a conventional unbalance scheme using a current transformer in the capacitor bank's neutral circuit. This protection scheme is designed to trip the capacitor bank when a given number of capacitor fuses have blown from the failure of capacitor cans. By tripping the capacitor bank, the protection scheme prevents excess voltage from being applied to the remaining capacitors in the bank, which can cause cascading failure of the surviving capacitor cans. However, some of these protection schemes also respond to any unbalanced or harmonic condition, and therefore will trip the capacitor bank during GICs. ${ }^{26}$

The experience of a few utilities has shown that GIC-related harmonic flow in neutrals of grounded capacitor banks is sufficient to operate neutral overcurrent relays that are not harmonically desensitized. During the March 13,1989, storm, Allegheny Power System experienced numerous operations on 10 of their 24 transmission-class capacitor installations. ${ }^{14}$ During the same period, Minnesota Power experienced an undesirable tripping of a 70-MVAR capacitor bank located on a $230-\mathrm{kV}$ bus and a $30-\mathrm{MVAR}$ bank on a $115-\mathrm{kV}$ bus. The relays protecting these banks were standard electromechanical time-overcurrent relays without any harmonic filters or restraint.

Only a few failures of capacitor banks, however, have been reported. One capacitor failure was reported in New York and one on the Hydro-Québec system at a static VAR 
compensator during the March 13 geomagnetic disturbance. These failures may have been caused by transients during the sectionalization of the power network.

\subsubsection{Static VAR Compensators (SVCs)}

SVCs, which provide rapid voltage regulation and reactive power compensation via thyristor-controlled capacitor banks, are relatively new devices for controlling VARs and voltages; therefore, the only experiences with them to be reported concern those during the March 13, 1989, storm. Hydro-Québec experienced the most problems with SVCs, which are coupled to the Hydro-Québec 735-kV system with dedicated transformers. The geomagnetic disturbance caused seven SVCs to trip out on the Hydro-Québec system: two SVCs at the Chibougamau substation, two SVCs each at the Albanel and Némiscau substations and one SVC at La Vérendrye. The loss of the SVCs caused the separation of the Hydro-Québec power system and the loss of approximately $21,500 \mathrm{MW}$ of generation. ${ }^{1}$ The generation was gradually restored over a nine-hour period: $25 \%$ was restored after three hours, $48 \%$ was restored after five hours, $65 \%$ was restored after seven hours, and $83 \%$ was restored after nine hours. ${ }^{18}$ The SVCs-caused system separation also resulted in overvoltage damage to two step-up transformers at the La Grande 4 generating station, to surge arresters at the La Grande 2 and Churchill Falls generating stations, and to a shunt reactor at the Némiscau substation, and damage to the SVCs themselves. An SVC transformer at the Chibougamau substation was also damaged by the overvoltage following system separation. Further, the SVC thyristors at the Nemiscau substation were damaged and the SVC capacitor banks at the Albanel substation failed. ${ }^{18}$

It is surmised that, during the March 13 storm, saturation of the system transformers produced a high level of harmonics in the line voltage. SVC coupling transformers, which also became saturated, transferred enough harmonics to the capacitor banks to cause the capacitor protection system to trip the SVCs. ${ }^{27}$ The SVCs at the Chibougamau substation tripped first, followed by the SVCs at the Albanel and Némisacau substations, and then the SVC at the La Vérendrye substation. Seven SVCs were lost in one minute, and about eight seconds later, because of low voltage conditions, the $735-\mathrm{kV}$ lines began to trip, which caused automatic load rejection of the LaGrande generation. This abnormal shutdown of the 735-kV system caused the SVC phase-C transformer at the Chibougamau substation to fail because of overvoltage. The 
SVCs at the La Vérendrye and Chibougamau substations were then subjected to a severely distorted voltage containing second- and fourth-order harmonics that resulted from the dc saturation of the system transformer cores. At the Chibougamau substation, overload protection tripped two SVCs, and at the La Vérendrye substation, overvoltage protection tripped one SVC that was in service at the time. The SVCs at the Némiscau and Albanel substations were tripped by capacitor unbalance and resistor overload protection devices of the third harmonic filter branch. $^{18}$

\subsubsection{Distribution System Problems}

To date, problems due to GIC on distribution systems have included blown fuses and voltage problems. Fuse blowing due to GIC was reported by Davidson for the storm of March 24, 1940..$^{28.29}$ Disturbances on ten power systems located in New England, New York, eastern Pennsylvania, southern and eastern Minnesota, and Ontario, Québec, caused a few transformer fuses to blow on a 2400/4150-V radial distribution system. Few details about the fuse operations are available.

On Feb. 11, 1958, during the same time as wide-spread circuit breaker operations in the Swedish 400/220/130-kV grid, part of the main Finnish coaxial cable telecommunication network broke down because of fuse blowing in the ac power supplies of repeater stations. Some fires were also experienced in the Swedish telecommunications system. ${ }^{28}$

On March 13, 1989, United Power Association (UPA) located in Elk River, Minnesota, experienced voltages problems at the Wabedo substation that UPA believes were due to GICs. ${ }^{30}$ UPA suspects that GICs caused the transformer supplying circuit 7 (south) of the Wabedo substation, which had been heavily loaded during that time to saturate and subsequently suppress the circuit voltage because of the increased VAR demand of the transformer. The lowered circuit voltage caused the voltage-regulator tap controller to operate and raise the voltage. UPA believes that the GICs decayed quite quickly following the voltage-regulator tap operation, leaving the circuit voltage quite high. The voltage-regulator tap controller was probably not able to reduce the circuit voltage fast enough following the decay of the GICs, resulting in customer TV and 
satellite antenna dish failures because of high voltage at the customers' homes. ${ }^{31}$ Six UPA customers reported these types of problems.

\subsection{COMMUNICATIONS AND CONTROL FACILITIES}

In addition to disrupting electric power transmission, geomagnetic disturbances can also interfere with utility communication systems. The effects of geomagnetic disturbances on communication systems as discussed below vary with the type of communications media that are employed. The types of communication systems typically used by electric utilities include radio systems (microwave and ultra-high, very-high, and high-frequency mobile), wire-based systems (metallic cables and power-line carrier), satellite, and fiber optics.

Wire-based systems such as cable communications are affected by solar-flare-induced changes in the magnetosphere that surrounds the earth, radio communications are affected by solar-flare-induced changes in the ionosphere layer of the atmosphere, and satellite communications are affected by flare-induced perturbations of satellite orbits and equipment. ${ }^{5}$

\subsubsection{Radio Communications and Controls}

The effect of geomagnetic disturbances on radio communication depends on the mode of radio transmission, which is either sky wave or ground wave. Sky waves are used primarily for long-distance radio communications, travel from the radio transmitter up to the electrically conducting layers of the earth's atmosphere known as the ionosphere, and are reflected back by these same layers to a receiver on the earth's surface. Ground waves are used for short-distance transmission, such as UHF radio communications, and travel directly from the radio transmitter to a radio receiver without using the earth's atmosphere for reflection. Sky-wave transmissions are affected by the electrical characteristics of the ionosphere, which vary with solar radiation. Ground-wave transmissions, however, are affected by the electrical characteristics of the earth's soil and sea, by the curvature of the earth, and by local weather conditions such as humidity.

Enhanced ionization in the ionosphere affects sky-wave radio transmissions. This ionization occurs as a result of extreme ultraviolet and $x$-radiation from solar flares and of the injection of energetic electrons and protons into the ionosphere from solar wind via the 
magnetosphere. The ionosphere is frequently characterized as consisting of three layers $(\mathrm{D}, \mathrm{E}$, and F) to represent the atmospheric depth to which various solar ionization effects reach.

High ionization of the D layer due to a bright solar eruption or flare can cause attenuation of the field intensity of high-frequency (3-30 MHz) radio transmissions and complete absorption of low- and medium-frequency (below $3 \mathrm{MHz}$ ) radio transmissions. Enhanced ionization of the D-layer, which can occur any time during the day and can last several minutes to several hours, results in a phenomenon called "sudden ionospheric disturbance" or "short-wave fadeout." During this phenomenon, high-frequency radio communication becomes impossible because of the reduction of the maximum usable frequency, Lower-, medium-, and high-frequency radio waves are not only absorbed but also refracted long distances, resulting in fading, noise, and interference. Fadeouts are less severe and shorter in duration as the frequency rises and are usually not noticeable above $40 \mathrm{MHz}$. The radio systems that are most subject to fadeout are the high- and low-band very-high-frequency (VHF) systems used in mobile voice communications for dispatching line crews. High-frequency radio systems operating in the mid-latitudes, for example, may experience a reduction of up to $50 \%$ of their maximum usable frequency. The disturbed ionosphere can also cause small random variations in the phase and amplitude of microwave (1-30 $\mathrm{GHz}$ ), UHF (300 MHz-3 GHz), VHF (30-300 MHz), and satellite transmissions. Ionospheric storms, which usually accompany magnetic disturbances and affect the entire earth, can occur approximately 18 hours after a sudden ionospheric disturbance and last from several minutes to several days. ${ }^{5}$ The storms reduce the field intensity of sky-wave radio transmissions above 1.5 $\mathrm{MHz}$ and cause rapid fading and blasting, commonly known as "flutter fading."

Polar cap absorption (PCA), which generally follows a major solar flare by an hour or two, can narrow the frequency available for radio transmissions by simultaneously lowering the maximum usable frequency and raising the lowest usable frequency. ${ }^{5}$ PCAs result from the ionization of $\mathrm{O}_{2}$ and $\mathrm{N}_{2}$ in the $\mathrm{D}$ layer of the ionosphere. PCAs are usually followed by a breakup in the ionospheric layers that creates a phenomenon called "auroral flutter." The flutter phenomenon is most noticeable on amplitude-modulated and suppressed-carrier amplitudemodulated radio transmissions. 
High solar activity can also cause high ionization of the E-layer and completely block out reflections of radio waves from the higher layers. This type of phenomenon occurs most commonly during the day but also occurs at night.

High ionization of the F-layer can also occur during solar activity and can cause enhanced propagation of VHF radio signals. This enhanced propagation can enable reception of radio transmission over distances of several thousands of miles.

Solar flares can also affect radio systems that depend primarily on ground-wave transmission rather than on wave reflections from the ionosphere, such as those that use upper VHF frequency ranges, UHF frequency ranges, and terrestrial microwave. Most microwave links are designed with a high fade margin to prevent degradation of service for even severe rain storms. However, geomagnetic disturbance effects may require the use of larger antennas with increased gain.

On March 13, 1989, there were numerous radio communication problems reported by electric utilities, such as fading of microwave and carrier communications and loss of telemetry. Some of the other events reported for terrestrial radio communications included problems with the operation of the long-distance radio-navigation system (LORAN), which operates at approximately $100 \mathrm{kHz}$ to $2 \mathrm{MHz}$, complete fadeout of the U.S. Navy's marine high-frequency (10-20 MHz) radio systems, short-wave fadeouts in Minnesota, and mobile radio transmissions from California's Highway Patrol that overpowered local Minnesota radio transmissions.

\subsubsection{Wire-Based Communications}

The effects of geomagnetic induction on long telegraph cables were the earliest evidence of solar disturbance effects on wire-based communication systems. As early as 1860 it was noted that during intense periods of the aurora borealis, telegraphic systems were observed to operate without the dc power sources otherwise required, or rendered inoperative ${ }^{32,33}$. High ESP gradients due to geomagnetic storms can cause fading and noise on wire-based communication systems and can also affect wires providing power to repeaters, resulting in voltage fluctuations and, in severe cases, failure of power supplies. 


\subsubsection{Fiber Optics}

Little empirical data exists on the operation of fiber optic communications during geomagnetic storms. A nonpropagating media for EMF, fiber optics may be the least affected by geomagnetic disturbances. However, components used in the power supplies for active fiber optic systems and in the interfaces between the fiber optic cable, as well as other fiber optic electronic equipment, are susceptible to geomagnetic storm disturbances. For example, geomagnetic disturbances induce voltages on the metallic conductors used to power fiber optic repeaters on long circuits such as submarine cables. The use of local power where available or the use of extended-range fiber optic systems that do not require repeaters can reduce the effects of geomagnetic disturbances. Also, many fiber optic cables have metallic members or protective armor that may conduct GIC and disturb the electronics in fiber optic links.

\subsubsection{Powerline Carrier}

During geomagnetic disturbances, power-line carrier systems experience a decrease in the signal-to-noise ratio due to the buildup of GICs which produces low-frequency and harmonicrelated noise. The increased use of highly-sensitive microelectronic-based carrier equipment has increased the susceptibility of carrier systems to geomagnetic disturbances.

\subsection{POWER PLANTS}

Several electric utilities have experienced generator trips during intense geomagnetic storms. ${ }^{18}$ There were also several alarms in generation stations due to phase-unbalance negativesequence currents. There are also concerns about the effects of harmonic currents on generators, although there have been no reported incidents of damages due to harmonics to date.

Delta-wye transformer connections, which are universally used for generator step-up transformers, block the flow of GICs to the generator; however, harmonic and negative-sequence currents can still appear at the generator. These currents can cause generator heating and mechanical vibrations. The conventional negative-sequence protection for generators, which uses phase-shifting networks to generate the tripping signal for the protection system, is designed to protect against fundamental-frequency imbalance. These phase-shifting networks do not respond 
the same at harmonic frequencies. Also, some protection systems use fundamental-frequency bandpass filters to prevent response to harmonic currents. During geomagnetic disturbances, generators and turbines will not be damaged by GICs directly, but may be damaged by the imbalance and harmonic distortion caused by the saturation of transformers. Although no damage has been reported to date, the heating and mechanical vibration caused by geomagnetic disturbances tend to result in fatigue and shortening of lifespan, rather than immediate generator or turbine failure. ${ }^{34}$ 


\section{MEASURED DATA}

\subsection{INTRODUCTION}

The electric utility industry has monitored the effects of geomagnetic storm activity during solar cycles 20,21, and 22 (the present cycle). Unfortunately, extensive monitoring was generally conducted during periods of relatively low geomagnetic activity from 1969 to 1972 and from 1977 to 1989. The interest in monitoring increased again after the storm of March 1989. The available data is limited both in quantity and quality, and much of the data from monitoring during the earlier periods has been lost or discarded. The two quantities most often measured were the geomagnetic fields and the GICs in transformer neutrals. In addition, there were some measurements of ESP, system harmonics, and changes in VAR demand.

In addition to system monitoring during solar storms, some special experiments have been conducted and others are scheduled during 1991. Most of these experiments involve the injection of dc current into transformer neutrals to monitor the effects.

After the severe geomagnetic storm of March 13, 1989, the utility industry became seriously interested in building a data base from disturbance monitoring of GIC effects. EPRI is sponsoring a monitoring and communications network named Sunburst which will cover the U.S. and Canada. Sunburst should be in place in the next several years, and in its ultimate possible implementation could provide real-time GIC reports, and archive GIC events occurring throughout the Sunburst network.

\subsection{GEOMAGNETIC FIELD MEASUREMENTS}

Most geomagnetic field disturbance measurements have been made by government observatories, although a few electric utilities own and operate their own magnetometers. There are at least 28 magnetometers in the U. S. and Canada, most of which are operated by the National Oceanic and Atmospheric Administration's (NOAA's) Space Environment Services Center (SESC) in Boulder, Colorado, by other U. S. government agencies, and by the Geological 
Survey of Canada. ${ }^{35}$ Utilities will be adding more magnetometers as part of the Sunburst Network.

An example of magnetometer data measured at the Poste-de-la-Baleine Magnetic Observatory located at James Bay in Québec, Canada, on March 13, 1989, is shown in Fig. 3.1. Note that the relatively fast variations in the north-south magnetic fields, as shown in Fig. 3.1(a), result in relatively large east-west electric field variations (which are not shown). It is also noteworthy that fast variations in the east-west geomagnetic field occasionally occur, as shown in Fig. 3.1(b).

\subsection{GIC MEASUREMENTS}

During the period from 1969 to $1972,64 \mathrm{dc}$ recording ampere meters were installed in the neutral leads of grounded-wye transformers. This was a period of low geomagnetic activity and most of the solar storms were classified as $\mathrm{K} \leq 6$. However, there were a few $\mathrm{K}-8$ and $\mathrm{K}-9$ storms that caused power systems disturbances. An example of one GIC recorded during a K-8 storm on August 4, 1972, at Minnesota Power's Arrowhead substation is shown in Fig. 3.2. ${ }^{36}$ The current changed from 0 to about $60 \mathrm{~A}$ over a period of approximately 3 minutes. A summary of the GIC recording from 1969 to 1972 in transformer neutrals across the U.S. is shown in Table 3.1 .

From 1978 to 1980, GIC-related data was collected by Minnesota Power and the University of Minnesota under EPRI sponsorship. A magnetometer and ESP measuring equipment were installed in Minnesota Power's Forbes Substation. GIC recorders were installed in a 500-kV line from Winnipeg, Manitoba, to Duluth, Minnesota. The 1978-1980 time frame was a period of low levels of geomagnetic activity. In addition to the limited data, there were also numerous errors and instrumentation malfunctions that resulted in some erroneous data. ${ }^{17}$

Allegheny Power System (APS) has been operating its network of GIC recorders since October 1989.35 Neutral dc currents are measured in a number of transformer and capacitor banks throughout the APS network. So far, APS has measured currents up to $40 \mathrm{~A}$, and, in general, has found that higher current levels occur during higher-K level storms, but there is not 

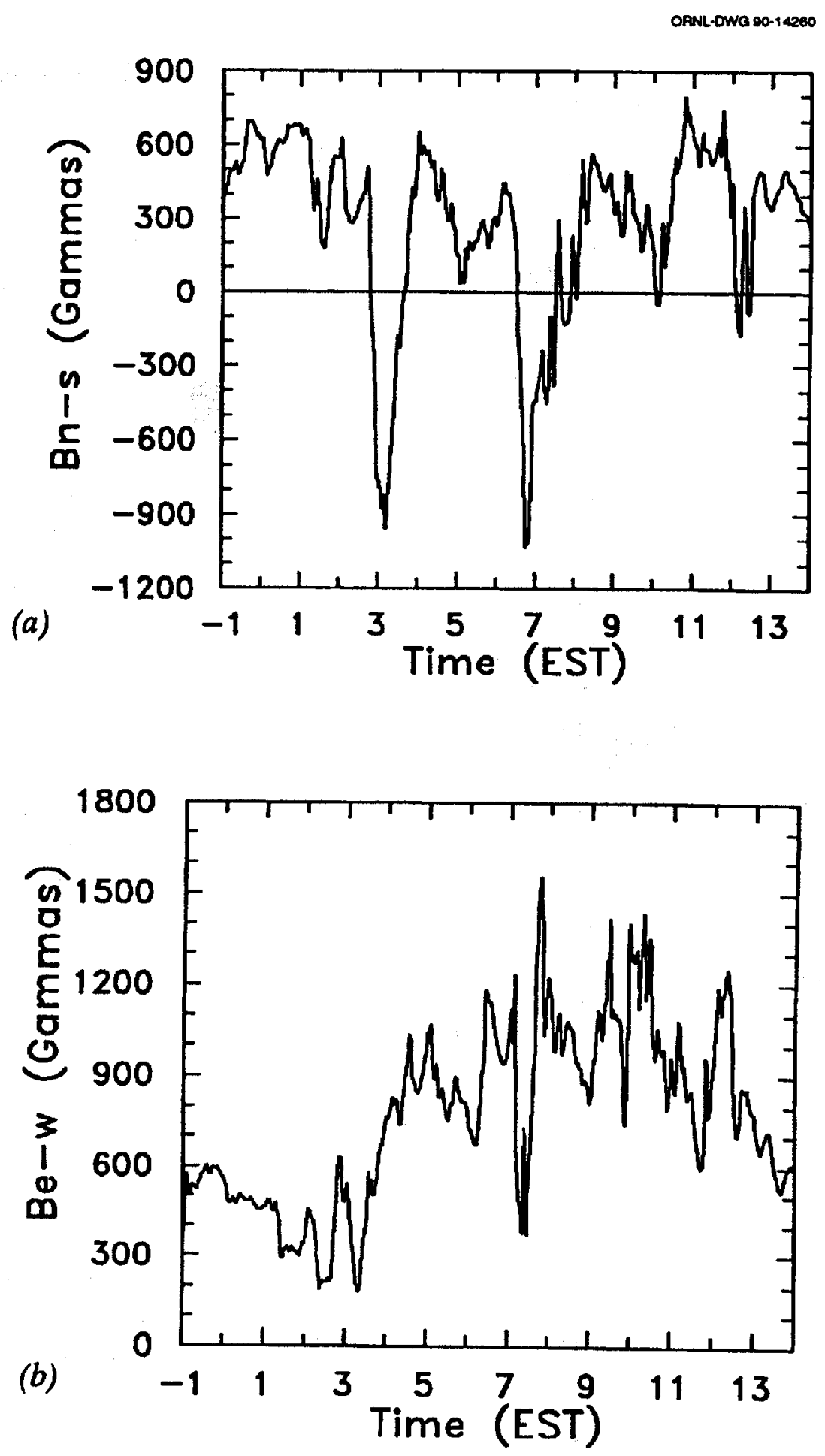

Fig. 3.1. Geomagnetic fields measured on March 13, 1989, by Poste-de-la-Baleine Magnetic Observatory, James Bay, Quebec, Canada. (a) North-south direction, (b) east-west direction. 


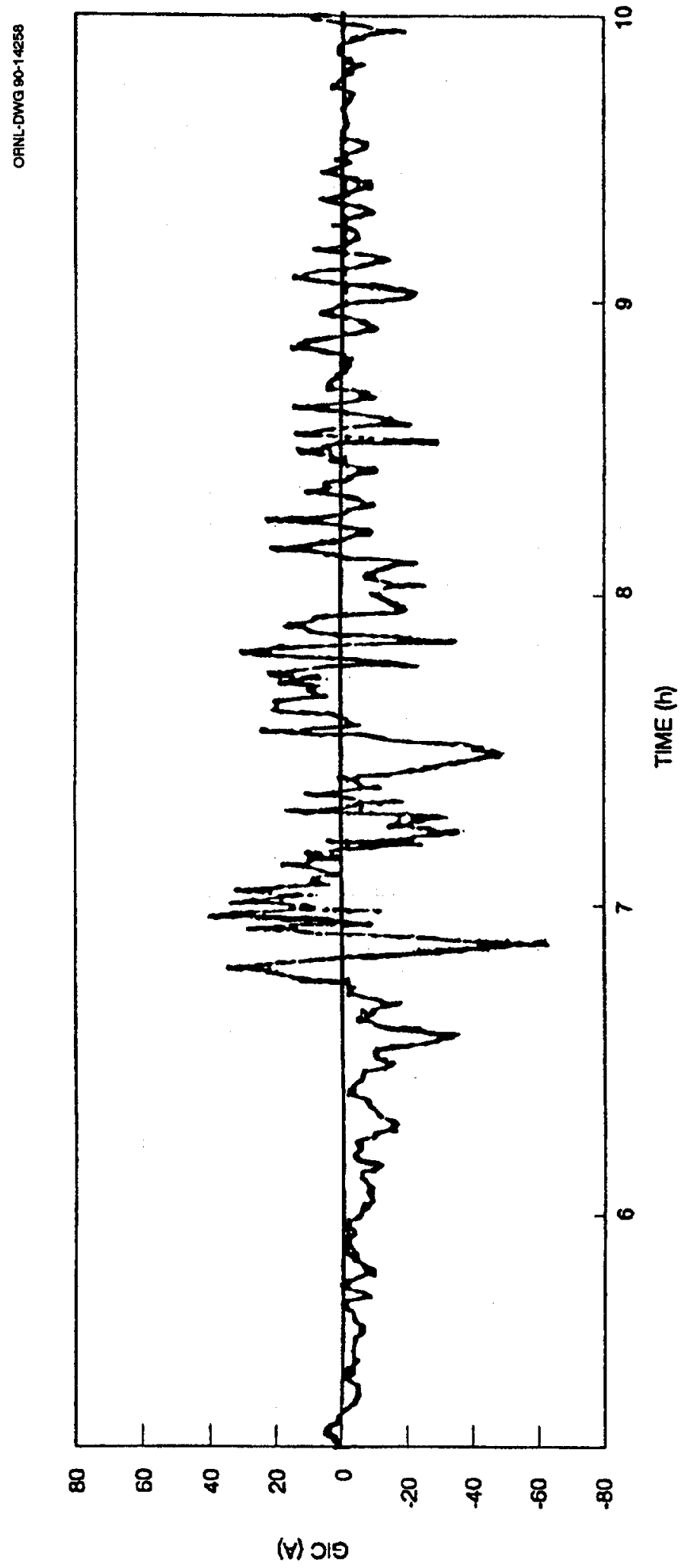

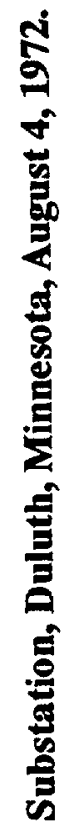

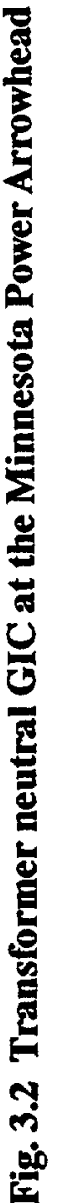


a good correlation. An interesting finding is that all the recorded GICs in the APS network appear to be in phase and to have the same relative magnitude. APS has also found that GICs are largest near the igneous rock formation. Similar results have been observed by other utilities in the Northeast such as the Philadelphia Electric Company.

Table 3.1 Geomagnetically induced currents recorded in transformer neutrals from March 1969 to September 1972 (39 months), ranked by maximum GIC

\begin{tabular}{|c|c|c|c|c|c|}
\hline Ranking & $\begin{array}{l}\text { Electric Power } \\
\text { Company }\end{array}$ & Substation & $\begin{array}{l}\text { Maximum } \\
\text { GIC in } \\
\text { Neutral } \\
\text { (A) }\end{array}$ & $\begin{array}{l}\text { Average No. } \\
\text { of GIC } \\
\text { Occurrences } \\
\text { per Month }\end{array}$ & $\begin{array}{c}\text { Average } \\
\text { GIC } \\
\text { Current } \\
\text { Level (A) }\end{array}$ \\
\hline 1 & $\begin{array}{l}\text { Newfoundland and } \\
\text { Labrador Power }\end{array}$ & Corner Brook & $100+$ & 39.00 & 16.50 \\
\hline 2 & $\begin{array}{l}\text { Philadelphia } \\
\text { Electric }\end{array}$ & Whitpain No. 1 & 98 & 3.92 & 9.89 \\
\hline 3 & $\begin{array}{l}\text { Philadelphia } \\
\text { Electric }\end{array}$ & Whitpain No. 3 & 86 & 4.95 & 9.28 \\
\hline 4 & $\begin{array}{l}\text { Philadelphia } \\
\text { Electric }\end{array}$ & Peachbottom & 76 & 6.35 & 10.25 \\
\hline 5 & $\begin{array}{l}\text { Consolidated } \\
\text { Edison }\end{array}$ & Pleasant Valley & 68 & 1.82 & 13.40 \\
\hline 6 & $\begin{array}{l}\text { Virginia Electric } \\
\text { Power }\end{array}$ & Elmont & 68 & 4.22 & 7.97 \\
\hline 7 & Minnesota Power & Arrowhead & 58 & 6.91 & 7.65 \\
\hline 8 & $\begin{array}{l}\text { Pennsylvania } \\
\text { Power and Light }\end{array}$ & Juniata No. 2 & 48 & 3.83 & 8.37 \\
\hline 9 & Otter Tail Power & Benidji & 44 & 4.18 & 6.38 \\
\hline 10 & $\begin{array}{l}\text { Pennsylvania } \\
\text { Power and Light }\end{array}$ & Juniata No. 1 & 44 & 3.75 & 11.42 \\
\hline 11 & $\begin{array}{l}\text { Central Maine } \\
\text { Power }\end{array}$ & Bucksport & 32 & 2.41 & 6.73 \\
\hline 12 & $\begin{array}{l}\text { Central Maine } \\
\text { Power }\end{array}$ & Wyman Hydro & 32 & 3.35 & 7.11 \\
\hline 13 & $\begin{array}{l}\text { Consolidated } \\
\text { Edison }\end{array}$ & Sprain Brook & 32 & 1.30 & 7.78 \\
\hline
\end{tabular}

Source: V. D. Albertson, "Measurements and Instrumentation for Disturbance Monitoring of Geomagnetic Storm Effects," Effects of Solar-Geomagnetic Disturbances on Power Systems, IEEE Publication 90TH0291-5 PWR, Special Panel Session Report, IEEE PES Summer Meeting, 1989. 
Table 3.1 (continued)

\begin{tabular}{|c|c|c|c|c|c|}
\hline Ranking & $\begin{array}{l}\text { Electric Power } \\
\text { Company }\end{array}$ & Substation & $\begin{array}{l}\text { Maximum } \\
\text { GIC in } \\
\text { Neutral } \\
\text { (A) }\end{array}$ & $\begin{array}{l}\text { Average No. } \\
\text { of GIC } \\
\text { Occurrences } \\
\text { per Month }\end{array}$ & $\begin{array}{c}\text { Average } \\
\text { GIC } \\
\text { Current } \\
\text { Level (A) }\end{array}$ \\
\hline 14 & Minnesota Power & Silver Bay & 28 & 4.29 & 7.11 \\
\hline 15 & $\begin{array}{l}\text { Texas Electric } \\
\text { Service }\end{array}$ & Everman & 24 & 2.34 & 6.33 \\
\hline 16 & $\begin{array}{l}\text { Southern California } \\
\text { Edison }\end{array}$ & Sylmar & 22 & 2.40 & 7.84 \\
\hline 17 & Otter Tail Power & Winger & 20 & 2.89 & 5.66 \\
\hline 18 & $\begin{array}{l}\text { Niagara Mohawk } \\
\text { Power }\end{array}$ & Rotterdam & 18 & 0.91 & 7.11 \\
\hline 19 & $\begin{array}{l}\text { Metropolitan } \\
\text { Edison }\end{array}$ & Hosensack & 16 & 3.76 & 5.70 \\
\hline 20 & $\begin{array}{l}\text { Metropolitan } \\
\text { Edison }\end{array}$ & N. Temple & 16 & 0.55 & 4.36 \\
\hline 21 & $\begin{array}{l}\text { Northern States } \\
\text { Power }\end{array}$ & Black Dog & 16 & 1.81 & 6.25 \\
\hline 22 & $\begin{array}{l}\text { Northern States } \\
\text { Power }\end{array}$ & $\begin{array}{l}\text { Minnesota } \\
\text { Valley }\end{array}$ & 16 & 1.47 & 8.40 \\
\hline
\end{tabular}

Source: V. D. Albertson, "Measurements and Instrumentation for Disturbance Monitoring of Geomagnetic Storm Effects," Effects of Solar-Geomagnetic Disturbances on Power Systems, IEEE Publication 90TH0291-5 PWR, Special Panel Session Report, IEEE PES Summer Mecting, 1989.

GICs are generally thought to occur in transmission systems, but a substantial GIC can occur in a subtransmission line connected to the transmission system through an auto-transformer. Such a case is a $69-\mathrm{kV}$ line connected to the Missouri Avenue Substation in Atlantic Electric's system. An example of a GIC measurement is shown in Figure 3.3 for a $\mathrm{K}-6$ geomagnetic storm starting on April 9, 1990. The peak current measured during a 100-hour period is about $8 \mathrm{~A}$ as shown in Fig. 3.3(a). In Fig. 3.3(b), peak current is about $3.5 \mathrm{~A}$ and the corresponding field is about $0.35 \mathrm{~V} / \mathrm{km}$. For a very severe $\mathrm{K}-9$ storm with an electric field of $6 \mathrm{~V} / \mathrm{km}$, peak currents on the order of $60 \mathrm{~A}$ to $80 \mathrm{~A}$ can be expected. 

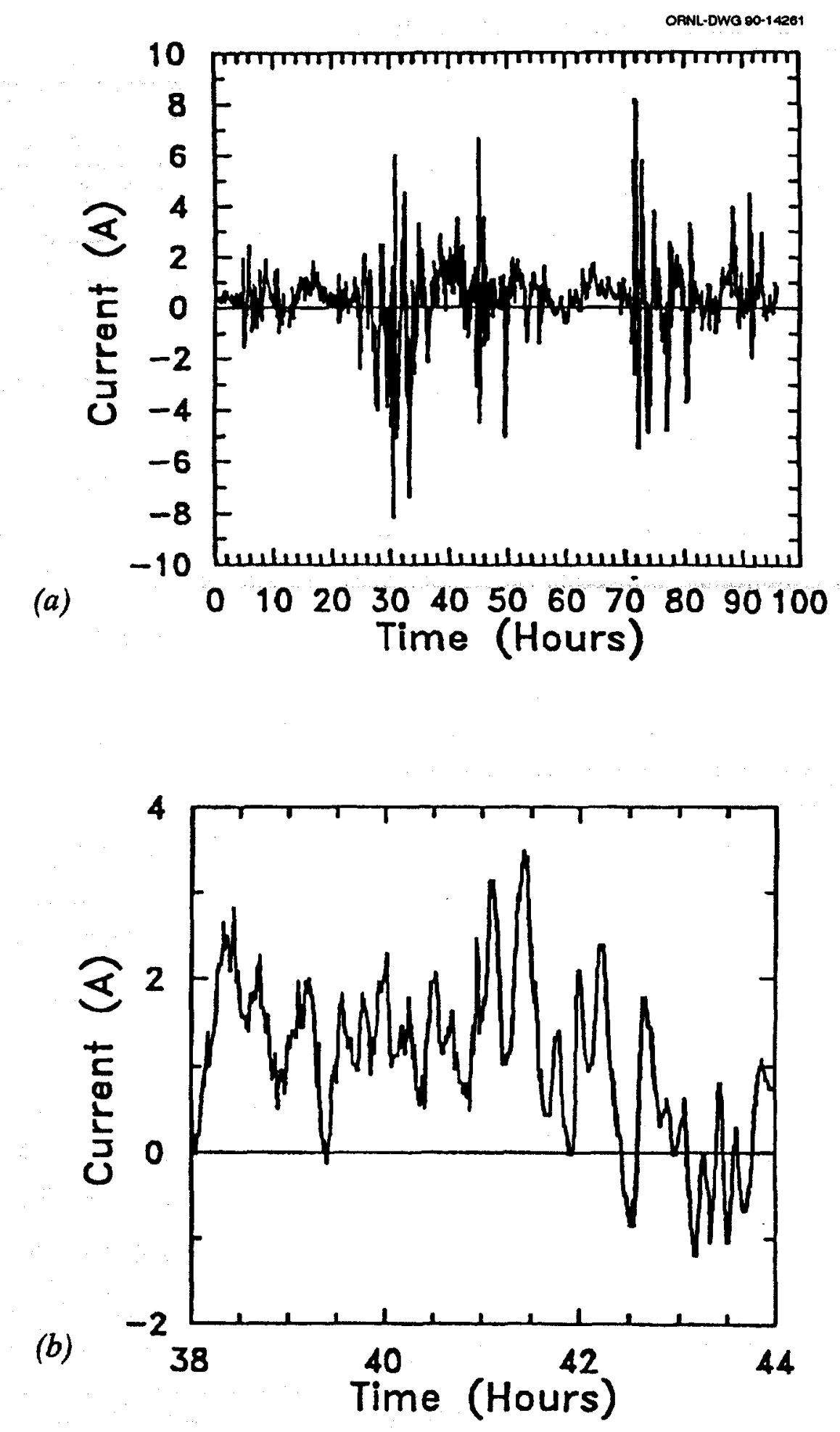

Fig. 3.3. Neutral current measured at the Missouri Ave. 6.9-kV/12-kV substation starting on April 4, 1990. (a) GIC Measured over a 100-h period, (b) GIC measured over a 6-h period. Source: C.K. Bush, Atlantic Electric Co. 


\subsection{ESP AND ELECTRIC FIELD MEASUREMENTS}

Hydro-Québec made measurements of ESP and average electric fields during the early eighties. Electric fields were determined by ESP measurements (ESP/distance between grounding points). Typical data of ESP activity at the Boucherville substation measured by Hydro-Québec are shown in Fig. 3.4 for July 13, 1982. Figure 3.5 shows the computed electric field (ESP gradient) from the recorded geomagnetic field based on the technique described in a previous report. ${ }^{37}$ There is very good agreement between the calculated and the measured data shown in Fig. 3.4(a). To compute the electric field, a ground resistivity of $55.6 \Omega-m$ was assumed, i.e., conductivity equal to $0.018 \mathrm{mhos} / \mathrm{m}$. Although measurements made by Hydro-Québec indicate that the ground resistivity over much of the region is about $20,000 \Omega-\mathrm{m}$, the ground resistivity at the Boucherville substation is low $-100 \Omega$-m or lower. ${ }^{38}$ Thus, the $55.6 \Omega$-m used in the calculations is reasonable. Minnesota Power Company plans to operate an ESP meter using insulated shield wires. Data from this measurement will not be available until after the summer of 1991.

\subsection{CAPACITOR CURRENT MEASUREMENTS}

APS has implemented a measurement program as a result of the capacitor problems that were described earlier in section 2.2.4 and has found that capacitor neutral ac currents and transformer dc current increase simultaneously during solar geomagnetic storms, indicating that system harmonics increase linearly with increasing transformer saturation. ${ }^{35}$

\subsection{TRANSFORMER TEMPERATURE}

Only limited data exists on transformer temperature rise during geomagnetic storms. APS monitored transformer tank temperature after the March 13, 1989 event. Data were recorded during two geomagnetic storms in the fall of 1989 . For some transformer designs, there appears to be a strong correlation between GIC level and tank temperature increase, but more data are need before a detailed analysis can be performed. ${ }^{14}$ However, Hydro-Québec measurements that were taken over a two-year period in a $735-\mathrm{kV}$ transformer located at LG2 did not reveal any correlation between temperature and GIC. 

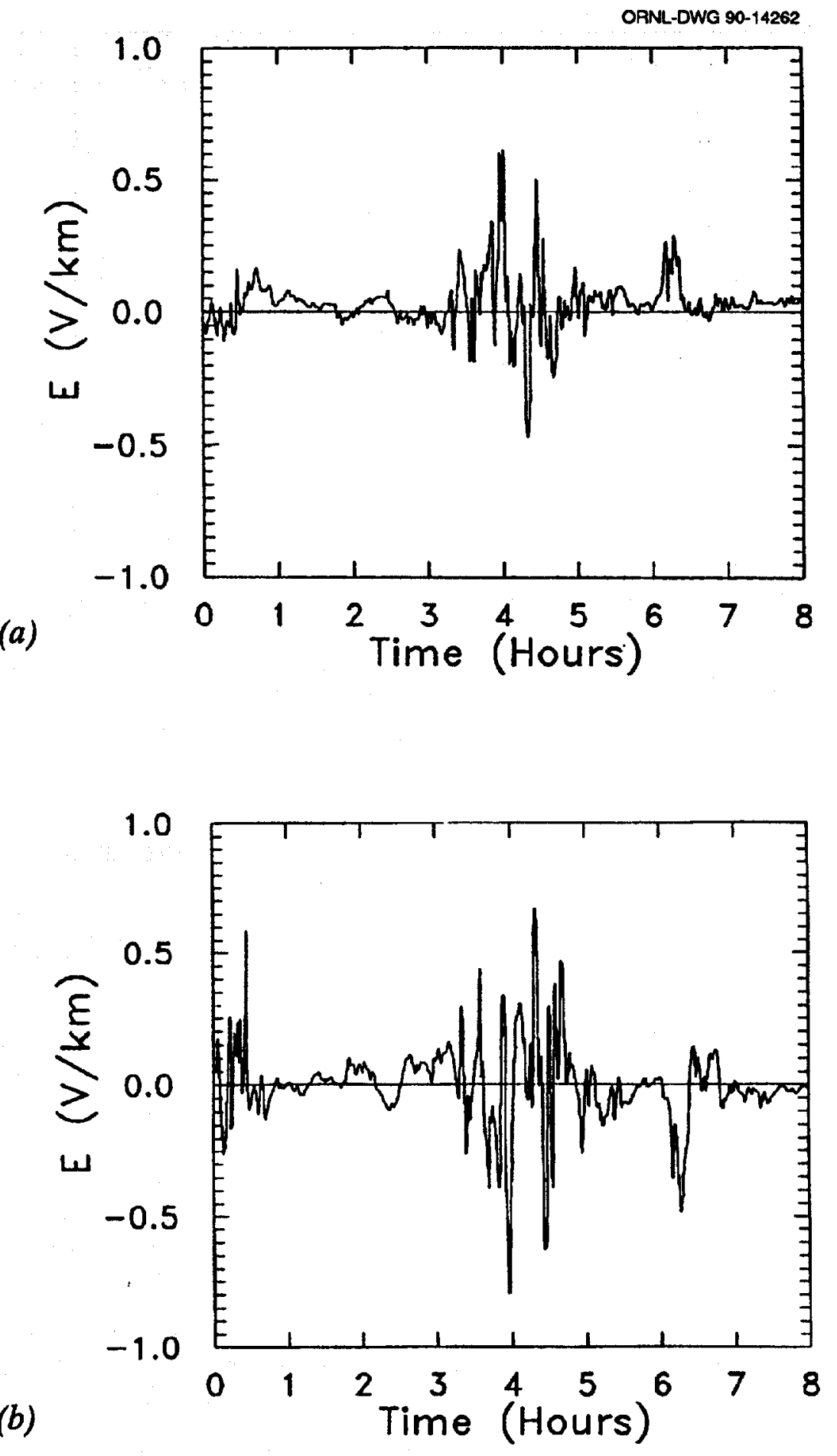

Fig. 3.4. ESP gradient measured at Hydro-Québec's Boucherville substation. (a) East-west direction, (b) north-south direction. Source: M. Granger of Hydro-Québec. 

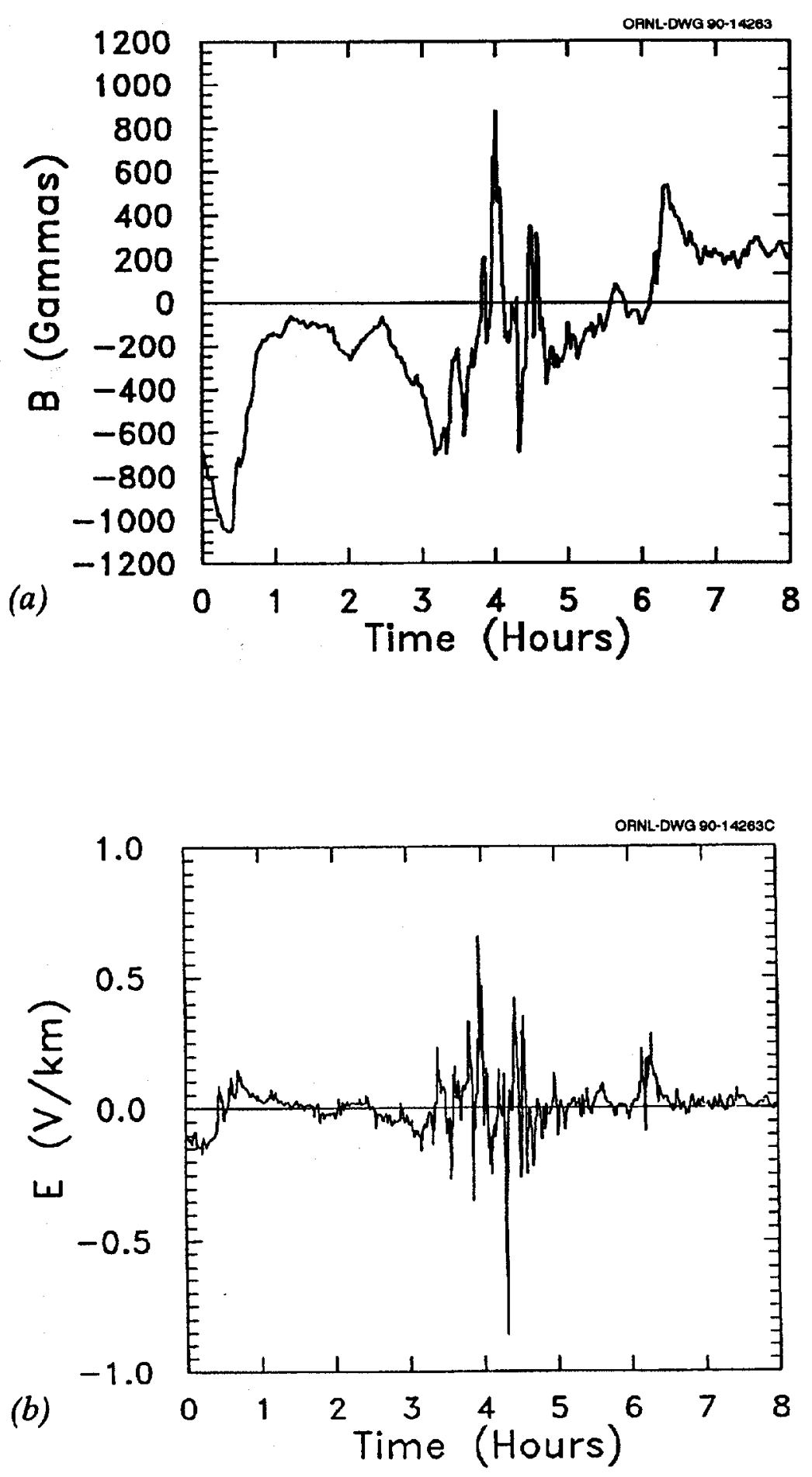

Fig. 3.5. Geomagnetic and electric fields at Hydro-Québec's Boucherville substation on July 13, 1982. (a) Measured north-south geomagnetic field disturbance, (b) computed eastwest electric field for a ground resistivity of 55.6 $\Omega-m$. 


\subsection{SPECIAL EXPERIMENTS}

A number of special experiments have been conducted by electric utilities and manufacturers of power system components to determine the effects of quasi-dc in ac power systems. These experiments and the important results are summarized in this section.

\subsubsection{Transformer De Excitation Field Test}

Minnesota Power conducted a field test in 1983 that was funded by EPRI to evaluate the response of autotransformers to dc excitation. The three types of autotransformers included in the test were single-phase shell form, three-phase three-legged core form, and three-phase shell form. ${ }^{39} \mathrm{~A}$ set of truck batteries wired in series to obtain $24 \mathrm{~V}$ was used to inject the dc excitation current. It was found that all of the transformers tested exhibited half-cycle saturation due to dc excitation, but single-phase transformers were particularly susceptible. The levels of harmonic currents and transformer reactive power requirements were found to be roughly proportional to the dc excitation current. High levels of harmonic currents were measured for the first, second, third, fourth, and sixth harmonics. For a 75-A neutral dc current, the second harmonic current levels were 84.6 A," 8.6 A, and 10.1 A for the single-phase shell, three-phase core-form and three-phase shell transformers, respectively. ${ }^{40}$

\subsubsection{De Injection in the Ac Transmission System}

In May 1988, dc currents were injected into Hydro-Québec's ac transmission system near the electrode of the HVDC converter at Des Cantons Substation. ${ }^{41}$ A dc current of 780 A was injected at the HVDC converter electrode, which resulted in neutral currents of about 16-A in several transformers. Harmonic currents were measured for the second through the seventh harmonic. In general, the second harmonic current was the largest, with an amplitude of about 1.5 times the phase dc current. The second largest harmonic current was the fourth harmonic, with an amplitude about equal to that of the dc current.

In September 1990, Hydro-Québec conducted a similar test at Radissen. Preliminary results indicate that transformers may saturate in $1 \mathrm{~min}$ or less after the dc current is injected.

\footnotetext{
* Calculated by the authors of ref. (40) from transformer test measurements given in ref. (39).
} 
It appears that the time required to drive transformers into saturation is about $1 \mathrm{~min}$ for phase current levels of about $17 \mathrm{~A}$. Hydro-Québec may perform a follow-up test at higher current levels.

\subsubsection{Distribution Transformer Test}

In June 1990, a distribution transformer test was conducted by Oak Ridge National Laboratory (ORNL) under Defense Nuclear Agency (DNA) sponsorship. ${ }^{42}$ The test team consisted of engineers and scientists from ORNL, ASEA Brown Boveri (ABB) Power Systems, Inc., Mission Research Corporation, and the Public Service Company of New Mexico (PNM). The transformers tested were:

- two three-phase 75-kVA wye-wye connected $12.47-\mathrm{kV} / 208-\mathrm{V} / 120-\mathrm{V}$ units,

- one three-phase 300-kVA 12.47-kV/480-V wye-wye connected unit, and

- one 75-kVA three-phase $12.47-\mathrm{kV} / 208-\mathrm{V} / 120-\mathrm{V}$ delta-wye connected unit.

The test confirmed that ungrounded-wye connected transformers and delta connected transformers do not provide a path to earth for GIC. Grounded-wye connected transformers begin to show saturation effects at GIC levels from $2 \%$ to $5 \%$ of the rated ac current, i.e., quasidc neutral current levels equal to $2 \%$ to $5 \%$ of 3 times the rated ac phase current. For GIC levels of $5 \mathrm{~A}$ in the high-voltage primary circuit and $50 \mathrm{~A}$ in the low-voltage secondary circuit, extensive harmonic distortion resulted. In general, harmonic distortion is passed to the attached equipment. Excessive distortion can result in equipment failure. ${ }^{43}$ The time required to drive the transformers into saturation was found to be about $1 \mathrm{~s}$ or less for a GIC level of $5 \mathrm{~A}$ in the high-voltage primary circuit.

\subsection{SYSTEM RESPONSE DATA}

The March 13, 1989, blackout of the Hydro-Québec Power System provides an example of the response of an entire power system to a very intense geomagnetic storm. ${ }^{18}$ At 2:44 a.m. Eastern Standard Time (EST), an intense storm was underway, and the Hydro-Québec operating staff were experiencing some difficulties in controlling voltage. Harmonics due to GICs were causing problems with HVDC converters, voltage regulation, and generator excitation. Total 
generation was $21,500 \mathrm{MW}$ with $9500 \mathrm{MW}$ supplied from the LaGrande Complex near James Bay, Québec. ${ }^{1}$

Some of the harmonic currents generated by saturated transformers flowed to ground through shunt capacitors associated with SVCs. Figure 3.6 shows the conditions of the HydroQuebec system prior to the system blackout. At 2:44:17 a.m., an SVC tripped at Chibougamau because of overcurrent. This started a sequence of events outlined below:

- 2:44:17 a.m. Tripping of static VAR compensator CLC 12 at Chibougamau.

2:44:19 a.m. Tripping of static VAR compensator CLC 11 at Chibougamau.

- 2:44:33 a.m. to Shutdown of the four SVCs at the Albanel and Némiscau 2:44:46 a.m. substations.

- 2:45:16 a.m. Tripping of static VAR compensator CLC 2 at La Vérendrye.

- 2:45:24.682 a.m. Tripping of line 7025 at the Jacques Cartier substation.

- 2:45:24.936 a.m. Tripping of line 7044 at the La Vérendrye substation.

- 2:45:24.948 a.m. Tripping of line 7016 at the La Vérendrye substation.

- 2:45:24.951 a.m. Tripping of line 7026 at Chamouchouane substation.

- 2:45:24.978 a.m. Tripping of line 7045 at the Grand-Brule and La Vérendrye substations.

By 2:46 a.m., most of the Hydro-Québec (HQ) system was down. The system frequency measured at Boucherville substation is shown in Fig. 3.7. Once the last SVC was tripped, the HQ system collapsed in less than $30 \mathrm{~s}$. Overvoltages due to the shutdown caused faults at two high-voltage transmission substation transformers.

The lines that connect to the Chibougamau station run southeast to the Chamouchousane station, north to the Albanel station, and west to the Abitibi station. The geomagnetic field disturbance recorded at the Ottawa Magnetic Observatory on March 13, 1989, between the hours of midnight and $8 \mathrm{a} . \mathrm{m}$. is shown in Fig. 3.8. Note that the normal ambient fields have been removed to show only the change in the geomagnetic field. Figure 3.9 is a half-hour time 


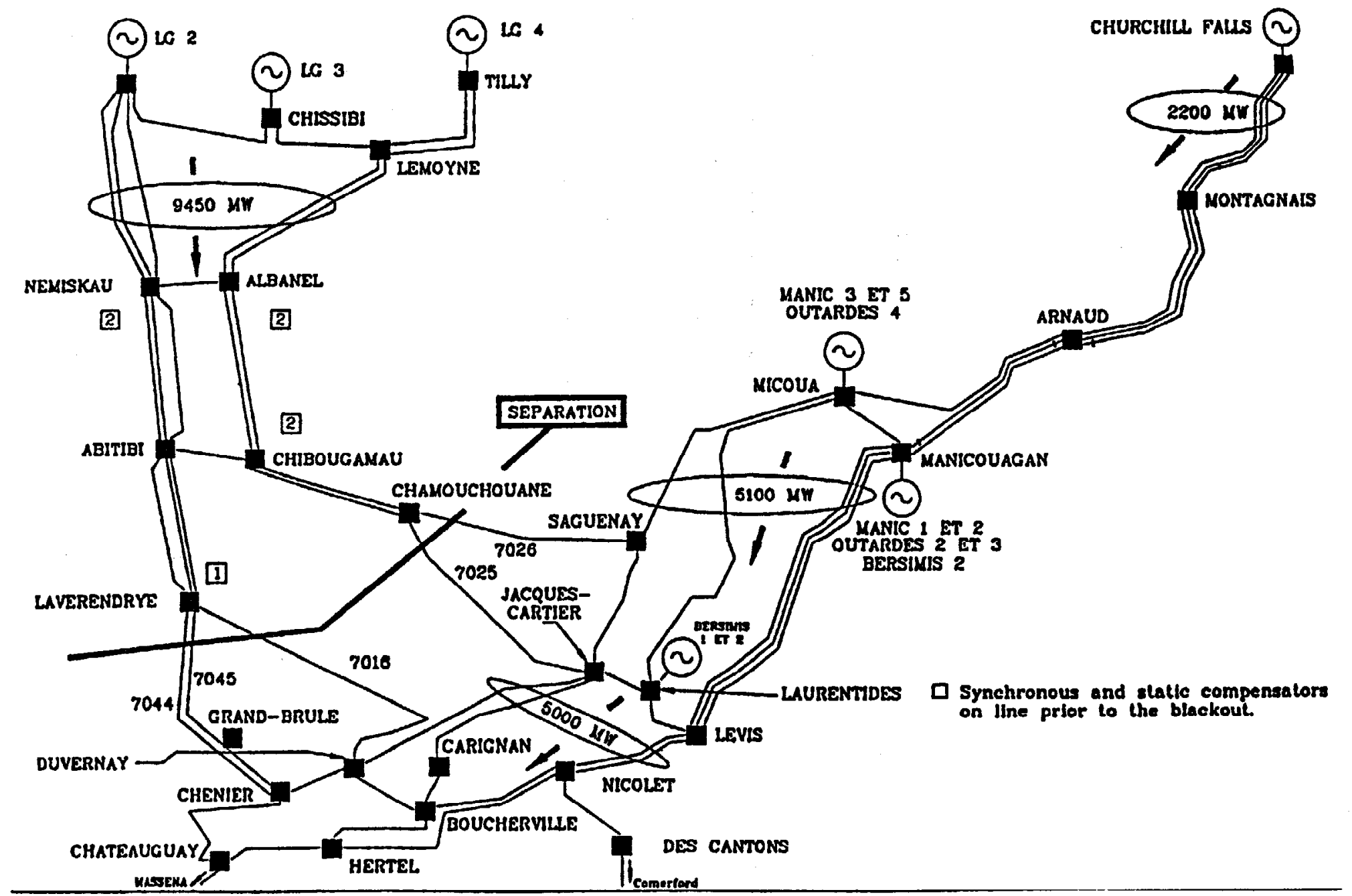
Source: Hydro-Quebec. 


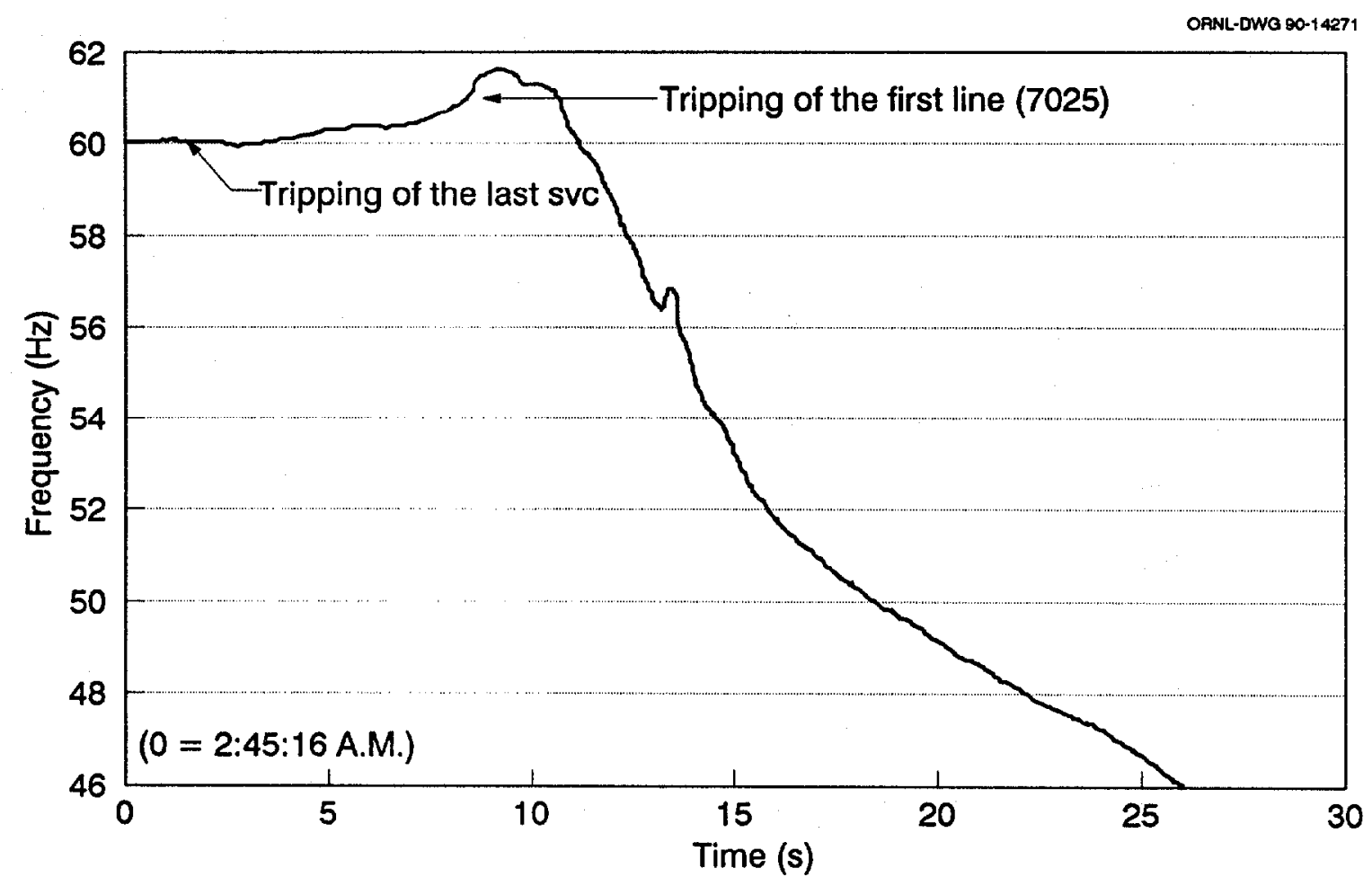

Fig. 3.7. Frequency at Boucherville Substation.

window of Fig. 3.8 and shows the change in the magnetic field during the time that $\mathrm{HQ}$ experienced problems. It is assumed that a similar geomagnetic field disturbance was also occurring in the vicinity of the Chibougamau station where the earth resistivity ranges from 10,000 to $20,000 \Omega-\mathrm{m}$. The electric field computed from the magnetic field disturbance (Fig. 3.9) is shown in Fig. 3.10. The electric field components were calculated for a ground conductivity of $1.0 \times 10^{-4}$ mhos per meter. Note that at 2:44:17 a.m. EST, an east-west electric field of about $-10 \mathrm{~V} / \mathrm{km}$ persists for about 30 seconds. A second east-west negative peak of about $8 \mathrm{~V} / \mathrm{km}$ and a north-south negative peak of $3 \mathrm{~V} / \mathrm{km}$ occurred at around 2:45:36 am. However, it appears that the first SVC trips were caused by an east-west field of about $10 \mathrm{~V} / \mathrm{km}$. It can therefore be concluded from the available data that the HQ power system was shut down by a severe geomagnetic storm with fields on the order of $10 \mathrm{~V} / \mathrm{km}(14 \mathrm{~V} / \mathrm{km}$ for a ground conductivity of $5.0 \times 10^{-5}$ mhos per meter). 

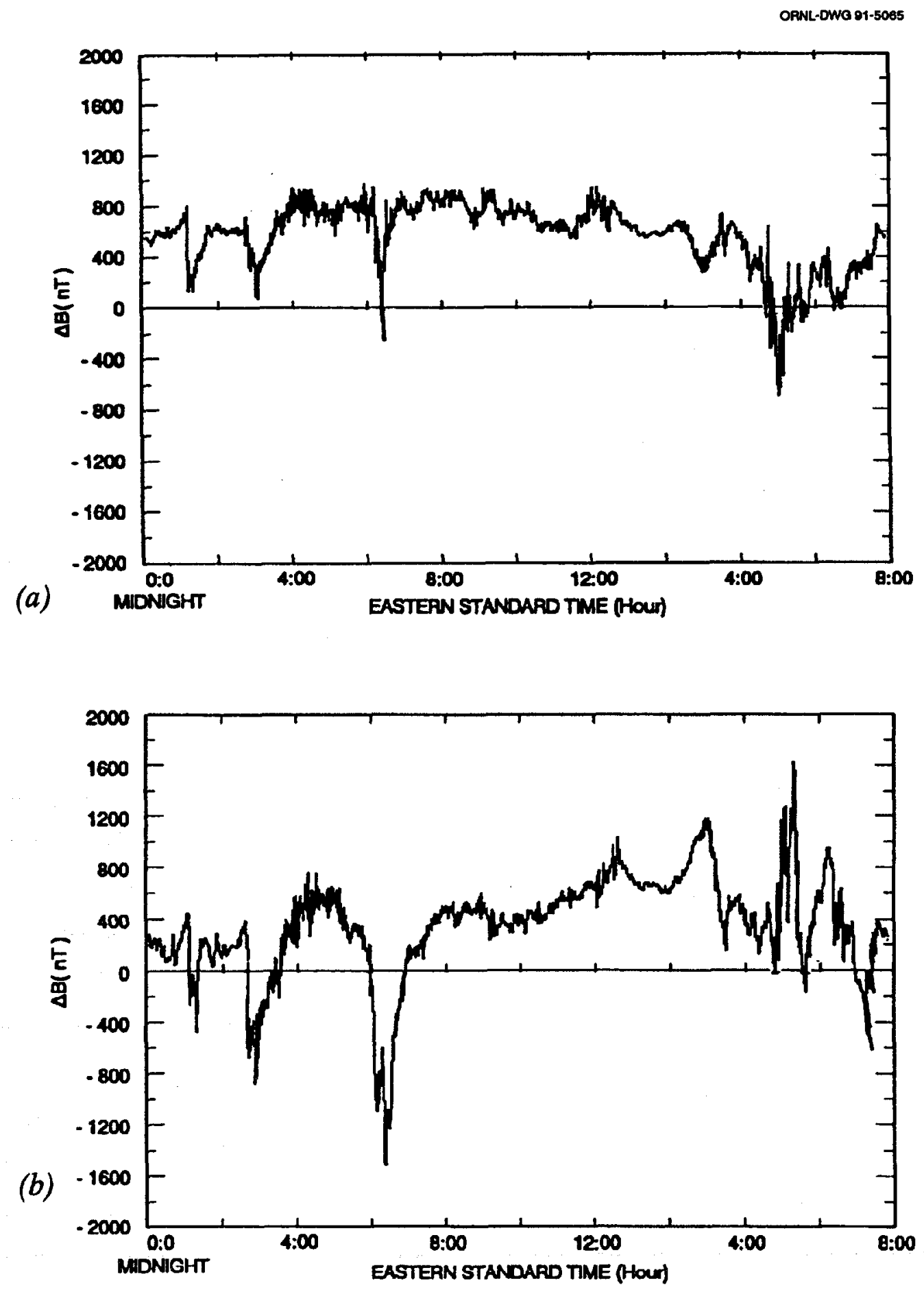

Fig. 3.8. Geomagnetic field disturbance recorded at the Ottawa Magnetic Observatory on March 13, 1989, between the hours of midnight and 8 a.m. (a) East-west geomagnetic field, (b) north-south geomagnetic field. 

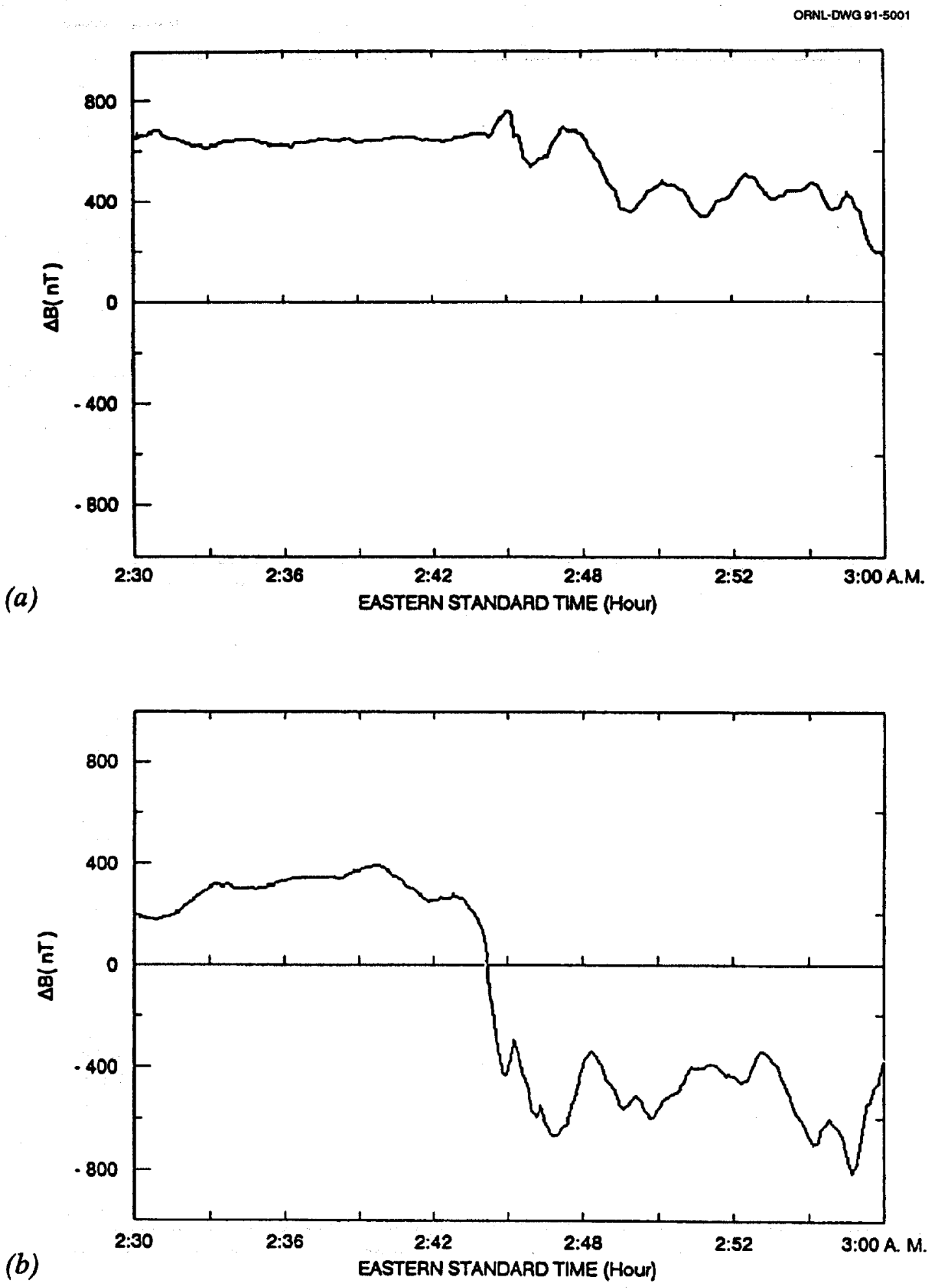

Fig. 3.9. Geomagnetic field disturbance recorded at the Ottawa Magnetic Observatory between 2:30 and 3:00 a.m. on March 13, 1989. (a) East-west geomagnetic field, (b) north-south geomagnetic field. 
ORNL-DWG $91-5002$
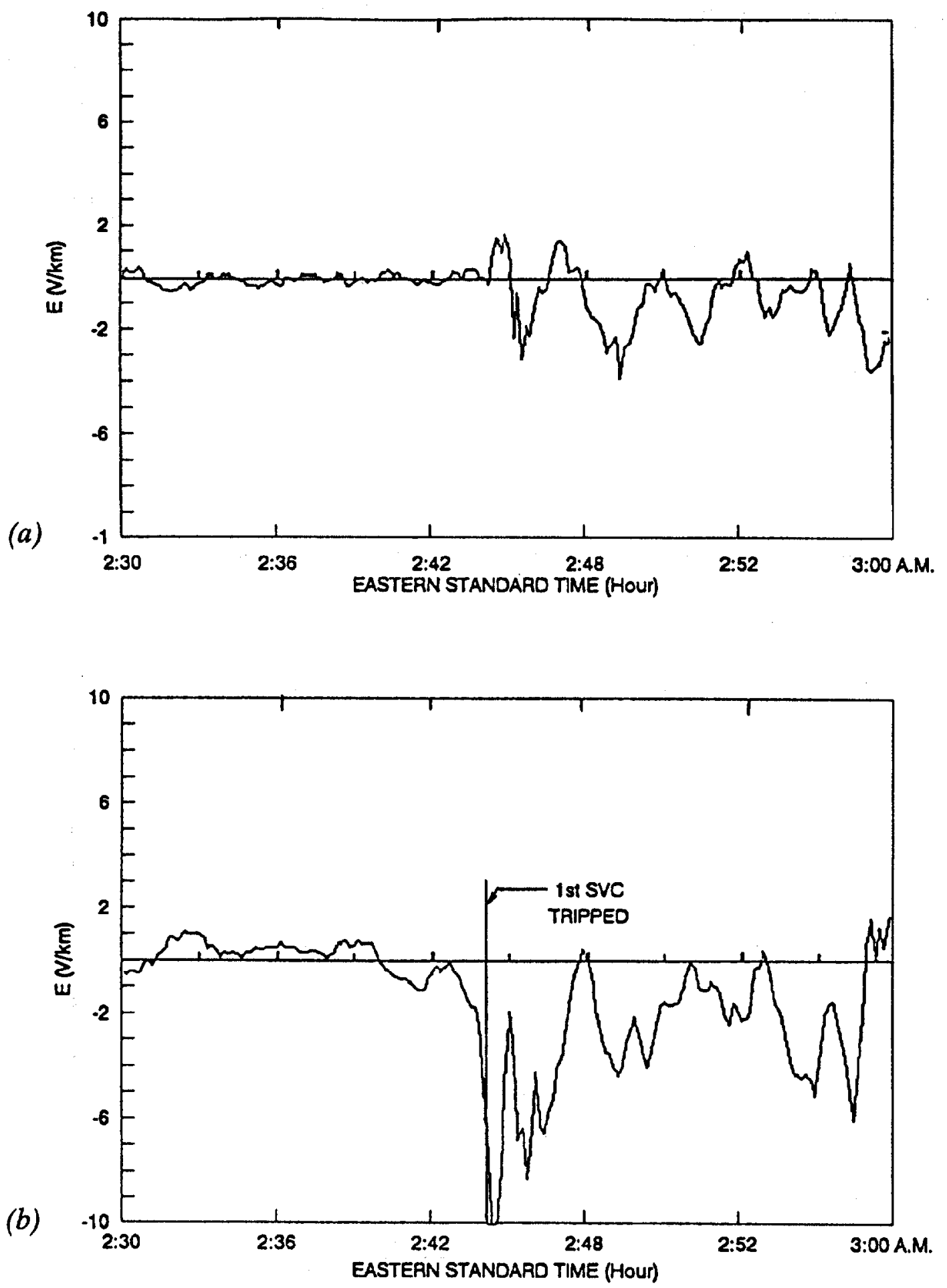

Fig. 3.10. Electric field for a ground conductivity of $1.0 \times 10^{-4} \mathrm{mhos} / \mathrm{m}$. (a) Northsouth electric field, (b) east-west electric field. 


\section{PROTECTION TECHNIQUES}

A number of hardware and operational solutions are being researched and implemented by the U.S. and Canadian electric utility industry in an attempt to reduce power system disturbances resulting from geomagnetic storms. The March 13, 1989, geomagnetic storm resulted in widespread power system disturbances in North America, a blackout at the HydroQuébec service area, damage to generator step-up transformers at the Salem generating station, and other system disturbances (see Appendix A). Fortunately, transmission systems were lightly loaded at the time of the geomagnetic disturbance, enabling most systems to compensate for the loss of reactive power and to maintain a reliable voltage profile. Some of the short-term and long-term solutions that are being tried and developed by electric utilities are discussed in this section.

\subsection{ANALYTICAL TOOLS}

Several computer programs are available for calculating the magnitude of GIC on power systems and for determining appropriate GIC mitigation strategies. One such computer program is that written in Fortran to predict the level of GICs in a large power system network based on ESPs and network configuration. The ESPs were estimated based on geographical and regional geological conditions and were modeled as voltage sources. The program has been successfully used to calculate the GICs for a large network consisting of 385 nodes on the Minnesota Power System. ${ }^{39}$

The Electromagnetic Transients Program (EMTP) has also been used to study GIC effects on the Hydro-Québec (HQ) System. A method was developed by the Institut recherche d'HydroQuébec (IREQ) and HQ to accelerate the transformer saturation process in the EMTP program without modifying the steady-state results, making digital simulation of GIC effects possible with EMTP. The computer program was used to simulate the power system disturbance that occurred on the James Bay Network during the geomagnetic storm of March 13, 1989. The simulation represented 10 power transformers, the transmission lines linking them, generating equipment, and load. ESPs of 1 and $2 \mathrm{~V} / \mathrm{km}$ were used; it was determined that using an ESP of 1.0 to 1.2 
$\mathrm{V} / \mathrm{km}$ would give a fairly accurate reproduction of the harmonic distortion profile on the system during the March 13th geomagnetic storm. The ESP level of $1 \mathrm{~V} / \mathrm{km}$ caused a GIC of $700 \mathrm{~A}$ to circulate throughout the James Bay Network. ${ }^{44}$

\subsection{HARDWARE}

A number of short-term and long-term hardware solutions are being implemented and investigated by the U.S. electric utility industry in an attempt to prevent the type of widespread power system disturbances that occurred in North America during the solar activity and resultant geomagnetic disturbance of March 13, 1989. Some of the hardware solutions include the adjustment of protective relays sensitive to geomagnetic disturbances and the development of a dc neutral-current blocking device for power transformers.

HQ is examining both short-term and long-term measures needed to improve power system performance during geomagnetic disturbances. In the short-term, protective relays that have been found sensitive to the effects of GICs have been adjusted to improve static VAR compensator reliability. $\mathrm{HQ}$ is also extending the use of voltage asymmetry measurements to other substations to alert systems operators of developing problems from geomagnetic storms. Voltage asymmetry is now being monitored at four key substations. When a $3 \%$ voltage asymmetry is detected at any of the locations, an alarm is sent to the system operator at the system control center so that power flows on transmission lines can be reduced.

\subsubsection{Relay Settings}

As discussed in Section 2, harmonic currents generated by half-cycle saturated power transformers during geomagnetic storms can affect the operation of protective relays. Following the March 13, 1989, HQ blackout, HQ for the short-term either raised or disconnected the settings on their protective relays for two sites of SVCs to prevent the SVCs from tripping during geomagnetic storms. HQ has raised the settings for high-voltage transformer overcurrent protection from 1.4 per unit with a 0.65 -s trip time to 2.0 per unit with the same trip time as before, where 1 per unit equals $250 \mathrm{~A} \mathrm{rms}$. The overcurrent protection for thyristor-switched capacitors that was responsible for initiating tripping of the SVCs at the Chibougamau and La Vérendrye substations has been reset from 1.5 per unit with a 0.65 -s trip time to 2.0 per unit with 
the same trip time where 1 per unit equals $4,000 \mathrm{~A} \mathrm{rms}$. The overload protection for thyristorswitched capacitors has been raised from 1.08 per unit and 1.3 per unit with a 5 -s trip time to 1.83 per unit with a $10-\mathrm{s}$ trip time, where 1 per unit equals $2,300 \mathrm{~A}$ rms. The $16-\mathrm{kV}$ bus overvoltage protection for the substations at Chibougamau and La Verrendrye has been disconnected. Raising the settings on these protective relays reduces the likelihood of inadvertent tripping of SVCs for the short-term; however, it may accelerate the aging of the SVC components and power transformers. ${ }^{18}$

\subsubsection{Neutral Blocking and Bypass Device for Transformers}

A capacitor in the neutral of a wye-connected power transformer has been determined by the University of Minnesota and Minnesota Power ${ }^{39}$ to be the most effective point at which to place devices for blocking or limiting the flow of GICs into and out of the power system. Series capacitors, which are needed for VAR compensation on transmission lines, are another effective means of blocking GICs. Transformers that are connected to transmission lines and that have series capacitors to provide reactive compensation are not affected by GICs since the capacitors block the flow of the quasi-dc GICs. The installation of series capacitors on each phase of a transmission line could effectively protect multiple transformers against GICs; however, the solution would be more expensive than placing a capacitor in the neutral of a single transformer.

Minnesota Power, under an EPRI-sponsored project, developed a neutral blocking and grounding device to protect susceptible transformers from GICs. ${ }^{39}$ A prototype of the device was built and tested in the laboratory. The neutral blocking and grounding device (NBGD) consisted of a blocking capacitor, a pyrotechnically triggered spark gap, and a manual bypass switch. The capacitor allowed ac currents to flow through the neutral, but blocked quasi-dc GICs from reaching the transformer core. The spark gap protected the capacitor from overvoltages due to faults. The present design for the NBGD includes the use of an air spark gap instead of the pyrotechnically triggered spark gap switch. ${ }^{45}$ Each unit for the earlier NBGD design was estimated by EPRI to cost $\$ 8000$ (1983 dollars) and another $\$ 17,000$ to install for a total of $\$ 25,000 .^{46}$ The more sophisticated and complex present NBGD design may cost on the order of $\$ 100,000 . .^{47}$ NBGD devices will probably be used only to protect high-risk transformers because of the relatively high cost of the protection. 


\subsubsection{Capacitor Protection}

Microprocessor-based overcurrent relays that are harmonically desensitized through the use of digital filtering algorithms are being evaluated by one utility ${ }^{19}$ for high-voltage capacitor bank protection.

\subsection{OPERATIONAL CHANGES}

Utilities are still seeking general methods to operate their systems under the influence of a geomagnetic storm. Good, rapid, reliable forecasting is needed, however, to alert them if a storm is imminent. Because of the risk of more severe problems, some utilities are now cutting back loading on critical circuits when the onset of a storm is detected, but it has been reported that many millions of dollars of revenue would have been forfeited if utilities in the northeast had taken load-shed actions for every storm alert that was announced.

Several electric utilities and power pools have implemented operating procedures to mitigate the effects of geomagnetic disturbances. Allegheny Power Service Corporation, Northeast Power Coordinating Council (NPCC), Pennsylvania-New Jersey-Maryland Interconnection (PJM), Public Service Electric \& Gas of New Jersey, and the Western Area Power Administration (WAPA) are a few of the utilities that have developed guidelines for dealing with geomagnetic disturbances. Some of the planning and operating guidelines that have been implemented by these utilities include the following. ${ }^{18}$

\section{Planning Procedures}

- Review operating practices especially for areas where voltages are approaching operating range limits and HVDC schemes are operating in excess of nominal fullload ratings.

- Adjust negative-sequence-current relay settings on transformers.

- Review harmonic unbalance relay settings.

- Verify and consider adjusting CT ratio or settings of ground backup and transformer differential relays including harmonic restraint.

- Install monitoring devices to measure transformer neutral currents and provide better data on GIC activity. 
- Simulate the effects of GICs on the power system to identify locations susceptible to transformer and/or reactor heating in the future.

- Perform more frequent inspections of transformers to check for abnormal noise, tank discoloration due to heating, and gas accumulator readings.

\section{Operating Procedures}

- Discontinue maintenance work and restore out-of-service transmission lines.

- Avoid taking long transmission lines out of service.

- Maintain system voltage within an acceptable operating range to protect against voltage swings.

- Reduce generator loading to provide reserve power and reactive capacity.

- Consider the impact of shunt capacitor banks and static VAR compensators that trip out on high-voltage transmission lines.

- Dispatch reserve generation to maintain system voltage and tie- line loading and to distribute operating reserves.

- Bring synchronous condenser equipment on line to provide reactive power reserves.

- Notify adjacent control areas about geomagnetic disturbance problems.

- Reduce power output at susceptible generator stations if erratic reactive power output from generators or excess reactive power consumption by generator step-up transformers is detected.

- Reduce power transfers to $95 \%$ of the transfer limits. 


\section{MAGNETOHYDRODYNAMIC ELECTROMAGNETIC PULSE AND GEOMAGNETIC STORMS}

\subsection{INTRODUCTION}

Magnetohydrodynamic electromagnetic pulse (MHD-EMP) is caused by distortions in the earth's magnetic field from a high-altitude nuclear detonation; MHD-EMP is also referred to as $E_{3}$ or the late-time portion of a high-altitude EMP (HEMP). A nuclear burst at high altitudes gives rise to an expanding ionized fireball consisting of bomb debris and hot gas. This plasma excludes the earth's magnetic field from the interior of the fireball; thus, as the fireball expands and rises, the geomagnetic field lines are deformed around the fireball, resulting in a transient magnetic field disturbance over a wide area. Directly under the burst point, an ionized region created by X-ray absorption provides a shield against the MHD-EMP signal, and the most intense $E_{3}$ signal at the earth's surface occurs at the edge of the shielded region. ${ }^{48}$ These events are depicted in Fig. 5.1 for a burst located $400 \mathrm{~km}$ over the North Pole (or near the magnetic North Pole). ${ }^{49}$ Note that over the north central U.S. the electric field lines are principally in the eastwest direction. The closer the lines in the field pattern, the more intense the peak value of the field. In Fig. 5.1, much of Canada is in the low-intensity region, whereas much of the northern U.S. is in the region of very strong $E_{3}$ fields. The low-intensity region is created by the shielding effects of the atmosphere ionized by X-rays from the nuclear burst.

In a manner similar to that of geomagnetic storms, the time-varying and spatially varying electric fields are associated with the magnetic flux environment caused by the disturbance of the earth's magnetic field. The magnitude of the tangential electric field is inversely proportional to the square root of the earth's conductivity and is a function of the time rate-of-change of the magnetic flux density (see Eq. 5.1). In the maximum MHD-EMP region, the electric field is expected to rise to a peak value in about 3 seconds or less with the overall duration being tens to hundreds of seconds. 


\subsection{COMPARISON OF THE GEOMAGNETIC STORM EARTH ELECTRIC FIELD AND THE MAGNETOHYDRODYNAMIC ELECTROMAGNETIC PULSE INDUCED FIELDS}

To gain an understanding of the possible effects of MHD-EMP on power transmission and distribution systems, it is useful to compare a measured geomagnetic storm environment with MHD-EMP environments. For the K-9 magnitude geomagnetic storm on March 13, 1989, magnetometer data for the north-south and east-west magnetic flux densities, $B$, extending over a period of about 15 hours were illustrated in Fig. 3.1. This particular storm resulted in a major power outage in the Hydro-Quebec power system.

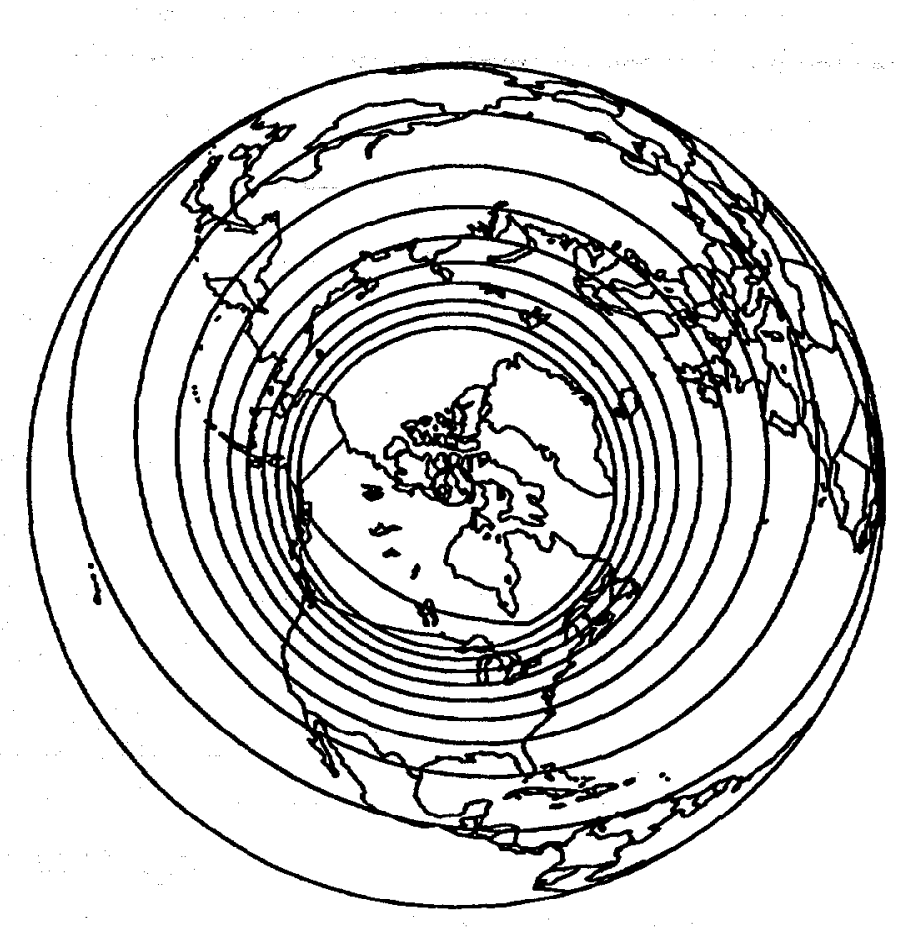

ORNL-OWG 90-14284

Fig. 5.1. Global magnetohydrodynamic electromagnetic pulse electric field pattern at 3.0 seconds. Source: Dr. M. L. Sloan of Austin Research Associates. 
Using the convolution integral for determining the earth-induced electric field, defined as

$$
E(t)=\frac{1}{\sqrt{\sigma \mu \pi}} \int_{0}^{t} \frac{1}{\sqrt{t-t^{\prime}}} \frac{\partial \mathrm{B}}{\partial t} \mathrm{~d} t
$$

the fields corresponding to these B-field environments have been computed for an assumed earth conductivity of $\sigma=1.0 \times 10^{-4}$ mhos/meter for comparison with MHD-EMP calculations. This relationship assumes spatially uniform ground conductivity and B field. Figures $5.2 \mathrm{a}$ and $5.2 \mathrm{~b}$ present these electric fields (E-fields), which also extend for the 15-hour period.

Recent studies of the early-time (0-10 s) MHD-EMP environment have been conducted by Austin Research Associates for an assumed earth conductivity of $\sigma=1.0 \times 10^{-4}$ mhos/meter. ${ }^{49}$ These calculations resulted in time-domain-varying electric field amplitudes for the east-west and north-south directions, and also showed a marked increase in the field amplitude as the observation point moved out from under the burst. Not included in these calculations was the later-time contribution of the MHD-EMP response arising from atmospheric heave, and persisting up to several hundreds of seconds. ${ }^{37}$ The heave fields, however, are expected to be much more localized to the burst-point region than are the early-time blast fields.

To develop a more complete representation for the MHD-EMP electric field environment for the purpose of performing a worst-case coupling analysis, the earth observation point having the largest early-time environment was selected. The later-time heave component to the electric field, suitably scaled to account for the low conductivity of the earth, was then added to the computed electric field response at this point. This resulted in a composite environment that can be compared with the geomagnetic storm excitation. Figure 5.3 presents the resulting maximum MHD-EMP electric field normalized so that the peak value is unity.

A possible method for comparing the MHD-EMP and the geomagnetic storm earthinduced electric fields is to plot the time domain behavior of the fields on the same graph. A difficulty in doing this, however, is that the geomagnetic storm-induced electric fields persist for hours, while the MHD-EMP response lasts only for several hundreds of seconds. A suitable time 

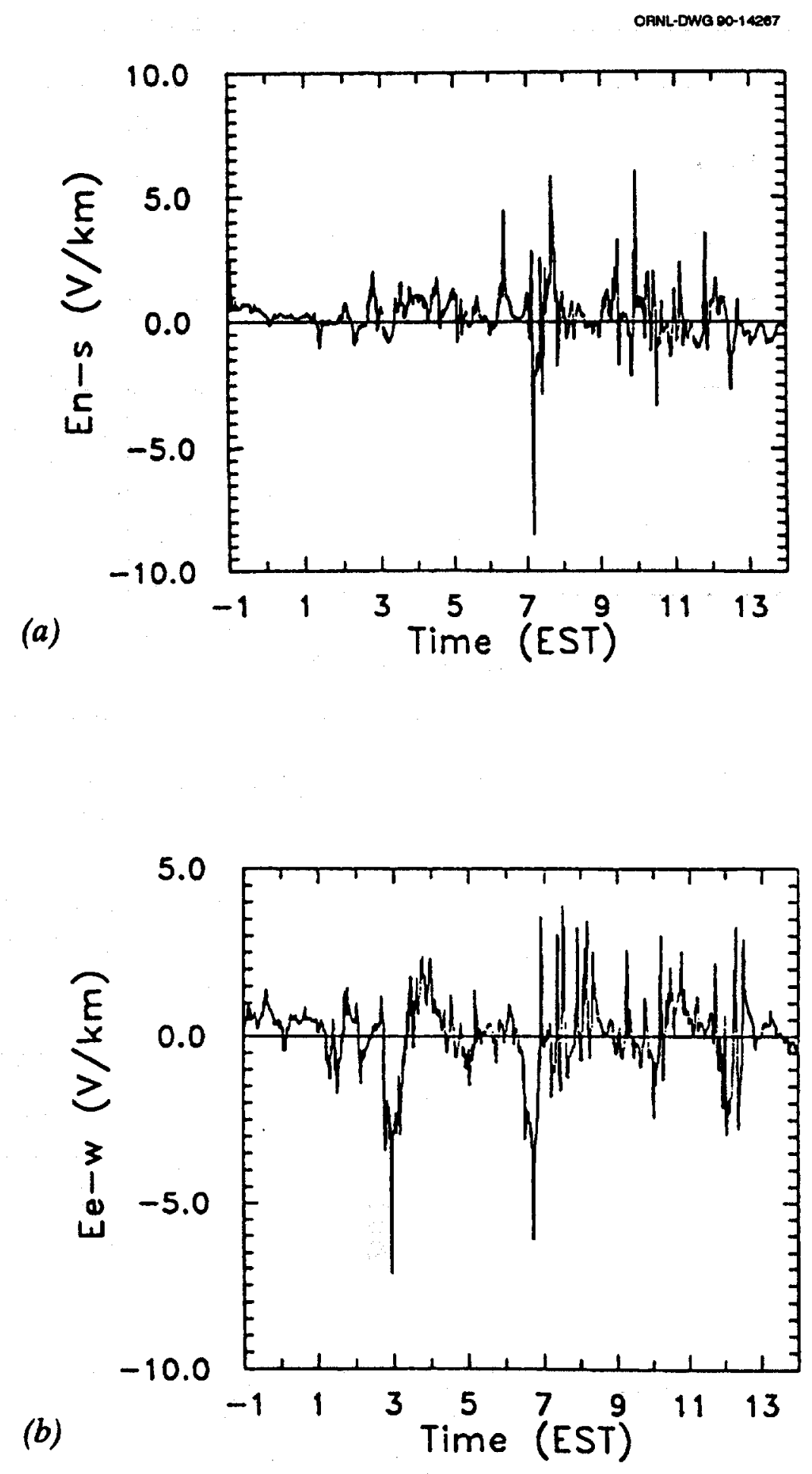

Fig. 5.2. Computed electric fields for measured fields in Fig. 3.1 with $\sigma=1.0 \times 10^{-4}$ mhos/meter. (a) North-south field, (b) east-west field. 


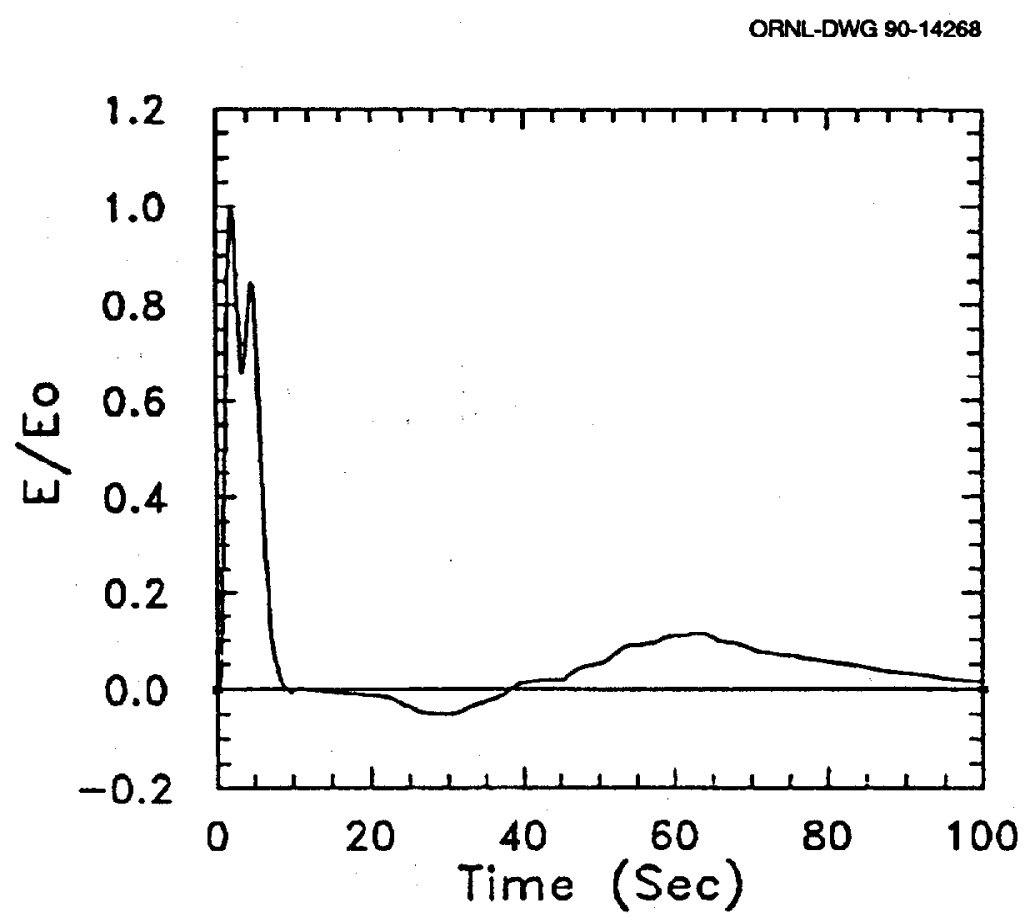

field.

Fig. 5.3. Normalized worst-case magnetohydrodynamic electromagnetic pulse electric

window for plotting the geomagnetic storm data is therefore difficult to define. One way to solve this problem is to examine the geomagnetic storm data to determine a point where there is a marked increase in the electric field response, and then to plot this response only in a small region surrounding the peak value. Figure 5.4 presents this plot for a spike in the geomagnetic storm data, with an approximate width of the spike being about 100-200 seconds, considerably longer than the spikes in the MHD-EMP response. Note that the data in Fig. 5.4 is not normalized to unity; the values are the actual electric field strengths.

An alternate approach to comparing the behavior of the two environments is to consider the Fourier spectrum. Fourier spectra are shown in Figure 5.5 for the normalized geomagnetic storm and MHD-EMP electric fields. It is clear from this figure that geomagnetic storm and MHD-EMP electric fields are sub-Hz phenomena and that their amplitudes are comparable at very low frequencies approximately below $0.1 \mathrm{~Hz}$. At the higher frequencies, the MHD-EMP electric field is dominant. Also, the geomagnetic storm electric field has much more variation than the 


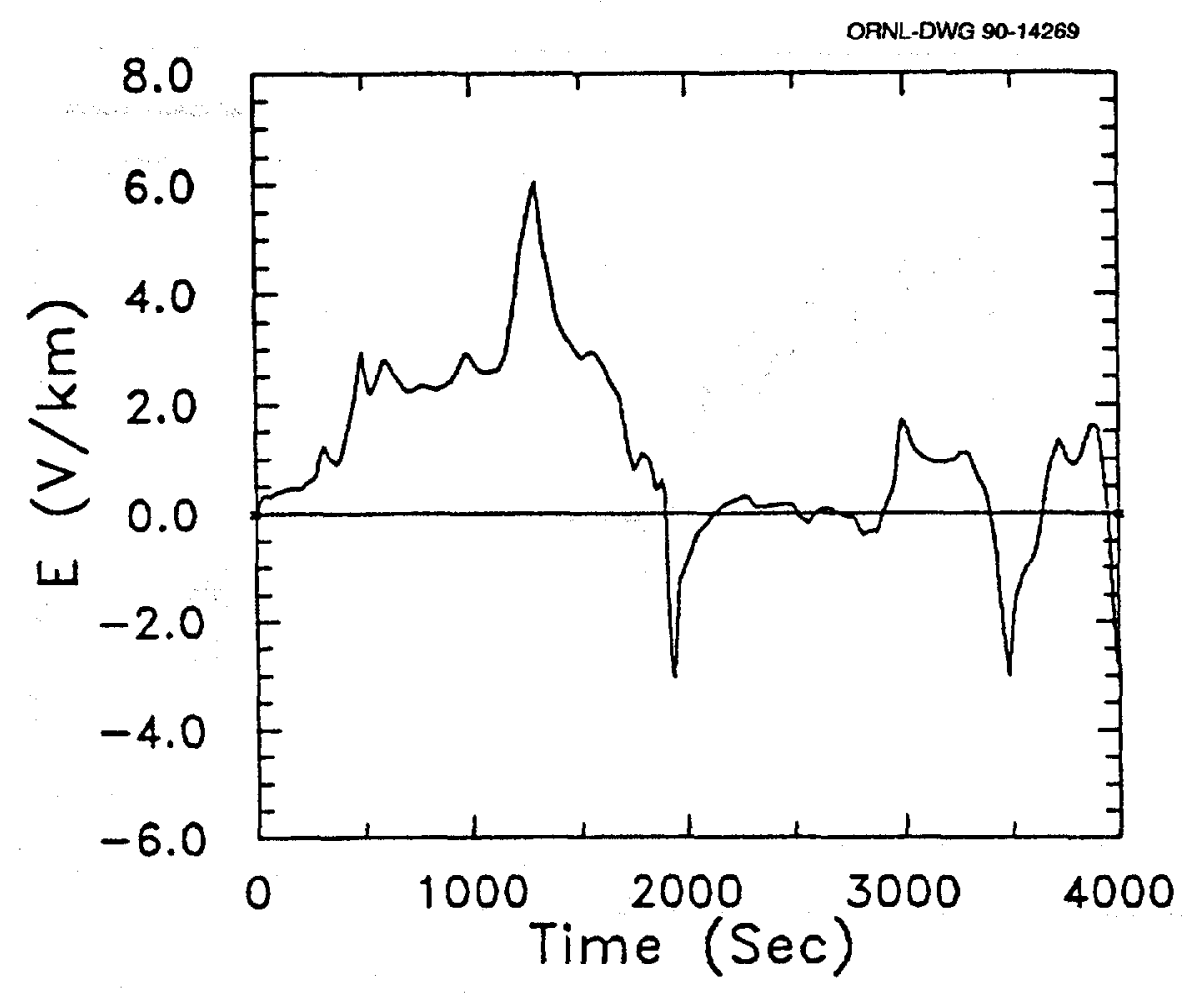

Fig. 5.4. Typical geomagnetic storm electric field.

MHD-EMP electric field. Nevertheless, both environments are quasi-dc relative to the $60-\mathrm{Hz}$ operational frequency of the power grid.

Conjecture about the possible response of a power system to these environments is interesting. If the system has a typical time constant on the order of 100 seconds, the geomagnetic storm environment will act like a simple dc source applied to the system. For the MHD-EMP environment to appear like a dc excitation to the system, the system time constants must be on the order of one second or less. Relaxation times for transmission systems can be on the order of several minutes; thus, the system may give little or no response to a low-level MHDEMP environment. However, if the level of excitation is sufficiently large, a dc analysis of the power system effects may be appropriate since the effects of transformer saturation could change the relaxation time to a few seconds. Clearly, additional research needs to be performed in this area to increase understanding of these effects on power systems. 


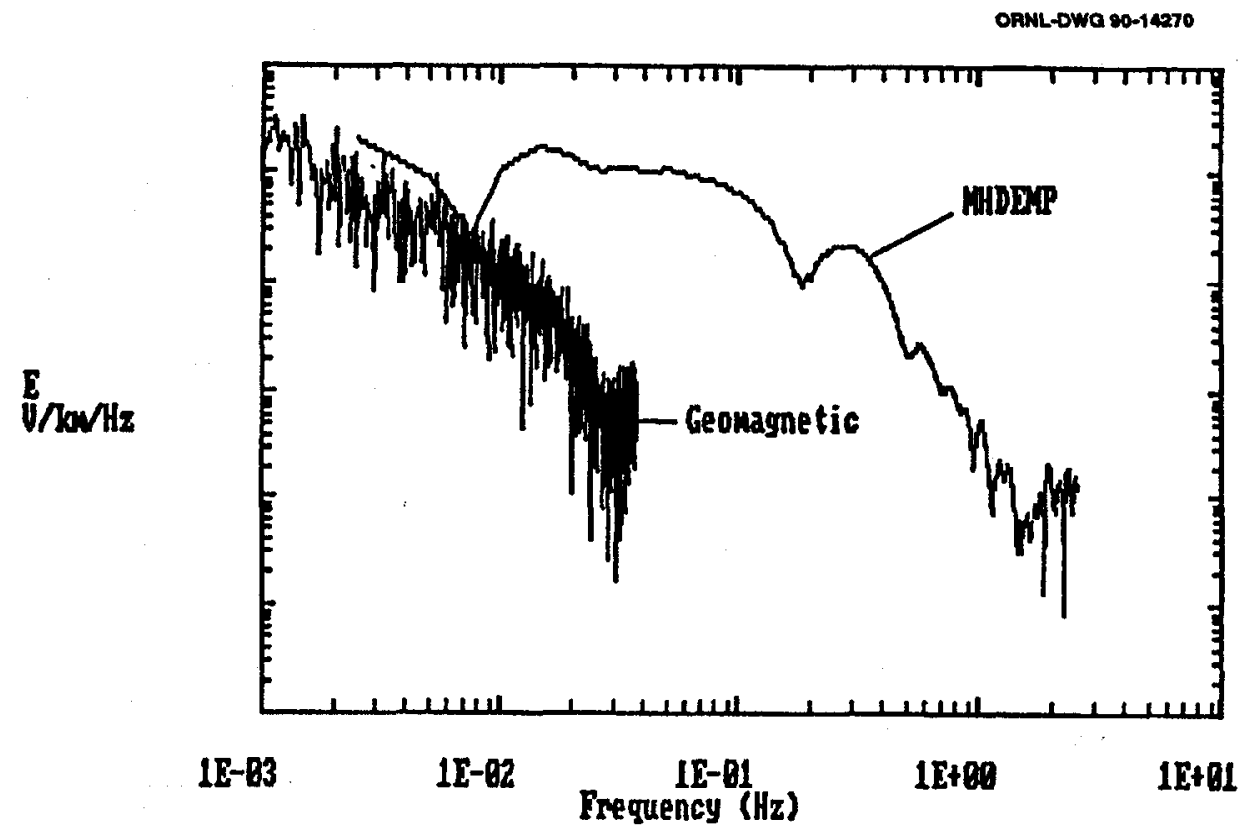

Fig. 5.5. Comparison of the spectra of the magnetohydrodynamic electromagnetic pulse electric field (shown separately in Fig. 5.3) and the geomagnetic storm electric field (shown separately in Fig. 5.4).

\subsection{EXTRAPOLATION OF GEOMAGNETIC STORM EFFECTS TO E $_{3}$}

The peak $\mathrm{E}_{3}$ electric field is much larger than that associated with geomagnetic storms, but its duration is much shorter. In a previous study, a peak MHD-EMP electric field of 24 V/km was used. ${ }^{37}$ Since the March 13, 1989, Hydro-Québec blackout probably resulted from fields that were about ten volts per kilometer, MHD-EMP could cause a similar widespread disturbance provided that power transformers could be driven into saturation in less than a minute which preliminary experimental results have indicated is possible. Since the early-time portion of the MHD-EMP waveform is less than ten seconds, the power transmission system's response is not clear. If a large quasi-dc voltage can drive power transformers into saturation in a few seconds, then the early-time fields are important for transmission systems. For distribution systems, the ORNL transformer test indicated that distribution transformers can be driven into saturation in about 1 second or less. ${ }^{42}$ The large peak value of the early-time MHD-EMP wave implies that the effect may be more pronounced for distribution and sub-transmission lines, which 
are relatively shorter than transmission lines. The early-time MHD-EMP may therefore be important in the analysis of distribution systems, and the late-time MHD-EMP may therefore be important in the analysis of transmission systems. It is also possible that the early-time MHDEMP wave could affect transmission systems: an EPRI-sponsored study at the Georgia Institute of Technology has found transformer saturation times as small as about 3 seconds for large ESP gradient excitations on the order of $60 \mathrm{~V} / \mathrm{km}^{8}{ }^{8}$

To extrapolate the $\mathrm{E}_{3}$ response from measured data, consider the Missouri Avenue substation data discussed in Section 3. The $E_{3}$ response of the Missouri Avenue substation's 69$\mathrm{kV}$ lines can be extrapolated from the measured response if it is assumed that both the $\mathrm{E}_{3}$ and the geomagnetic storm field patterns in the local region are similar. This assumption is not unreasonable. The peak current response can be estimated from the late-time MHD-EMP wave as about $E_{0}$ amperes $\left(0.1 E_{0} \times 10 \mathrm{~A} / \mathrm{V} / \mathrm{km}\right)$, where $E_{0}$ is the peak MHD-EMP amplitude in $\mathrm{V} / \mathrm{km}$. The late-time MHD-EMP amplitude is assumed to equal $0.1 \mathrm{E}_{0}$ for simplicity. For example, an MHD-EMP wave with a peak amplitude of $20 \mathrm{~V} / \mathrm{km}$ would result in a quasi-dc current of about $20 \mathrm{~A}$ at the Missouri Avenue Substation.

For a distribution line, no measured data exists for an extrapolation. However, the shorter lengths and higher circuit resistances of distribution lines and the higher amplitude of the early-time MHD-EMP will result in peak current levels similar to those for the sub-transmission case previously discussed. 


\section{SUMMARY AND CONCLUSIONS}

\subsection{ELECTRIC UTILITY EXPERIENCE}

Perturbations in the earth's magnetic field during geomagnetic storms induces voltage gradients along the surface of the earth. This results in ESPs that are impressed between any two grounded neutral points of power transmission lines that have wye-connected transformers or autotransformers. The quasi-dc GICs produced by the ESPs cause transformers to be driven into half-cycle saturation.

The first reported effects of a geomagnetic storm on electric power systems in the United States appeared after the solar storm on March 24, 1940. Power system disturbances due to geomagnetic storms have been observed during subsequent sunspot cycles up to the present time. The saturated transformers generate harmonic currents and consume reactive power from the power system. Utilities have experienced system voltage depression, variations in real and reactive power flows in transmission lines, protection misoperations causing line trips, shunt capacitor and static VAR compensator (SVC) trips, and transformer and capacitor failures. These problems have resulted in local power disruptions and, in one case, a major widespread blackout of the HQ power system.

The vulnerability of electric power systems to geomagnetic storms will likely increase during the next ten to twenty years. This increase is due to the continuing trends of transmitting larger blocks of electric power over longer and longer transmission lines and of operating generation and transmission systems closer to their limits.

\subsection{MEASURED DATA}

Utilities in the northern U.S. and Canada have collected data during geomagnetic storms and have conducted special experiments to determine the impact of GICs on power equipment, but because the data collected have been limited, utilities are now installing instrumentation systems to collect data during future storms. Enough data exists, however, to indicate that 
relatively low levels of geomagnetic storm-induced electric fields of a few volts (1 to 2) per $\mathrm{km}$ over large distances can cause power system operating problems. The time required for this geomagnetically induced excitation to cause problems is not clear, but preliminary test data indicates that large power transformers can saturate in about 1 min or less. Tests by ORNL indicate that grounded-wye-connected distribution transformers can be driven into saturation in about $1 \mathrm{~s}$ or less for a GIC level of $5 \mathrm{~A}$ in the neutral of the high-voltage winding.

\subsection{MAGNETOHYDRODYNAMIC ELECTROMAGNETIC PULSE}

MHD-EMP results from a phenomenon similar to that which produces solar-induced geomagnetic storms, i.e., perturbations in the earth's magnetic field. The MHD-EMP electric field is much more intense but much shorter in duration than that associated with solar-induced geomagnetic storms. From the available data it appears that the late-time MHD-EMP wave could affect transmission systems in a manner similar to that of solar-induced geomagnetic storms. The transient time response of transmission systems may be too long for the early-time MHD-EMP to have any affect, but more study - and data are needed before conclusions can be drawn. The early-time MHD-EMP may affect distribution lines, however, because of the high intensity of the excitation and the shorter-transient time response of distribution systems. In contrast, few distribution system problems due to solar-induced geomagnetic storm activity have been reported in the last few years because relatively small fields result from solar storm activity.

\subsection{CONCLUSIONS}

Geomagnetic storms can cause severe problems for electric power systems, especially those power systems in northern areas with igneous rock geology and in coastal regions. The vulnerability of electric power systems to geomagnetic disturbances is likely to increase during the 1990 s because of the combination of equipment, design, and operating circumstances associated with modern-day power systems. It is very difficult to prevent GICs in power systems cost-effectively. However, one utility under EPRI sponsorship is developing a capacitor-based blocking and bypass device for wye-connected power transformers as a possible affordable approach. Also, series capacitors when used for VAR compensation on transmission lines is another effective means of blocking GICs. Utilities have adopted operational strategies that may help mitigate GIC impacts, but additional mitigation studies are needed. To increase 
understanding of GIC effects, monitoring systems are being installed in electric power systems to collect data during future solar storms.

MHD-EMP will likely affect transmission systems similarly to solar-induced geomagnetic storms, but more data and additional studies are needed for conclusive assessments. Unlike solarinduced geomagnetic storms, MHD-EMP is also likely to affect distribution systems. Damage to power system components due to overheating is unlikely because of the short duration of the MHD-EMP signal; however, a widespread blackout caused by the combined MHD-EMP effects on both the transmission and the distribution systems cannot be ruled out at this time. 


\section{REFERENCES}

1. J. G. Kappenman and V. D. Albertson, "Bracing for the Geomagnetic Storms," IEEE Spectrum 27(3), 27-33 (March 1990).

2. P. R. Barnes and J. W. Van Dyke, "Potential Economic Costs From Geomagnetic Storms," Geomagnetic Storm Cycle 22: Power System Problems on the Horizon, Special Panel Session Report, IEEE PES Summer Meeting, IEEE Publication 90TH0357-4-PWR, pp. 80-83, 1990.

3. A. P. Sanghri, "Economic Cost of Electricity Supply Interruptions, " Energy Economics 4(3), 180-198 (July 1982).

4. V. D. Albertson, "Geomagnetic Disturbance Causes and Power System Effects," Effects of Solar-Geomagnetic Disturbances on Power Systems, Special Panel Session Report, IEEE PES Meeting, 90TH0291-5 PWR, pp. 3-9, July 12, 1989.

5. Dan Nordell et al., "Solar Effects on Communications," Geomagnetic Storm Cycle 22: Power System Problems on the Horizon, Special Panel Session Report, IEEE PES Summer Meeting, IEEE Publication 90TH0357-4-PWR, pp. 3-10, 1990.

6. 1989 Electricity Supply \& Demand For 1989-1998, North American Electric Reliability Council, Princeton, New Jersey, October 1989.

7. R. Pirjola, "On Currents Induced in Power Transmission Systems During Geomagnetic Variations," IEEE Trans. Power Apparatus and Syst., PAS-104 (10), 2825-2831 (October 1985).

8. A. P. S. Meliopoulos, Georgia Tech, private communication with P. R. Barnes, Oak Ridge Natl. Lab., September 25, 1990.

9. J. D. Aspnes, R. D. Merritt, and S. I. Akasofu, "The Effects of Geomagnetically Induced Current on Electric Power Systems," Northern Eng. 13(3), p. 34 (1982).

10. W. F. Davidson, "The Magnetic Storm of March 24, 1940 - Effects in the Power System," Edison Electr. Inst. Bull., 365-366 (July 1940).

11. V. D. Albertson and J. C. Slothower, "The Effects of Solar Magnetic Activity on Electric Power Systems," J. Minn. Acad. Sci. 34, 94-100 (November 2, 1967).

12. V. D. Albertson, "General Overview: Geomagnetic Storms and Electric Power System Effects," presented at EPRI GIC Conference, Burlingame, Calif., Nov. 8-10, 1989. For more information, contact Yolanda Gale at the Electric Power Research Institute, (415) 8552946.

13. Robert J. Ringlee and James R. Stewart, "Geomagnetic Effects on Power Systems," IEEE Power Eng. Rev. 9(7), pp. 6-9 (July 1989). 
References

14. P. R. Gattens et al., "Investigation of Transformer Overheating Due to Solar Magnetic Disturbances," Effects of Solar-Geomagnetic Disturbances on Power Systems, Special Panel Session Report, IEEE PES Summer Meeting, IEEE Publication 90TH0291-5 PWR, 1989.

15. M. Granger, Hydro-Québec, private communication to P. R. Barnes, Oak Ridge Natl. Lab., on review comments by Leonard Balduc of the Research Institute of Hydro-Québec, January 29, 1991.

16. P. M. Balma, "Geomagnetic Effects on a Bank of Single Phase Generator Step-Up Transformers," presented at EPRI GIC Conference, Burlingame, Calif., November 8-10, 1989. For more information, contact Yolanda Gale at the Electric Power Research Institute, (415) 855-2946.

17. J. G. Kappenman, V. D. Albertson, and N. Mohan, Investigation of Geomagnetically Induced Currents in the Proposed Winnipeg-Duluth-Twin Cities $500 \mathrm{kV}$ Transmission Line, EPRI EL-1949, EPRI Research Project 1205-1, prepared by Minnesota Power and Light Company and University of Minnesota for Electric Power Research Institute, Palo Alto, Calif., July 1981.

18. "March 13, 1989 Geomagnetic Disturbance," pp. 36-55 in 1989 System Disturbances, North American Electric Reliability Council, Princeton, New Jersey, August 1990.

19. J. G. Kappenman, D. L. Carlson, and G. A. Sweezy, "GIC Effects on Relay and CT Performance," Effects of Solar-Geomagnetic Disturbances on Power Systems, Special Panel Session Report, IEEE PES Summer Meeting, IEEE Publication 90TH0291-5 PWR, 1989.

20. J. W. Chadwick, Jr., "Geomagnetically Induced Currents (GIC) and Power System Protection," presented at EPRI GIC Conference, Burlingame, Calif., Nov. 8-10, 1989. For more information, contact Yolanda Gale at the Electric Power Research Institute, (415) 8552946.

21. P. O. Persson, "Disturbances in Directly Earthed Transmission Power Systems Caused by Geomagnetic Storms," pp. 13-18 in Proceedings of the 3rd Symposium and Technical Exhibition on Electromagnetic Compatibility, Rotterdam, Holland, May 1-3, 1979, ed. T. Dvorák, 1979.

22. J. D. Aspnes and R. P. Merritt, "Effect of DC Excitation on Instrument Transformers, Geomagnetically Induced Currents," IEEE Trans. Power Apparatus and Syst. PAS-102 (11), 3706-3712 (November 1983).

23. J. G. Kappenman, V. D. Albertson, and N. Mohan, "Current Transformer and Relay Performance in the Presence of Geomagnetically-Induced Currents," IEEE Trans. Power Apparatus and Syst. PAS-100(3), 1078-1088 (March 1981).

24. D. H. Boteler et al., "Effects of Geomagnetically Induced Currents in the B. C. Hydro 500 kV System," IEEE Trans. Power Delivery 4(1), 818-823 (January 1989).

25. N. Mohan, J. G. Kappenman, and V. D. Albertson, "Harmonics and Switching Transients in the Presence of Geomagnetically-Induced Currents, "IEEE Trans. Power Apparatus and Syst. PAS-100(2), 585-593 (February 1981). 
References

26. IEEE Power System Relaying Committee, Working Group K11, "The Effects of Solar Magnetic Disturbances on Protective Relaying," Geomagnetic Storm Cycle 22: Power System Problems on the Horizon, Special Panel Session Report, IEEE PES Summer Meeting, IEEE Publication 90TH0357-4-PWR, pp. 11-27, 1990.

27. D. Larose, "The Hydro-Québec System Blackout of March 13, 1989," Effects of SolarGeomagnetic Disturbances on Power Systems, Special Panel Session Report, IEEE PES Summer Meeting, IEEE Publication 90TH0291-5 PWR, 1989.

28. A. J. Pesonen, "Effects of Solar-Induced Currents on Power Systems - A Brief Survey," CIGRE Study Committee 36, paper discussed at the joint meeting of CIGRE SC 36 and SC 23 in Madrid, Spain, pp. 22, May 1979.

29. D. J. Williams, "Magnetic Storm and Electric Power Line Disturbance Cycles," J. Cycle Res. 10 (3), 73-87 (July 1961).

30. D. J. Christofersen, United Puwer Association, letter correspondence to P. R. Barnes, Oak Ridge Natl. Lab., April 29, 1991.

31. D. J. Christofersen, United Power Association, private communication with P. R. Barnes, Oak Ridge Natl. Lab., April 1991.

32. G. B. Prescott, "The Great Auroral Exhibition of August 28th to September 4th, 1859. 1. Observations made at Boston, Mass., and its Vicinity," Am. J. Sci. and Arts 29, 92-95, (1860).

33. W. M. Boerner et al., "Impacts of Solar and Auroral Storms on Power Line Systems," Proceedings of the 5th International Wroclaw Symposium on Electromagnetic Compatibility, September 17-19, 1980.

34. R. A. Walling and A. H. Khan, "Solar-Magnetic Disturbance Impact on Power System Performance and Security," presented at EPRI GIC Conference, Burlingame, Calif., November 8-10, 1989. For more information, contact Yolanda Gale at the Electric Power Research Institute, (415) 855-2946.

35. D. A. Fagnan, P. R. Gattens, and R. D. Johnson, "Measuring GIC in Power Systems," Geomagnetic Storm Cycle 22: Power System Problems on the Horizon, Special Panel Session Report, IEEE PES Summer Meeting, IEEE Publication 90TH0357-4-PWR, pp. 53-61, 1990.

36. V. D. Albertson, "Measurements and Instrumentation for Disturbance Monitoring of Geomagnetic Storm Effects," Effects of Solar-Geomagnetic Disturbances on Power Systems, Special Panel Session Report, IEEE PES Summer Meeting, IEEE Publication 90TH0291-5 PWR, 1989.

37. J. R. Legro, N. C. Abi-Samra, and F. M. Tesche, Study to Assess the Effects of Magnetohydrodynamic Electromagnetic Pulse on Electric Power Systems, ORNL/Sub83/43374/1/V3, Oak Ridge Natl. Lab., Martin Marietta Energy Systems, Inc., Oak Ridge, Tenn., May 1985. 
38. M. Granger, Hydro-Québec, private communication to P. R. Barnes, Oak Ridge Natl. Lab., September 21, 1990.

39. J. G. Kappenman et al., Mitigation of Geomagnetically Induced and DC Stray Current, EPRI Report EL-3295, Research Project 1770-1, Section 7, pp. 7-1 to 7-20, December 1983.

40. J. G. Kappenman, "Transformer DC Excitation Field Test \& Results," Effects of SolarGeomagnetic Disturbances on Power Systems, Special Panel Session Report, IEEE PES Summer Meeting, IEEE Publication 90TH0291-5 PWR, p. 20, 1989.

41. L. Bolduc, Pierre Pellelier, and Jean-Guy Borsclair, "DC Current in the AC Transmission Systems Near the Electrode of the HVDC Converter at Des Cantons Substation," presented at EPRI GIC Conference, Burlingame, Calif., November 8-10, 1989. For more information, contact Yolanda Gale at the Electric Power Research Institute, (415) 855-2946.

42. B. W. McConnell, P. R. Barnes, and F. M. Tesche, Results of An Experiment to Determine the Impact of Quasi-dc Currents on Three-Phase Distribution Transformer Installations, ORNL-6670, Oak Ridge Natl. Lab., Martin Marietta Energy Systems, Inc., Oak Ridge, Tenn., to be published.

43. R. C. Dugan, Harmonic Considerations for Electrical Distribution Feeders, ORNL/Sub/8195011/4, prepared by McGraw-Edison Power Systems for Oak Ridge Natl. Lab., Martin Marietta Energy Systems, Inc., Oak Ridge, Tenn., March 1988.

44. L. Bolduc et al., "Currents and Harmonics Generated in Power Transformers By DC Polarization," presented at the meeting of the IEEE T\&D Working Group on Geomagnetic Disturbances and Power System Effects, IEEE PES Summer Meeting, Minneapolis, Minn., July 18, 1990.

45. J. G. Kappenman et al., "GIC Mitigation: A Neutral Blocking/Bypass Device to Prevent the Flow of GIC in Power Systems," IEEE Trans. Power Delivery 6(3), 1271-1281 (July 1991).

46. John Douglas (technical background information provided by Robert Iveson, Stig Nilsson, and Narain Hingorani), "A Storm from the Sun," EPRI Journal 14(5), 14-21 (July/August 1989).

47. John Kappenman, Minnesota Power \& Light, personal communication to P. R. Barnes, Oak Ridge Natl. Lab., January 24, 1991.

48. J. R. Legro et al. Study to Assess the Effects of Magnetohydrodynamic Electromagnetic Pulse on Electric Power Systems, Phase I Final Report, ORNL/Sub-83/43374/1/V3, prepared by Westinghouse Electric Corporation for Oak Ridge Natl. Lab., Martin Marietta Energy Systems, Inc., Oak Ridge, Tenn., May 1985.

49. M. L. Sloan, Austin Research Associates, private communication to P. R. Barnes, Oak Ridge Natl. Lab., August 29, 1990. 


\section{APPENDIX POWER SYSTEM DISTURBANCES DUE TO MARCH 13, 1989, GEOMAGNETIC STORM}

The March 13,1989, geomagnetic storm had a widespread impact on electric utility companies in North America. The IEEE T\&D Working Group on Geomagnetic Disturbances and Power System Effects has compiled the following list of abnormal events that occurred at a number of electric power systems in the United States and in Canada. The events are given in Central Standard Time (CST).

Table A1. Abbreviations and acronyms for power system events

\begin{tabular}{|c|c|c|}
\hline & Electric Power Company & Headquarters \\
\hline $\mathrm{AE}$ & Atlantic Electric Co. & Pleasantville, NJ \\
\hline APS & Allegheny Power System, Inc. & New York, NY \\
\hline CPA & Cooperative Power Association & Eden Prairie, MN \\
\hline HQ & Hydro-Québec & Montreal, Québec, Canada \\
\hline IIGE & Iowa-Illinois Gas \& Electric Co. & Davenport, Iowa \\
\hline MHEB & The Manitoba Hydro-Electric Board & Winnipeg, Manitoba, Canada \\
\hline MP & Minnesota Power & Duluth, $\mathrm{MN}$ \\
\hline NSP & Northern States Power Co. & Minneapolis, $\mathrm{MN}$ \\
\hline $\mathrm{OH}$ & Ontario Hydro & Toronto, Ontario, Canada \\
\hline $\mathrm{PE}$ & Philadelphia Electric Co. & Philadelphia, PA \\
\hline PSE\&G & Public Service Electric and Gas Co. Company & Newark, NJ \\
\hline UPA & United Power Association & Elk River, MN \\
\hline WAPA & Western Area Power Administration & Golden, $\mathrm{CO}$ \\
\hline WE & Wisconsin Electric Power Co. & Milwaukee, WI \\
\hline
\end{tabular}


Table A2. Sequence of power system disturbances and events that occurred at each electric utility as a result of the March 13, 1989, geomagnetic storm

\begin{tabular}{|c|l|c|c|}
\hline $\begin{array}{c}\text { Electric } \\
\text { Utility }\end{array}$ & \multicolumn{1}{|c|}{ Power System Disturbance } & Date & $\begin{array}{c}\text { Time } \\
\text { (CST) }\end{array}$ \\
\hline AE & $\begin{array}{l}\text { Voltage fluctuations greater than 5\% (source: C. F. } \\
\text { Bush, AE). }\end{array}$ & $3 / 13 / 89$ & various \\
\hline APS & $\begin{array}{l}\text { Heating and gasing on 8 EHV transformers. } \\
\text { Autotransformer at Meadowbrook substation } \\
\text { experienced overexcitation and damage. Transformer } \\
\text { removed from service because of elevated levels of } \\
\text { carbon dioxide, methane, hydrogen, and acetylene. } \\
\text { Eight spots found on surface of tank where paint was } \\
\text { blistered by hot spots due to transformer heating. } \\
\text { Transformer internal temperature was estimated at } \\
\text { approximately 400 C at maximum flux density. }\end{array}$ & $3 / 13 / 89$ & $7: 20$ p.m. \\
\hline CPA & $\begin{array}{l}\text { Voltage fluctuations and capacitor banks switching } \\
\text { on. } \\
\text { High system voltage alarms. } \\
\text { Voltage fluctuations and capacitors switching off. } \\
\text { Alexandria TV station reported voltage supply } \\
\text { problems at microwave sites between 16:00 on 3/13 } \\
\text { and 01:00 on 3/14. }\end{array}$ & $3 / 13 / 89$ & $7: 24$ p.m. \\
\hline
\end{tabular}


Table A.2. (continued)

\begin{tabular}{|c|c|c|c|}
\hline $\begin{array}{l}\text { Electric } \\
\text { Utility }\end{array}$ & Power System Disturbance & Date & $\begin{array}{l}\text { Time } \\
(\mathrm{CST})\end{array}$ \\
\hline HQ & $\begin{array}{l}\text { Voltage fluctuations at La Grande. } \\
\text { On the Montreal-James Bay corridor, } 7 \text { static VAR } \\
\text { compensators (SVCs) tripped in } 1 \text { min, all by } \\
\text { overcurrent protection. La Grande station became } \\
\text { isolated when } 5 \text { lines tripped due to instability } \\
\text { resulting from lack of voltage support. La Grande } \\
\text { lost } 9,450 \mathrm{MW} \text { of capacity. Transformer damaged at } \\
\text { La Grande. SVCs at Chibougamau, Némiscau, and } \\
\text { Albanel damaged. Surge arresters at Churchill Falls, } \\
\text { Montagnais, LG-2, and Abitibi station damaged. } \\
\text { Underfrequency load shed occurred in Montreal and } \\
\text { Québec City. Speed and magnitucle of load shed was } \\
\text { not sufficient to avoid collapse of the HQ system. } \\
\text { Gentilly \#2 nuclear station tripped on overfrequency. } \\
1352 \mathrm{MW} \text { lost on HVDC interties. } \\
25 \% \text { of HQ load }(5000 \mathrm{MW}) \text { restored. } \\
48 \% \text { of HQ load }(10,500 \mathrm{MW}) \text { restored. } \\
64 \% \text { of HQ load }(14,200 \mathrm{MW}) \text { restored. } \\
83 \% \text { of HQ load }(17,500 \mathrm{MW}) \text { restored. }\end{array}$ & $3 / 13 / 89$ & $\begin{array}{l}\text { 1:45 a.m. } \\
\text { 6:00 a.m. } \\
\text { 8:00 a.m. } \\
\text { 10:00 a.m. } \\
\text { 12:00 noon }\end{array}$ \\
\hline IIGE & $\begin{array}{l}\text { Experienced minor voltage fluctuations on system at } \\
05: 15 \text { and again at } 16: 00 \text {. }\end{array}$ & $3 / 13 / 89$ & 5:15 a.m. \\
\hline
\end{tabular}


Table A.2. (continued)

\begin{tabular}{|c|c|c|c|}
\hline $\begin{array}{l}\text { Electric } \\
\text { Utility }\end{array}$ & Power System Disturbance & Date & $\begin{array}{l}\text { Time } \\
\text { (CST) }\end{array}$ \\
\hline \multirow[t]{13}{*}{ MHEB } & Solar alarms at Dorsey on $602 \mathrm{~F}$. & $3 / 12 / 89$ & 7:29 p.m. \\
\hline & Negative sequence alarms at Dorsey. & $3 / 13 / 89$ & $12: 19$ a.m. \\
\hline & Grands Rapids Unit \#1 phase unbalance alarm. & & 1:00 a.m. \\
\hline & $\begin{array}{l}\text { Winnipeg voltage dropped } 2.5 \mathrm{kV} \text { in } 6 \text { minutes, } \\
\text { recovering in another } 2 \text { minutes. System frequency } \\
\text { dropped } 0.04 \mathrm{~Hz} \text {. Dorsey synchronous condensers } \\
\text { varied from }-140 \text { MVAR to }+280 \text { MVAR in a 6- } \\
\text { min period }\end{array}$ & & 1:39 a.m. \\
\hline & $\begin{array}{l}\text { Brandon Generating Station experienced ghost } \\
\text { markings on generator } \# 5 \text { slip rings. }\end{array}$ & & $1: 45$ a.m. \\
\hline & $\begin{array}{l}\text { Winnipeg voltage dropped by } 1 \mathrm{kV} \text { and Dorsey } \\
\text { synchronous condensers varied from }-130 \mathrm{MVAR} \text { to } \\
0 \text { and back to }-130 \mathrm{MVAR} \text { over } 5 \text {-min period. }\end{array}$ & & 1:58 a.m. \\
\hline & $\begin{array}{l}\text { Winnipeg voltage dropped by } 0.5 \mathrm{kV} \text { and Dorsey } \\
\text { synchronous condensers varied from }-125 \text { to }+25 \\
\text { MVAR and back to }-125 \mathrm{MVAR} \text { over } 5 \text {-min period. }\end{array}$ & & 2:35 a.m. \\
\hline & $\begin{array}{l}\text { Radisson-Churchill } 230-k V \text { line tripped by " } 50 \mathrm{~N} " \\
\text { relay. }\end{array}$ & & 8:26 a.m. \\
\hline & $\begin{array}{l}\text { Radisson-Churchill } 230-\mathrm{kV} \text { line tripped again by } \\
\text { " } 50 \mathrm{~N} \text { " relay. }\end{array}$ & & 10:02 a.m. \\
\hline & $\begin{array}{l}\text { Radisson-Churchill } 230-\mathrm{kV} \text { line tripped again by } \\
\text { "50N" relay. }\end{array}$ & & 10:51 a.m. \\
\hline & $\begin{array}{l}\text { Radisson-Churchill 230-kV line tripped again by } \\
\text { "50N" relay. }\end{array}$ & & 10:59 a.m. \\
\hline & $\begin{array}{l}\text { Radisson-Churchill } 230-\mathrm{kV} \text { line tripped again by } \\
\text { "50N" relay }\end{array}$ & & 2:28 p.m. \\
\hline & $\begin{array}{l}\text { Kelsey } 138-k V \text { line R } 26 \mathrm{~K} \text { tripped by " } 94 \mathrm{~A} \text { " and } \\
\text { "50L" relays. }\end{array}$ & & unknown \\
\hline
\end{tabular}


Table A.2. (continued)

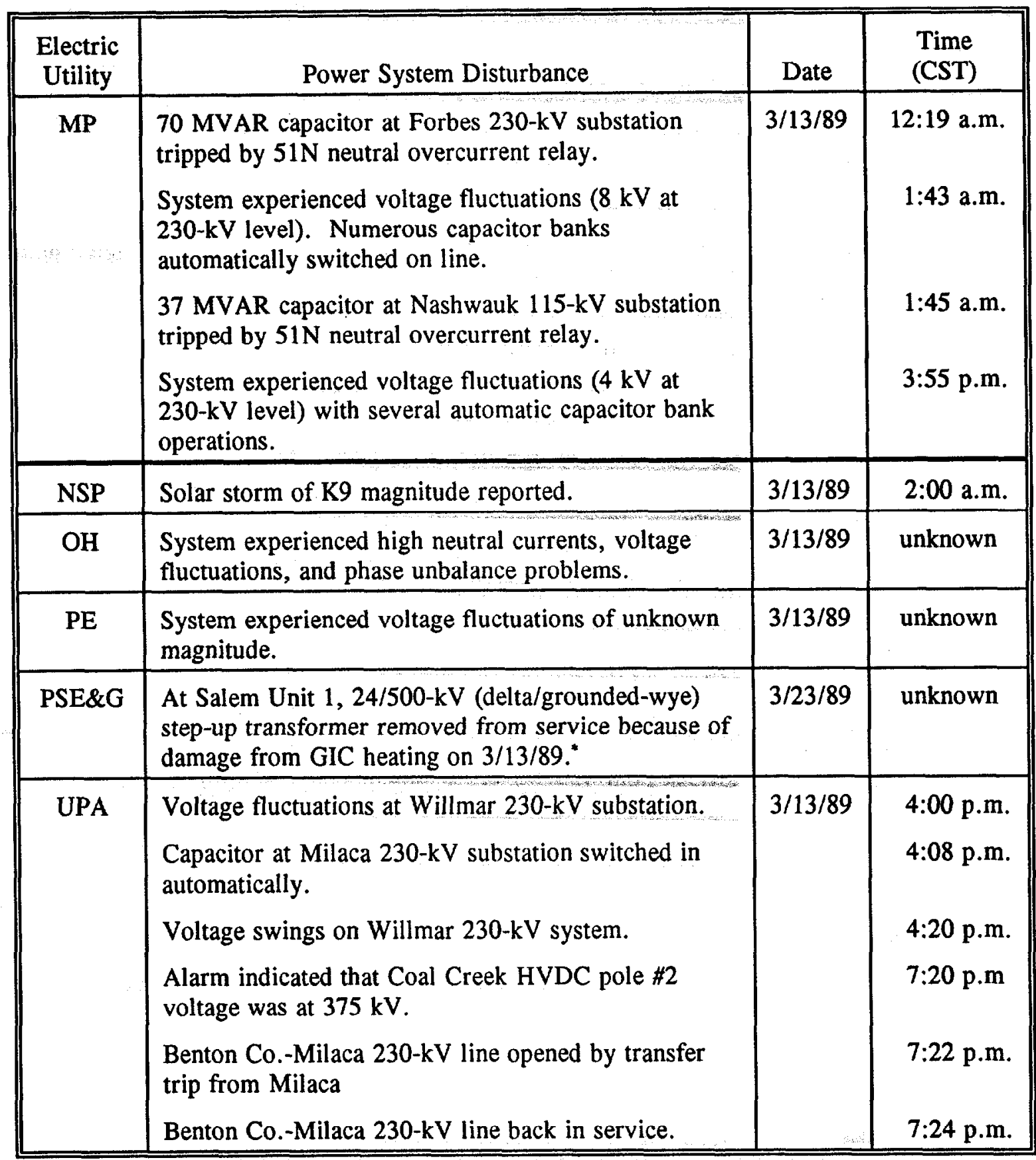

"P. M. Balma, "Geomagnetic Effects on a Bank of Single Phase Generator Step-Up Transformers," presented at EPRI GIC Conference, Burlingame, Calif., November 8-10, 1989. For more information, contact Yolanda Gale at the Electric Power Research Institute, Phone Number: (415) 855-2946. 
Table A.2. (continued)

\begin{tabular}{|c|c|c|c|}
\hline $\begin{array}{l}\text { Electric } \\
\text { Utility }\end{array}$ & Power System Disturbance & Date & $\begin{array}{l}\text { Time } \\
(\mathrm{CST})\end{array}$ \\
\hline WAPA & $\begin{array}{l}\text { Fargo static VAR system tripped on harmonic } \\
\text { unbalance. } \\
\text { Fargo static VAR system returned to service. } \\
\text { Miles City-Custer line tripped by negative sequence } \\
\text { relay. Miles City HVDC converter station carrying } \\
180 \mathrm{MW} \text { to western system tripped. } \\
\text { Miles City HVDC converter station returned to } \\
\text { service. } \\
\text { Miles City-Custer line tripped by negative sequence } \\
\text { relay. Miles City HVDC converter station tripped. } \\
\text { Bole, Montana } 230 / 69-k V \text { transformer tripped by } \\
\text { transformer differential relay. Oscillograph triggered } \\
\text { at Jamestown and Fargo by polarization and } 2 \text { nd and } \\
\text { 3rd harmonics. Static VAR generator tripped at } \\
\text { Fargo. } \\
\text { Miles City-Custer line and Miles City converter } \\
\text { station returned to service. } \\
\text { Bole substation returned to service. }\end{array}$ & $3 / 13 / 89$ & $\begin{array}{l}\text { 01:46 a.m. } \\
\text { 01:55 a.m. } \\
\text { 3:58 p.m } \\
\text { 4:00 p.m. } \\
\text { 4:09 p.m }\end{array}$ \\
\hline WE & $\begin{array}{l}\text { Transformer noise at Point Beach Nuclear Station. } \\
\text { Transformer negative sequence current detected. }\end{array}$ & $3 / 13 / 89$ & unknown \\
\hline
\end{tabular}




\section{INTERNAL DISTRIBUTION}

1-10. P. R. Barnes

11. V. D. Baxter

12. G. E. Courville

13. S. J. Dale

14. P. S. Gillis

15. E. L. Hillsman

16. J. O. Kolb

17. M. A. Kuliasha

18. V. C. Mei

19. C. G. Rizy
20-29. D. T. Rizy

30. J. W. Van Dyke

31. R. B. Shelton

32. J. N. Stone

33. ORNL Patent Office

34. Central Research Library

35. Document Reference Section

36. Y-12 Technical Library

37-46. Laboratory Records

47. Laboratory Records-RC

\section{EXTERNAL DISTRIBUTION}

\section{$\underline{\text { ORNL LIST }}$}

48. V. D. Albcrtson, Dept. of Electrical Engineering, University Of Minnesota, 123 Church Street, S.W., Minneapolis, MN 55455.

49. J. C. Allen, Southwestern Electric Power co., P. O. Box 21106, Shreveport, LA 71156.

50. R. W. Allen, New England Power Service Co., 25 Research Drive, Westboro, MA 01582.

51. G. Applegren, Main Coordination Center, 1n301 Swift Road, P.O. Box 278, Lombard, Illinois 60148.

52. M. R. Apprill, Engineering \& System Operations, Missouri Public Service, 10700 East 350 Highway, Kansas City, MO 64138.

53. G. H. Baker, HQ DNA/RAEE, 6801 Telegraph Road, Alexandria, VA 22310-3398.

54. P. Balma, Public Service Electric, 80 Park Plaza, Newark, NH 07101.

55. D. L. Bartel, Wisconsin Power \& Light Co., 222 West Washington Ave., P. O. Box 192, Madison, WI 53701-0192.

56. J. E. Benning, Power System Engineering/Operations, PSI Energy, 1000 East Main Street, Plainfield, IN 46168.

57. Robert E. Benson, Chief Electrical Engineer, New York State Electric \& Gas Corp., 4500 Vestal Parkway East, Binghamton, NY 13903. 
58. G. D. Birney, Western Area Power Administration, P. O. Box 3402, Golden, CO 80401.

59. P. D. Blair, Energy and Materials Program, Congress of the United States, Office of Technology Assessment, Washington, DC 20510.

60. L. Bolduc, Hydro Quebec, 1800 Montee Ste Julie, Varennes, QC, Canada, J3X 1 S1.

61. W. T. Boston, Tennessee Valley Authority, 6N 31B Signal Place, 1101 Market Street, Chattanooga, TN 37402-2801.

62. Larry Bressler, Western Area Power Administration, P. O. Box 3402, Golden, CO 80401.

63. B. G. Buchanan, Computer Science Department, University of Pittsburgh, 206 Mineral Industries Building, Pittsburgh, Pennsylvania 15260.

64. W. J. Budney, Distribution Systems, Public Service Electric \& Gas Co., 80 Park Plaza, Newark, NJ 07101.

65. C. K. Bush, Atlanta Electric, P.O. Box 1264, Pleasantville, NJ 08232.

66. R. F. Campbell, Transmission \& Electrical Projects, Tennessee Valley Authority, 3N 53A Missionary Ridge Place, Chattanooga, TN 37402-2801.

67. H. S. Cabayan, Lawrence Livermore National Laboratory, P.O. Box 5504, L-81, Livermore, CA 94550.

68. J. Chadwick, 902 Glamis Circle, Signal Mountain, TN 37377.

69. D. J. Christofersen, Manager, Electrical Engineering Division, United Power Association, P. O. Box 800, Elk River, MN 55330-0800.

70. P. Chrzanowski, Evaluation \& Planning Program, Lawrence Livermore National Lab, P.O. Box 808, L-81, Livermore, CA 94550.

71. R. F. Chu, Research Engineer, Philadelphia Electric Co., Research Division (S10-1), 2301 Market Street, Philadelphia, PA 19101.

72. C. F. Clark, Bonneville Power Administration, P. O. Box 3621, Portland, OR 97208.

73. Lynn Coles, Principal Policy Advisor, SERI, 1617 Cole Boulevard, Golden, CO 80401.

74. R. Coles, Geological Survey of Canada, Geophysics Division, One Observator Crescent, Ottawa, CANADA K1A OY3.

75. O. R. Compton, Richmond Plaza, P. O. Box 26666, Richmond, Virginia 23261. 
76. G. H. Coplon, U.S. Department Of Energy, Rm. 8F089, 1000 Independence Avenue, S.W., Washington, DC 20585.

77. G. Cucchi, PJM - Valley Forge Corporate Ctr., 955 Jefferson Avenue, Norristown, PA 19403.

78. J. J. Cuttica, Research and Development, Gas Research Institute, 8600 W. Bryn Mawr Avenue, Chicago, Illinois 60631.

79. G. Dahlen, Royal Institute of Technology, Tds, P.O. Box 70043, S-10044, Stockholm, Sweden.

80. L. W. DeJong, Iowa Public Service Co., P. O. Box 778, Sioux City, IA 51102.

81. A. R. Donnell, Northwestern Public Service Co., 3rd St. \& Dakota Ave., S.E., Huron, SD 57350.

82. Raymond Dunlop, Director of Research, New England Power Service Co., 25 Research Drive, Westborough, MA 01582.

83. H. Elbadaly, Underground T\&D Research Manager, Consolidated Edison Company, 4 Irving Place, New York, NY 10003.

84. D. Fagnan, Philadelphia Electric Co., 2301 Market Street, Philadelphia, PA 19101.

85. W. E. Ferro, Electric Research and Management, Inc., P.O. Box 165, State College, PA 16804.

86. N. Fraser, Ontario-Hydro (HH A25), 700 University Avenue, Toronto, Ontario, M5G 1X6, CANADA.

87. R. Gates, EMP Program Manager, FEMA, RM 606, 500 C Street, S.W., Washington, DC 20472.

88. P. R. Gattens, Allegheny Power, 800 Cabin Hill Dr., Greensburg, PA 15601.

89. M. R. Gent, President, North Amcrican Electric Reliability Council, 101 College Road East, Princeton, New Jersey 08540-8060.

90. C. R. Gordon, HQ DNA/RAEE, 6801 Telegraph Road, Alexandria, VA 22310-3398.

91. M. Granger, Hydro-Quebec, Planning Systems Division, 855 East Ste-Catherine, 20 ieme etage, Montreal Quebec, Canada, H2L 4PS.

92. J. D. Gregory, Southern Company Services, Inc., P. O. Box 2625, Birmingham, AL 35202-2625. 
93. V. Guten, National Security Agency (M-352), Fort Mead, MD 20755.

94. I. Gyuk, Program Manager, U.S. Department of Energy, 1000 Independence Ave., S.W., Washington, DC 20585.

95. Wayne Hilson, Manager, Transmission and Electrical Systems Department, Missionary Ridge, 3 North 41, 1101 Market Street, Chattanooga, TN 37402-2801.

96. E. R. Holcomb, Texas Utilities Electric Co., 1506 Commerce Street, Dallas, TX 75201.

97. M. B. Hunter, Puget Sound Power \& Light Co., 13635 N.E. 80th Street, Redmond, WA 98052-4098.

98. Joe Iannucci, Pacific Gas \& Electric, 3400 Crow Canyon, San Ramon, CA 94583.

99. J. Kappenman, Minnesota Power, 30 W. Superior St., Duluth, Minnesota 55802.

100. S. Kashyap, Defense Research Establishment - Ottawa, Electronics Division, 3701 Carling Ave., Ottawa, Ontario K1A0Z4, Canada.

101. J. L. King, System Executive Operations, Entergy Corporation, P. O. Box 61005, 225 Baronne St., New Orleans, LA 70161.

102. Joseph L. Koepfinger, Director, Systems Studies and Research, Duquesne Light Company, One Oxford Center, 301 Grant Street (19-5), Pittsburgh, PA 15279.

103. J. L. Koepfinger, Director, Sys. Studies \& Research, Duquesne Light Co., 301 Grant St. (19-5), Pittsburgh, PA. 15279.

104. B. Korbutiak, Alberta Power, Ltd., 10035 195th St., Edmondton, Alberta T5J 2V6, CANADA.

105. R. A. Kramer, Northern Indiana Public Service Co., 5265 Hohman Avenue, Hammond, IN 46320.

106. J. Kulsetås, Division Manager/Research Director, Norwegian Electric Power Research Institute, Division of High Voltage Technology, N-7034 Trondheim, Norway.

107. E. Larsen, General Electric, ESDS Bldg. 2, Rm 642, One River Road, Schenectady, NY 12345.

108. Major Robert Launstein, Defense Nuclear Agency, DNA/RAEE, 6801 Telegraph Rd., Alexandria, VA 22310.

109. J. L. Layton, Systems Operation, Carroll Electric Membership Corp., 155 Temple Road, Carrollton, GA 30117. 
110. G. R. Leidich, System Planning Engineering Dept., Centerior Energy, 6200 Oak Tree Boulevard, Independence, $\mathrm{OH} 44131$.

111. R. C. Liebentritt, Omaha Public Power District, 444 South 16th Street Mall, Omaha, NE 68102-2247.

112. R. C. Liimatainen, Committee on Science, Space and Technology, 374 Rayburn House Office Bldg., Rm. B., Washington, DC 20515.

113. J. Lloyd, CEHND-ED-SY, U.S. Army, Engineering Division Huntsville, P.O. Box 1600, Huntsville, AL 35807.

114. C. L. Longmire, Mission Research Corporation, P.O. Drawer 719, Santa Barbara, CA 93102.

115. D. J. Lorden, New England Power Service, 25 Research Drive, Westborough, MA 01582.

116. A. P. Meliopoulos, Georgia Tech, School of Electrical Engineering, Atlanta, GA 30332.

117. S. R. Mendoza, Salt River Project, P.O. Box 52025, Phoenix, AZ 85072-2025.

118. N. V. Mesland, Tot Keuring Van Elektrotechnische, Materialen, 6800 ET Arnhem, P.O. Box 9035, The Netherlands.

119. D. E. Morrison, 333 Oxford Road, East Lansing, Michigan 48823.

120. Walter E. Myers, R\&D Manager, Bonneville Power Administration, P. O. Box 3621, Portland, OR 97208.

121. D. L. Nickel, Manager, ABB Power Systems, Inc., 777 Penn Center Blvd., Pittsburgh, PA 15235-5927.

122. S. Nilsson, Program Manager, Electric Power Research Institute, Electrical Systems Division, 3412 Hillview Avenue, P.O. Box 10412, Palo Alto, CA 94303.

123. B. M. Pasternack, American Electric Power Service Corp., 1 Riverside Plaza, P.O. Box 16631, Columbus, OH 43216-6631.

124. J. Z. Ponder, PJM Interconnection, 955 Jefferson Ave., Norristown, PA 19426.

125. J. W. Porter, Electric Power Research Institute, Suite 100, 1019 Nineteenth St. N.W., Washington, DC 20036.

126. M. Rabinowitz, Electric Power Research Institute, 3412 Hillview Avenue, P.O. Box 10412, Palo Alto, CA 94303. 
127. J. J. Ray, Division of Syst. Planning, BPA, P.O. Box 3621, Portland, OR 97208.

128. T. W. Reddock, Electrotek Concepts, Inc., 10305 Dutchtown Rd., Suite 103, Knoxville, TN 37932.

129. J. R. Rempel, Physicist, Defense Intelligence Agency, Washington, DC 20340-6761.

130. H. L. Robidoux, Metropolitan Edison Company, 2800 Pottsville Pike, P. O. Box 16001, Reading, PA 19640-0001.

131. F. Rosa, Division of System Intg., Nuclear Regulatory Commission, MS P1030, Washington, DC 20555.

132. V. G. Rose, Pacific Gas \& Electric Co., 123 Mission Street, San Francisco, CA 94106.

133. C. H. Rush, Construction Department, Philadelphia Electric Co., 2301 Market St. (S25-1), Philadelphia, PA 19101.

134. J. E. Scalf, Florida Power \& Light Company, P. O. Box 14000, 700 Universe Blvd., Juno Beach, FL 33408.

135. Virgil Schafer, Engineering Division Manager, Tri-State Generation and Trans. Assoc., 12076 Grant Street, Denver, CO 80233.

136. W. G. Schiffmacher, Long Island Lighting Company, Office of Engineering \& Constr., 1660 Walt Whitman Road, Melville, NY 11747.

137. W. J. Scott, Hq DNA/RAEE, 6801 Telegraph Road, Alexandria, VA 22310-3398.

138. Joe Sefcik, Nuclear Design, Lawrence Livermore National Lab, P.O. Box 808, L-22, Livermore, CA 94550.

139. C. H. Shih, Manager, Elcctrical Research, American Electric Power Service Corp., 1 Riverside Plaza, Columbus, OH 43215.

140. M. L. Sloan, Austin Research Associate, 1101 Capital of Texas Highway S., Building B, Suite 210, Austin, TX 78746.

141. R. B. Spence, Bonneville Power Administration, P.O. Box \#3621 - MOEA, Portland, OR 97208.

142. G. I. Stillman, Research \& Development, New York Power Authority, 1633 Broadway, New York, NY 10019.

143. P. Sullivan, Philadelphia Electric Co., 2301 Market Street (S10-1), Philadelphia, PA 19101. 
144. R. L. Taylor, Director - Power Supply, Florida Power \& Light Co., 9250 W. Flagler, Miami, FL 33102.

145. L. L. Taylor, Northern States Power Company, 414 Nicollet Mall, Minneapolis, MN 55401.

146. E. R. Taylor, ABB Power Systems, Inc. , 777 Penn Center Blvd., Pittsburgh, PA 15235-5927.

147. A. N. Terreri, Electrical Operations, Green Mountain Power Corp., P. O. Box 850, South Burlington, VT 05402.

148. F. M. Tesche, Consulting Scientist, 6921 Spanky Branch Dr., Dallas, TX 75248.

149. M. V. Thaden, Potomac Electric Power Co., 1900 Pennsylvania Ave., NW, Rm. 311, Washington, DC 20068.

150. G. F. Thompson, Northeast Utilities Service Co., P. O. Box 270, Hartford, CT 061410270 .

151. J. Towle, 3906 Bagley Ave. N., Suite 100, Seattle, WA 98103.

152. E. F. Vance, 6885 Rendon Bloodworth Road, Fort Worth, TX 76140.

153. D. R. Volzka, Senior Project Engineer, Wisconsin Electric Power Company, 333 West Everett Street, Milwaukee, WI 53201.

154. Jan Wagers, Power Systems Planning, City of Colorado Springs, Department of Utilities, 30 South Nevado, Colorado Springs, CO 80903.

155. R. Walling, General Electric Company, Building 2, Rm 507, One River Road, Schenectady, NY 12345.

156. R. C. Webb, Defense Nuclear Agency, RAEE, 6801 Telegraph Road, Alexandria, VA 22310.

157. L. B. Wideman, Houston Lighting \& Power Co., P. O. Box 1700, Houston, TX 77001.

158. E. P. Wigner, Consultant, 8 Ober Road, Princeton, NJ 08540.

159. M. W. Wik, Forsvarets Materielverk, Stockholm, S-11588, Sweden.

160. M. Williams, Professor, Department of Economics, Northern Illinois University, DeKalb, Illinois 60115.

161. D. Woodford, Suite 400, 1619 Pembina Ave., Winnipeg, Manitoba, R-3T-2G5, Canada. 
162. S. E. Wright, Electric Power Research Institute, 3412 Hillview Ave., P.O. Box 10412, Palo Alto, CA 94303.

163. F. S. Young, Director, Electrical Systems Division, Electric Power Research Institute, P.O. Box 10412, Palo Alto, CA 94303.

164. R. M. Youngs, Seattle City Light, 1015 Third Avenue, Seattle, WA 98104.

165. R. W. Zwickl, Space Environment Laboratory, Mail Stop R/E/SE, Boulder, CO 80303.

166. J. A. Zychinski, Union Elcctric Company, P. O. Box 149, M/C 661, St. Louis, MO 63166.

167. Office of Assistant Manager for Energy, Research and Development, DOE-ORO, P.O. Box 2001.

168-177. OSTI, U.S. Department of Energy, P.O. Box 62, Oak Ridge, TN 37831.

\section{DNA LIST}

178. Air Force Space Command, Headquarters, DEES/D C DE MIO, Peterson AFB, CO 80914-5001.

179. Atomic Energy, The Penatogon, Assistant to the Secretary of Defense, Executive Assistant, Washington, DC 20301-3050.

180. BDM International Inc., Library, P.O. Box 9274, Albuquerque International, Albuquerque, NM 87119.

181. BDM International Inc., E. Dorchak, 7915 Jones Branch Drive, McLean, VA 221023396.

182. Booz-Allen \& Hamilton, Inc., Technical Library, 4330 East West Highway, Bethesda, MD 20814-4455.

183. Central Intelligence Agency, OSWR/STD/MTB, Washington, DC 20505.

184. Central Intelligence Agency, OSWR/NED, Washington, DC 20505.

185. Defense Communications Engineer Center, Code R410, 1860 Wiehle Avenue, Reston, VA 22090-5285.

186. Defense Intelligence Agcncy, Director, RTS-2B, Washington, DC 20340.

187. Defense Intelligence Agency, Director, VP-TPO, Washington, DC 20340. 
188. Defense Nuclear Agency, RAEV, 6801 Telegraph Road, Alexandria, VA 22310.

189-198. Defense Nuclear Agency, RAEE, 6801 Telegraph Road, Alexandria, VA 22310.

199-200. Defense Nuclear Agency, TTL, 6801 Telegraph Road, Alexandria, VA 22310.

201. Defense Nuclear Agency, RAAE, 6801 Telegraph Road, Alexandria, VA 22310.

202. Defense Research Establishment Ottawa, S. Kashyap, Ottawa, Ontario, Canada K1A0Z4.

203. Defense Technical Information Center, DTIC/FDAB, Cameron Station, Alexandria, VA 22304-6145.

204. Department of the Navy, Command \& Control Programs, OP 941, Washington, DC 20350.

205. Department of Commerce, NOAA/MASC Security Office, MC43, G. Reeve, 325 Broadway, Boulder, CO 80303.

206. Department of Commerce, NOAA/MASC Security Office, MC43, W. Utlaut, 325 Broadway, Boulder, CO 80303.

207. Department of Commerce, NOAAMASC Security Office, MC43, D. Peach, 325 Broadway, Boulder, CO 80303.

208. Department of the Air Force, Air Force CTR For Studies \& Analysis, AFCSA/SAMI (R. Griffin), Washington, DC 20330-5420.

209. E-Systems, Inc., ECI Division, Mail Stop 3, Tech Info CTR, P.O. Box 12248, St. Petersburg, FL 33733.

210. EG\&G Special Projects Inc., J. Giles, Albuquerque Operations, 2450 Alamo Avenue, SE, Albuquerque, NM 87106. 211. Electro-Magnetic Applications, Inc., D. Merewether, P.O. Box 8482, Albuquerque,
NM 87198-8482.

212. General Research Corp., W. Naumann, P.O. Box 6770, Santa Barbara, CA 93160 6770.

213. Harry Diamond Laboratories, Director, SLCHD-NW-TN (G MERKEL), 2800 Powder Mill Road, Adelphi, MD 20783-1197.

214. Harry Diamond Laboratories, Director, SLCHD-NW-EP (21100), 2800 Powder Mill Road, Adelphi, MD 20783-1197. 
215. Harry Diamond Laboratories, Director, W. Patterson, 2800 Powder Mill Road, Adelphi, MD 20783-1197.

216. Harry Diamond Laboratories, Director, SLCIS-IM-TL (81100), 2800 Powder Mill Road, Adelphi, MD 20783-1197.

217. IIT Research Institute, I. Mindel, 10 W. 35th Street, Chicago, IL 60616-3703.

218. Institute for Defense Analyses, Tech Info Services, 1801 N. Beauregard Street, Alexandria, VA 22311-1772.

219. Jaycor, R. Poll, P.O. Box 1577, Santa Monica, CA 90406-1577.

220. Jaycor, E. Wenaas, P.O. Box 85154, San Diego, CA 92186-5154.

221. Jaycor, M. Schultz, Jr., 1608 Spring Hill Road, Vienna, VA 22182-2270.

222. Joint Strategic Target Planning Staff, The Joint Staff, JLWT (Threat Analysis), Offutt AFB, NE 68113-50001.

223. Joint Strategic Target Planning Staff, The Joint Staff, JKC (DNA REP), Offutt AFB, NE 68113-50001.

224. Kaman Sciences Corporation, DASIAC, Santa Barbara Operations, P.O. Box 1479, Santa Barbara, CA 93102-1479.

225. Kaman Sciences Corp., Library/B. Kinslow, P.O. Box 7463, Colorado Springs, CO 80933-7463.

226. Kaman Sciences Corp., Washington Operations Division, DASIAC, 2560 Huntington Ave., Suite 200, Alexandria, VA 22303.

227. Kamana Sciences Corporation, Technical Library, Dikewood Division, 6400 Uptown Blvd., N.E. Suite 300E, Albuquerque, NM 87110.

228. Metatech Corporation, W. Radasky, P.O. Box 1450, Golcta, CA 93116-1450.

229. Mission Research Corp., J. Lubell, 4935 North 30th Street, Colorado Springs, CO 80919-4199.

230. Mission Research Corp., A. Chodorow, 1720 Randolph Rd., SE, Albuquerque, NM 87106-4245.

231. Mission Research Corp., Tech Info Center, P.O. Drawer 719, Santa Barbara, CA 93102-0719.

232. National Security Agency, Director, R-54, Fort George G Meade, MD 20755-6000. 
233. Naval Research Laboratory, Commanding Officer, Code 2627 (TECH LIB), Washington, DC 20375-5000.

234. Office of the Sec of Defense, Director, Document Control, Net Assessment, Room 3A930, The Pentagon, Washington, DC 20301.

235. Office Secretrary Defense, U S Nuclear Command \& Central Sys Support Staff, SAB H Sequine, Pentagon, Room 3E 172, Washington, DC 20301-3040.

236. Pacific-Sierra Research Corp., H. Brode, 12340 Santa Monica Blvd, Los Angeles, CA 90025-2587.

237. R \& D Associates, Document Control, P.O. Box 92500, Los Angeles, CA 90009.

238. R \& D Associates, J P Castillo, P.O. Box 9377, Albuquerque, NM 87119-9377.

239. Rockwell International Corp., G. Smith, P.O. Box 3105, Anaheim, CA 92803-3105.

240. S-Cubed, J. Knighten, A Division of Maxwell Laabs, Inc., P.O. Box 1620, La Jolla, CA 92038-1620.

241. Science \& Engrg Associates, Inc., Robert L. Charters, P.O. Box 3348, Seattle, WA 98009-3348.

242. Science Applications Intl. Corp., P.J. Dowling, 2860 S Circle Dr., St. 2400, Colorado Springs, CO 80906.

243. Science Applications Intl. Corp., W. Chadsey, P.O. Box 1303, McLean, VA 221021303.

244. Spacc \& Naval Warfare Systems CMD, Commander, Technical Library, Department of the Navy, Washington, DC 20363-0001.

245. SRI International, J. Prewitt, 333 Ravenswood Ave., Menlo Park, CA 94025-3434.

246. Strategic Air Command/XRFS, Headquarter, XRFS, Department of the Air Force, Offutt AFB, NE 68113-5001.

247. The Joint Staff, J-3/Nuc. Operations Br., Strat. Operations Br., Washington, DC 20318 .

248. The Joint Staff, C3S (ER) Analysis Div, Washington, DC 20318.

249. The Joint Staff, J-6F D Butts, Washington, DC 20318.

250. TRW Inc., DH4/2461, G.E. Morgan, TRW Space \& Defense, One Space Park, Redondo Beach, CA 90278-1071. 
251. U S Army Engineer Div Huntsville, Division Engineer, CEHND-SY J LOYD, P.O. Box 1600, West Station, Huntsville, AL 35807-4301.

252. U S Army Strategic Defense Command, CSSD-SL, P.O. Box 1500, Huntsville, AL 35807.

253. U S Army Nuclear \& Chemical Agency, Commander, MONA-NU (D. Bash), 7500 Backlick Rd., Bldg. 2073, Springfield, VA 22150-3198.

254. Under Secretary of Defense, Director, Strat \& Theater NUC Forces, The Pentagon, RM 3E 129, Strat \& Theater NUC Forces (O\&SS), Washington, DC 20301-3090.

255. USA Survivability Management Office, Director, SLCSM-SE J BRAND, 2800 Powder Mill Road, Adelphi, MD 20783-1145.

256. USAF/LEEEU, HQ, LEEE, Washington, DC 20330.

257. Weapons Laboratory, NTN, Kirtland AFB, NM 87117-6008.

258. Weapons Laboratory, NTAA, Kirtland AFB, NM 87117-6008.

259. Weapons Laboratory, WL/SUL, Kirtland AFB, NM 87117-6008. 